\title{
"THE DUST WAS LONG IN SETTLING": HUMAN CAPITAL AND THE LASTING IMPACT OF THE AMERICAN DUST BOWL
}

\author{
Vellore Arthi \\ University of Essex \\ v.arthi@essex.ac.uk
}

Forthcoming in the Journal of Economic History

\begin{abstract}
I find that childhood exposure to the Dust Bowl, an environmental shock to health and income, adversely impacted later-life human capital — especially when exposure was in uteroincreasing poverty and disability rates, and decreasing fertility and college completion rates. The event's devastation of agriculture, however, had the beneficial effect of increasing high school completion, likely by pushing children who otherwise might have worked on the farm into secondary schooling. Lastly, New Deal spending helped remediate Dust Bowl damage, suggesting that timely and substantial policy interventions can aid in human recovery from natural disasters.
\end{abstract}

Keywords: Dust Bowl, environmental shock, human capital formation, early-life health

Acknowledgements: I am grateful to James Fenske and Jane Humphries for their support in the preparation of this paper, as well as to Bill Collins and two anonymous referees for their invaluable comments on this work. I would also like to thank Douglas Almond, Stephen Broadberry, Mary Elisabeth Cox, Price Fishback, Jed Friedman, Walker Hanlon, Richard Hornbeck, Cormac Ó Gráda, Kevin O’Rourke, Deborah Oxley, Eric B. Schneider, Igor Zurimendi, and audiences at the 2015 Economic History Society Conference, 2015 Oxford-Warwick-LSE Workshop, 2014 ASSA Annual Meeting, 2014 Economic History Association Annual Meeting, 2014 Cliometrics Annual Conference, 2013 Economic History Society Residential Training Course, 2013 Merton Graduate Research Forum, 2013 Centre for Economic and Business History Postgraduate Conference, 2013 Oxford Economic \& Social History Graduate Workshop, and seminars at the University of Cambridge, the University of Essex, Harvard University, the London School of Economics, the Paris School of Economics, Royal Holloway University of London, and the World Bank for their helpful comments on earlier versions of this work. 
"All day the dust sifted down from the sky, and the next day it sifted down. An even blanket covered the earth...Every moving thing lifted the dust into the air: a walking man lifted a thin layer as high as his waist, and a wagon lifted the dust as high as the fence tops, and an automobile boiled a cloud behind it. The dust was long in settling back again."

— John Steinbeck, The Grapes of Wrath (1939, pp. 6, 4)

The American Dust Bowl, a prolonged ecological event characterized by drought, accelerated soil erosion, and severe dust storms, represents one of the most devastating environmental catastrophes in American history (Worster 1979). During this crisis, which lasted throughout the 1930s, a series of dust storms ravaged the US Great Plains, destroying land, property, and agricultural livelihoods; disrupting public services; and causing injury to health and nutrition (Carlson 1935; Hansen and Libecap 2004; Hornbeck 2012). Recent literature indicates that early-life shocks such as these can radically change the course of human capability formation, and thus shape adult outcomes (Almond 2006; Heckman 2007; Almond and Currie 2011b; Bhalotra and Venkataramani 2012). In light of this literature, the Dust Bowl's shocks to health and incomes would be expected to have non-negligible adverse effects on wellbeing in later-life; however, these long-run human costs have been little studied, meaning we may currently underestimate the full toll of this important event in American history. ${ }^{1}$

Accordingly, the aim of this paper is to analyze the long-term consequences of the Dust Bowl for the human capital of the children who lived through it. To do this, I take a difference-in-differences approach, using plausibly exogenous variation in childhood Dust Bowl exposure to explain variation in human capital in adulthood. Specifically, I draw on a sample of over 4 million individuals who were born between the years 1900 and 1959 in 15 Great Plains and adjacent states, and who were enumerated as adults in the 1980-2000 U.S. Censuses. These IPUMS microdata offer rich individual-level information on a range of human capital outcomes, including educational attainment and later-life disability (Ruggles et al. 2010). Each individual in the sample is then assigned a measure of Dust Bowl exposure in early life. The temporal component of childhood Dust Bowl exposure arises from cohort membership: of this sample, 1918-1941 birth cohorts were exposed to the Dust Bowl

\footnotetext{
${ }^{1}$ Two exceptions are Fishback and Thomasson (2014) and Cutler, et al. (2007), which examine the effect of early-life exposure to a bundle of 1930s-era shocks (that is, the Great Depression and the Dust Bowl) on later-life wellbeing.
} 
either as children or in utero, and are considered to have been treated. This cohort variation in Dust Bowl eligibility is then interacted with spatial variation in the severity of the Dust Bowl in the state of birth, proxied by measures of Dust Bowl-induced soil erosion taken from Richard Hornbeck (2012).

Using these data, I test for the degree to which this natural disaster scarred human capital in the long run, the developmental pathways through which such scarring occurred, and the capacity for investment in human capital — here, in the form of New Deal-era public spending - to remediate the shock. I find that exposure to the Dust Bowl in childhood had statistically significant and economically meaningful adverse impacts on later-life outcomes, for instance, increasing disability and reducing fertility and college completion. I show that the results hold even after accounting for the possibly confounding effects of the Great Depression, migration, selective fertility, and selective mortality. Many of the worst adverse effects are found amongst those exposed prenatally and in early childhood, suggesting that congenital complications in capability development, together with low parental incomes in utero and thereafter, may be to blame for such later-life disadvantage. Lastly, resultsespecially those concerning New Deal spending-indicate that post-shock investment had the capacity to compensate for damage to child endowments.

This study makes two main contributions. First, it enriches our understanding of the Dust Bowl. The Dust Bowl's impacts on land management and conservation, agricultural recovery, and migration have been well studied, and qualitative sources on the Dust Bowl's short-term health effects abound (see, e.g., Donald Worster (1979), J. Douglas Helms et al. (1996), Zeynep Hansen and Gary Libecap (2004), Geoff Cunfer (2005), Price Fishback et al. (2011), and Hornbeck (2012)). While two recent studies, David Cutler et al. (2007) and Price Fishback and MelissaThomasson (2014), have examined the impact of early-life exposure to a bundle of 1930sera shocks on wellbeing in adulthood, to my knowledge, no existing study has attempted to quantify the long-term human costs of this natural disaster as separate from the larger macroeconomic shocks of the Great Depression. ${ }^{2}$

\footnotetext{
${ }^{2}$ Cutler et al. (2007) find limited and largely insignificant effects of what they term "Dust Bowl-era" shocks (childhood economic conditions as measured by crop yields, income, and employment at the region-year level, and father's farm status at the individual level) on adult health outcomes (e.g. the likelihood of diabetes, stroke, and high blood pressure) taken from the Health and Retirement Survey. Although the shock measures employed in Cutler et al. (2007) may partially conflate Dust Bowl and Depression effects, Fishback and Thomasson (2014) are more pointedly focused on tracking the long-term effects of early-life exposure to the Great Depression. Using
} 
As such, it is possible the literature currently underestimates the damage caused by the Dust Bowl. By quantifying the event's later-life impacts on human capital, I more fully account for its human toll.

Second, this paper contributes to our understanding of the technology of human capital formation. By accounting for differences in the timing of Dust Bowl exposure, I provide suggestive evidence on both the channels by which adverse environmental shocks may affect different capabilities, and the sensitive periods for the development of these outcomes. More importantly, this study is one of few to examine the question of remediation. In contrast to household-level investment responses, which may be endogenous, here, the large-scale and plausibly exogenous compensatory investment represented by New Deal expenditure allows me to better test the extent to which children can bounce back from early-life deprivation. By showing that New Deal spending was effective in aiding recovery from Dust Bowl damage, I not only provide new historical evidence on this program's long-run impact, but I also provide new empirical evidence on the capacity for recovery from adverse shocks to a child's human capital endowment. In doing so, this study is one of the few in the capability formation literature that examines the contemporaneous public policy responses to disaster.

\section{RELATED LITERATURE}

During the period from 1930 to 1940, poor rainfall, high temperatures, and strong winds precipitated a series of massive dust storms across the US Great Plains (Stephens 1937; Lord 1938; Wallace 1938; Cunfer 2005). These storms blew away roughly 480 tons of fertile topsoil per acre, with many regions losing over 75 percent of their original topsoil by 1940 (Hansen and Libecap 2004; Hornbeck 2012). Winds decimated existing crops through exposure and abrasion, and prevented new ones from being planted (Soil Conservation Service 1935). Meanwhile, dirt deposited downwind suffocated livestock and buried crops and property (Worster 1979; Hansen and Libecap 2004; Egan 2006). Accordingly, agricultural yields were low (Bennett 1939; Bonnifield 1979) and recovery was slow (Hornbeck 2012).

The Dust Bowl was not just an environmental crisis, but a human tragedy as well. As the country struggled with the Great Depression, the Dust Bowl compounded misfortunes, especially for the farming communities of the Great Plains (Wallace 1938; Cutler et al. 2007). Economic hardship was widespread: meager

measures of childhood income, they find strong evidence of adverse effects on adult wellbeing as reported in IPUMS. 
harvests meant low incomes, nutritional deprivation, and, for some, farm foreclosure and migration (Bonnifield 1979; Worster 1979). More directly, the drought could prove fatal (Fishback et al. 2011), while poor air quality led to eye infections, influenza, and respiratory illnesses such as "dust pneumonia" (Soil Conservation Service 1935; Worster 1979; Hurt 1981; Hansen and Libecap 2004; Egan 2006; Burns et al. 2012). What was once home became surreal and terrifying, "as nearly a literal hell on earth as can be imagined" (Lord 1938).

Research indicates that stress, deprivation, and early-life shocks to income and health can have long-term adverse impacts on wellbeing (Barker and Osmond 1986; Almond and Currie 2011b). Human capital development may be impaired directly through childhood illness and deprivation, and indirectly, through poor prenatal conditions (e.g. maternal stress, illness, or malnutrition). These poor early-life circumstances hamper the successful development of capabilities such as cognitive and non-cognitive skills, metabolism, and immunity, and have been implicated in conditions from heart disease to schizophrenia (see the overview of the famine and fetal programming literatures in Cormac Ó Gráda (2011)). ${ }^{4}$ In turn, low human capital stocks negatively impact other outcomes such as later-life income and employment (Heckman 2007; Bhalotra and Venkataramani 2012). Given the Dust Bowl's well-documented destruction, Dust Bowl survivors are likely to suffer just such damage to human capital. It is this insight that motivates the following analysis.

\section{EMPIRICAL APPROACH}

\section{Data}

To measure the impact of early-life Dust Bowl exposure on later-life human capital, I draw from IPUMS a sample of individuals born between 1900 and 1959 in 15 Great Plains and adjacent states (see Figure 1), for whom we can observe stable human capital outcomes in adulthood. Specifically, I take data from the 5 percent samples of the 1980, 1990, and 2000 censuses, which provide detailed individual-level information on a range of human capital and wellbeing outcomes such as educational attainment, poverty, and the incidence of disability (Ruggles et al. 2010). These particular census waves are chosen in part because they capture outcomes, such as educational

\footnotetext{
${ }^{4}$ For instance, infections such as pneumonia in early life have been shown to subvert cognitive development by producing an inflammatory response that diverts resources from normal mental development processes as survival is prioritized (Bhalotra and Venkataramani 2012).
} 
attainment or completed fertility, which might not be stable until middle age; and outcomes, such as disability, which might not manifest until later in adulthood. ${ }^{5}$ They are also chosen for the specific outcomes they contain. For instance, certain disability outcomes are available only in the 2000 census, while college and high school completion can only be calculated from highest grade variable listed in 1980. Summary statistics on the adult human capital outcomes used in this study, by gender, are available in Table 1. Graphs of outcome summary statistics by gender and birth year, with 95 percent confidence intervals, are provided in Figures A1a-A1i in Section 4 of the Online Appendix.

Using the year and state of birth listed in IPUMS, I assign each individual a measure of childhood exposure to the Dust Bowl. Temporal variation in Dust Bowl exposure comes from cohort membership. I consider an individual to have been treated by the Dust Bowl if they were a child at any point during the Dust Bowl. I take the Dust Bowl period to last from 1930-1940, and I define childhood as the ages -1 to 12 to capture the period in utero to the onset of puberty. Accordingly, those born 1918-1941 are taken as treated in the main analysis, while the remaining individuals, who were either too young or too old to have been children at the time of the Dust Bowl, serve as control cohorts. The inclusion of a range of different birth-year cohorts within each of the treated and control groups provides the variation necessary to disentangle age-at-exposure effects from cumulative (i.e., chronology-related) effects.

To identify the spatial component of Dust Bowl exposure during childhood, I use measures of soil erosion for 15 Great Plains and adjacent states (see Figure 1a), which account for 23 percent of US population (U.S. Census Bureau 2002), and 47 percent of US landmass (U.S. Census Bureau 2013) in 1930. Beyond what is typically thought of as the core Dust Bowl region, this group of states adds both similar nearby states in which there was relatively little damage, and states which are typically overlooked but which nevertheless suffered substantial erosion during the Dust Bowl. ${ }^{6}$ Thus, this choice of states offers sufficient variation in erosion to enable analysis when erosion must

\footnotetext{
${ }^{5}$ Although we might worry about attrition before enumeration, I show in a series of robustness checks that cohort-level mortality is unrelated to Dust Bowl exposure. This fact, together with the presence of pre- and post-Dust Bowl birth cohorts, and the effective controls for age implied by the presence of both birth year and census year fixed effects, ameliorates concerns about attrition unrelated to Dust Bowl severity (i.e., that related solely to the age at enumeration).

${ }^{6}$ The choice of these 15 states accords with qualitative and quantitative accounts such as the Soil Conservation Service (1935), the Great
} 
be assigned at the birth-state level, which is the most granular level for which nativity information is available in the IPUMS data.

Erosion measures are taken from the US Soil Conservation Service. Beginning in 1934 in response to the Dust Bowl, and continuing over its course, the Soil Conservation Service conducted comprehensive surveys of soil conditions across the United States, identifying thousands of areas of erosion classified by the severity (e.g. slight, moderate, severe) and type (e.g. sheet, wind, gullying) of damage observed (Soil Conservation Service 1935). By 1948, the office had created the first of a series of maps cataloging the cumulative erosion experienced over the full Dust Bowl period. I take my erosion figures from this cumulative erosion map, which characterizes erosion severity by percentage of original topsoil lost: high (75 percent or more), medium (25-50 percent), and low (0-25 percent) erosion (Hornbeck 2012). To control for possible changes to county boundaries during the Dust Bowl period, per Hornbeck (2012), 1910 county boundary definitions are enforced for measures of erosion, population, and farm value.

Since the severity of the Dust Bowl in human terms depends on population distribution over space within a given state, I weight erosion measures by population, taken from the US Census, such that states with a greater proportion of population residing in high-erosion counties are deemed to have been more severely treated by the Dust Bowl. As an alternative means of weighting erosion, I also use measures weighted by the farm population. Erosion measures are constructed at the state level so as to correspond to individual outcomes from IPUMS, which can only be measured at the birth state level. ${ }^{7}$

One limitation of the erosion data is the lack of baseline erosion measures, since no erosion surveys were made prior to 1934 (Soil Conservation Service 1935; Hornbeck 2012). To account for possible measurement error due to the absence of information on pre-1930 erosion levels, I substitute data from the US Census of Agriculture

Plains Committee (cited in p. 669 of Hansen and Libecap 2004), Worster (1979), Hansen and Libecap (2004), Nealand (2008), and Hornbeck (2012), that place the epicenter of the Dust Bowl in the Great Plains region and nearby states. Indeed, previous studies using erosion-based methodologies to study Dust Bowl phenomena, such as Hansen and Libecap (2004) and Hornbeck (2012), have used a similar sample of states. By including states on either side of the core Great Plains region, I ensure sufficient variation in erosion severity to allow for difference-in-differences analysis. For further discussion of the states included in the sample, see Section 2 of the Online Appendix.

${ }^{7}$ IPUMS data and censuses do not include more granular nativity, such as birth county or birth city. 
on the percentage change in farm values between 1930 and 1940 for the erosion $_{s}$ term in equation (1) as a robustness check, since 1930 farm values proxy the quality of land prior to the Dust Bowl. ${ }^{8}$ Maps detailing the severity of Dust Bowl exposure by measures of erosion and change in farm values are detailed in Figure 1.

\section{Identification strategy}

I adopt a difference-in-differences approach, wherein plausibly exogenous environmental shocks to income and health — in the form of Dust Bowl-induced soil erosion — interact with cohort membership to impact later-life human capital. My baseline specification is as follows, and is estimated by OLS:

(1) $h_{i b s t}=\alpha+\beta_{1} \times$ treated $_{b} \times$ erosion $_{s}+x_{i b s t}^{\prime} \psi+\theta_{s}+\lambda_{b}+\eta_{t}+\gamma_{b s}+u_{i b s t}$

Here, $h_{i b s t}$ represents the later-life human capital outcome of interest for individual $i$ born in year $b$ in state $s$ and observed in census year $t$. The term treated $_{b} \times$ erosion $_{s}$ is the chief variable of interest, and refers to whether an individual was a child during the Dust Bowl and whether they were exposed to high erosion. It may thus be interpreted as the reduced form effect of childhood Dust Bowl exposure on adult outcomes. Treated ${ }_{b}$ is equal to 1 for individuals aged -1 to 12 at any time during the Dust Bowl, so as to capture the effects of the shock during childhood, which has been defined so as to span the period in utero up to the onset of puberty. ${ }^{9}$ Thus, in a sample comprising birth years 1900-1959, the Dust Bowl-treated cohort comprises children born 1918-1941. Erosion represents the erosion intensity in a given state over the Dust Bowl period-that is, the degree of exposure to this random environmental shock. Since county-level erosion is known but birth county is not, in the baseline, erosion $_{s}$ is constructed as the proportion of the state population in 1930 living in high-erosion counties within that state. Accordingly, it may be interpreted as the probability an individual born in a given state was born into a high-erosion

\footnotetext{
${ }^{8}$ Although drought might be considered an alternate measure of Dust Bowl exposure, it is poorly correlated with erosion and occurs most severely over the 1930-1940 period in states in the upper Midwest and Mountain West. These states experienced little to no erosion, and qualitative accounts place them well outside of the core Dust Bowl region.

${ }^{9}$ In alternative specifications, I modify the temporal measure of treatment to capture the age at exposure. Disaggregating exposure in this manner (i.e., by the developmental stage in which it occurred), and testing which specific outcomes are most responsive to exposure at different ages, helps shed light on possible mechanisms. For instance, they are suggestive of whether effects are likely direct (e.g. respiratory illness, absence from school) or indirect (e.g. poor nutrition due to low incomes, developmental complications due to poor maternal health).
} 
county. Since census data do not allow for the identification of those who may have migrated away from the birth state during childhood, the treated $_{b} \times$ erosion $_{s}$ term may be interpreted as an intent-to-treat estimate. Thus, its coefficient, $\beta_{1}$, describes the causal effect of Dust Bowl treatment relative to those not exposed.

Finally, $x_{i b s t}$ represents a vector of controls (in baseline, the individual's race; outside it, race, veteran status, and birth-state-birth-year per capita income), while $\theta_{s,}, \lambda_{b}, \eta_{t}$, and $\gamma_{b s}$ represent birth-state fixed effects, birthyear fixed effects, census-year fixed effects, and linear birth-state trends, respectively. Together, these variables control for several dimensions of unobserved heterogeneity while also stripping away the effects of larger-scale trends in outcomes during this period, such that $\beta_{1}$ may be interpreted as the causal effect of Dust Bowl exposure above and beyond these phenomena. ${ }^{10}$ Standard errors are two-way clustered by birth state and birth year so as to adjust for serial correlation in outcomes, and the equation is estimated separately for men and women to identify gender differences in Dust Bowl impacts.

For the purposes of identification, erosion must be plausibly exogenous, and the pre-trends in outcomes between high- and low-erosion birth states should be parallel. On the latter issue, comparisons of cohort trends in outcomes by above- and below-mean-erosion states indicate that parallel trends assumptions are upheld (not reported). I elaborate on the former issue below.

Although as an environmental phenomenon, we might expect that the Dust Bowl would be clearly exogenous, it could be endogenous if human activity exacerbated adverse weather conditions, or if individuals were selected into residence in the Great Plains. On the first point, although the contribution of Great Plains settlers to land degradation and dust storms has been long debated by scholars of the Dust Bowl (see, e.g., Worster, (1979), or Hansen and Libecap (2004)), more recent and in-depth analysis by Cunfer (2005) suggests that the Dust Bowl was largely driven by exogenous and cyclical climatic conditions and was not, as previous scholars have proposed and as had been popularly assumed, a man-made disaster. Thus, particularly when measured at the state level, it seems reasonable to treat the Dust Bowl as exogenous.

On the second point, we might worry that the Great Plains were settled by the poorest and most desperate

\footnotetext{
${ }^{10}$ Note that the un-interacted treated ${ }_{b}$ and erosion $_{s}$ terms have been excluded for collinearity with, and are instead absorbed by, the birth year $\left(\lambda_{b}\right)$ and birth state $\left(\theta_{s}\right)$ fixed effects, respectively.
} 
farmers, who may have taken marginal lands and cultivated them sub-optimally. If this were the case, then we might expect that individuals born in more severely-stricken states were substantially more sensitive to Dust Bowl shocks because of their poverty, or that they were more prone to pursue farming strategies that depleted the land. However, there is no clear indication that erosion severity and pre-Dust Bowl poverty were strongly associated on the eve of the Great Depression: the correlation between Dust Bowl erosion and per capita personal income in 1929 is a relatively weak 0.29. Furthermore, the difference-in-differences design accounts for the pre-Dust Bowl period. That is, it naturally compares individuals born in Dust Bowl states before and after the shock to those born in Dust Bowl states during the shock. Thus, if Great Plains residents were adversely selected (say, due to nineteenth-century homesteading policies), then the inclusion in the (untreated) control group of individuals selected in the same manner as those who were treated, and using the same sorts of farming techniques as those treated, would help mitigate the concern over the endogeneity of Dust Bowl victims. ${ }^{11}$ Lastly, after controlling, as I do, for state fixed effects and trends, it is unlikely that selective settlement or cultivation patterns in the lead-up to the 1930s would have effects on later-life outcomes except through the Dust Bowl.

\section{MAIN RESULTS}

I begin by testing the impact of Dust Bowl exposure on later-life outcomes by sex. ${ }^{12}$ Table 2 lists the estimates of $\beta_{1}$ from equation (1) for each of the later-life outcomes considered. I find that individuals exposed to the Dust Bowl as children suffered permanent damage to human capital and wellbeing on a scale that is both statistically and economically significant. Under the baseline specification in column (2), I find that exposed women had a 1.17 percentage point lower probability of completing college, and a 0.47 percentage point higher probability of living in poverty, defined as living at or below the census poverty line (see Section 2 of the Online Appendix). The poverty effects for men (column 1) are even starker: exposed men have a 0.80 percentage point

\footnotetext{
${ }^{11}$ The only way these two related concerns regarding settler sensitivity and influence on erosion might remain would be if the effects of land degradation were cumulative, and had only failed to produce dust storms and erosion during previous cycles of adverse weather because prior to the 1930s, the relevant threshold of land degradation had not yet been reached.

${ }^{12}$ I also examine race-based differences in the effects of the Dust Bowl, and find that non-white individuals exposed to the Dust Bowl have better high school completion and poverty outcomes than their white Dust Bowl-exposed counterparts, and that non-white Dust Bowl-cohort women also enjoy better outcomes on later-life disability (not reported). However, because there are very few nonwhite individuals in many of the states in the sample, the main analysis proceeds without interacting exposure with race.
} 
greater likelihood of living in poverty than men who were not exposed, and receive $\$ 15.05$ more in welfare payments. Furthermore, exposed men have a 1.10 percentage point greater chance of experiencing physical disability.

Columns (3) for men and (4) for women present the $\beta_{l}$ values for regressions in which the erosion $_{s}$ variable in equation (1) is instead defined as the proportion of the state's farm population (rather than total population) living in high-erosion counties (see Section 2 of the Online Appendix). In effect, these regressions test whether the Dust Bowl only mattered insofar as farmers were exposed: if a county hit by the Dust Bowl contained no farmers, it would not be considered exposed to the Dust Bowl, and would not contribute to the state's erosion level. Under this specification, exposed women see a fertility reduction of 0.35 children ever born, as well as a 2.09 percentage point decrease in the probability of completing college. The latter outcome is nearly twice as severe as in the baseline (i.e., population-weighted erosion) specification. Exposed women are 0.77 percentage points likelier to be living in poverty than their unexposed counterparts; exposed men, 1.27 percentage points likelier. Exposed men similarly have a 1.73 percentage point increase in the probability of physical disability, a figure roughly 50 percent more severe than the in the baseline.

Finally, in columns (5) - (6), percentage change in farm values between 1930 and 1940 takes the place of erosion as the measure of Dust Bowl severity. As before, the measure is population-weighted. That is, I use the share of the population living in counties that experienced above-average losses in farm value over the1930s. This farm-value-based measure is a useful exposure proxy since it does not penalize states that may naturally experience poor land quality or higher levels of pre-1930 erosion, traits that the baseline specification would attribute to the Dust Bowl. Here I find similar effects on poverty and welfare payments. However, a number of additional impacts are also statistically significant, most notably, disability: exposed men see a 1.12 percentage point greater chance of experiencing self-care and independent mobility disability, while exposed women experience $1.45,0.94$, and 1.29 percentage point increases in cognitive, vision and hearing, and self-care and independent mobility disabilities, respectively. Exposed women also see a 3.71 percentage point greater chance of high school completion than their unexposed counterparts. This seemingly counterintuitive finding (which also appears in the results in Tables 4-6 concerning agriculture, developmental stage, and public spending) may in fact 
reflect a drop in the opportunity cost of secondary schooling as farms, and thus, the demand for child farm labor, collapsed. I will return to this result in greater detail shortly. ${ }^{13}$

These results are intuitive, economically meaningful, and consistent with the literature on childhood shocks (e.g., Almond et al. 2007; Banerjee et al. 2010; Ó Gráda 2010). The Dust Bowl had negative consequences for health, human capital, and indicators of wellbeing, increasing poverty and disability, and decreasing rates of college completion. ${ }^{14}$ What is more, the long-run effects of the Dust Bowl on human capital appear to be on a similar scale to the event's short-run effects on land value. ${ }^{15}$

\section{MECHANISMS}

Next, I investigate pathways through which the Dust Bowl may affect later-life outcomes. First, I test whether the types and severity of adverse effects are linked to the developmental stage at which children were exposed to the Dust Bowl. Second, I test for the effects of New Deal spending in ameliorating adverse effects on children's health, nutrition, and education. I report these results in Tables 3-6. Here, I show that many of the adverse effects outlined in the preceding section — for instance, lower rates of postsecondary education — appear

\footnotetext{
${ }^{13}$ Although the high school movement (HSM), a nationwide expansion of secondary schooling from 1910-1940, was strong in many of the states in this sample (see, e.g., Goldin and Katz (2011)), it is unlikely that this movement accounts for the results found here. The bulk of the Dust Bowl cohort graduated high school after 1940, and calculations using data from Adriana Lleras-Muney (2002) show that the correlation between Dust Bowl severity and measures of high school movement intensity are very low. Furthermore, placebo regressions in which HSM eligibility replaces Dust Bowl eligibility show small, positive, and insignificant effects on high school completion (not reported). This suggests again that Dust Bowl severity is not systematically related to the strength of the high school movement in the states in question.

14 The magnitudes of effects found here are economically meaningful, particularly when taking into account the average levels of human capital presented in Table 1. For instance, a 1+ percentage-point reduction in the probability of college completion is large in a cohort whose average college completion rate is roughly 15 percent, and in an era where college graduates could expect a lifetime earnings premium of roughly 43percent over a high school graduate (Vandenbroucke, 2015; calculation is based on the expected lifetime earnings of white men in the U.S. born in 1930.) For a discussion of effect magnitudes of other early-life interventions, see Bhalotra and Venkataramani (2012), p. 32 and Almond and Currie (2011a), which provides a survey of similar studies.

${ }^{15}$ For instance, Hornbeck (2012) estimates the Dust Bowl-induced loss in farmland value over the 1930 s to be roughly $\$ 30$ billion in 2007 dollars. Taking just one dimension of human capital for comparison - namely, the probability of college completion-I perform a back of the envelope calculation using the size of the adverse college completion coefficient, the size of the Dust Bowl cohort, and the lifetime college earnings premium (relative to high school graduates, for white men born in 1930; see Vandenbroucke, 2015). This suggests that a 1-percentage point reduction in college completion would imply roughly $\$ 49$ billion less in lifetime earnings in 2007 dollars.
} 
to stem from low incomes and developmental complications in early life. Furthermore, I provide evidence that the New Deal was able to mitigate these environmental insults, suggesting that there is scope for compensating investments to remediate adverse shocks in early life.

\section{Developmental stage}

To pinpoint the effects of the timing of exposure, I estimate equation (1) substituting the proportion of a given age band spent during the Dust Bowl period for the original treated ${ }_{b}$ term. Thus, where all those aged -1 to 12 at any point between 1930 and 1940 would have been counted as treated on a binary basis, now each individual receives a duration-weighted measure of exposure during each development stage, defined as follows: -1 to 0 (in utero/neonatal), 1 to 3 (infancy), 4 to 6 (early childhood), 7 to 9 (school age), and 10 to 12 (early adolescence). See Section 2 of the Online Appendix for further discussion of development stage measures. ${ }^{16}$

In Table 3 I report estimates of $\beta_{1}$ for men, and in Table 4, those for women. ${ }^{17}$ I find that age at exposure matters, both to the severity and significance of adverse effects. Additionally, by disentangling the Dust Bowl's effects by developmental stage, these results provide suggestive evidence of the likely pathways of impact that the baseline regressions obscure.

For men, adverse effects on poverty (\$14.15-16.29 more in welfare receipts) and disability (1.69-1.89 percentage point higher rates of physical disability) are worst amongst those exposed in utero and in infancy. Adverse effects appear to dampen as the age of exposure rises, ${ }^{18}$ except notably in disability outcomes; in the early

\footnotetext{
${ }^{16}$ Note that each developmental-stage age bin contains many birth cohorts, each with very different durations of total childhood Dust Bowl exposure, and each belonging to the age bin in question at different points in chronological time. Accordingly, we can interpret the developmental stage results as age-at-exposure effects, rather than as total-exposure effects or effects related to the way the Dust Bowl changed local economies over time.

${ }^{17}$ Patterns by outcome and developmental stage are plotted in Figures A2-A10 in Section 4 of the Online Appendix.

${ }^{18}$ In Tables 3 and 4, as throughout this paper, I present intent-to-treat estimates. These suggest that effect sizes at older ages at exposure are often smaller than those in younger ages at exposure. It should be noted, however, that analysis using the 1940 census (not reported) indicates that the share of childhood migrants (i.e., those for whom erosion exposure may have been cut short), rises with age, although age-specific migration propensity appears to be similar irrespective of birth cohort. Although this fact does not change the intent-to-treat estimates, it does suggest that the gap between treatment-on-the-treated and intent-to-treat estimates will rise with age at exposure. Nevertheless, because age-specific differences in compliance are relatively small, the results on Dust Bowl impacts by developmental stage do not appear to be an artefact of age-specific migration.
} 
adolescence period, shocks that in early childhood produced greater likelihoods of physical disability instead produce lower likelihoods of physical and vision and hearing disabilities. ${ }^{19}$ These findings are consistent with the idea that congenital health defects (rather than, say, schooling disruptions) may be responsible for poor later-life outcomes and that these may act through disability, or even directly, to produce lower adult socioeconomic status.

For women, fertility outcomes are negatively affected across developmental stages. Exposed women experience a 0.18 to 0.27 -child reduction in fertility, with the greatest adverse impact occurring in the 4 to 6 age range. That fertility reduction effects are greatest for those exposed to the Dust Bowl well before puberty suggests early damage to reproductive health, perhaps through poor nutrition. This interpretation is corroborated by the fact that exposed women had neither the higher marriage ages nor the higher college-completion rates associated with the deferral of childbearing in favor of long-term career planning (Goldin and Katz 2002), nor did they experience income levels in adulthood that might have induced them to voluntarily restrict fertility. This finding is particularly striking given the nationwide post-war "baby boom" trend in fertility experienced by the generation born in the 1920s and 1930s (see Figure A1a in Section 4 of the Online Appendix).

Meanwhile, as with men, it is in early childhood that exposed women's college completion, poverty, and disability effects are worst. Women exposed between the ages -1 and 6 had a 1.36-1.54 percentage point lower chance of completing college, with the greatest adverse effects accruing to those exposed in utero. A similar pattern follows for probability of poverty ( 0.73 percentage points higher for those exposed -1 to 0 and 0.51 percentage points higher for those exposed 1 to 3) and for physical disability and self-care and independent mobility difficulty (1.28 and 0.57 percentage points higher for those exposed in utero, respectively). For both sexes, the preponderance of damage where exposure was in early childhood suggests that the pathway of impact is largely through subverted capability formation. ${ }^{20}$

\section{Public spending responses}

Dynamic models of capability formation, such as that outlined in James Heckman (2007), suggest that

\footnotetext{
${ }^{19}$ These findings are also consistent with the theory outlined in Heckman (2007), Cunha and Heckman (2008), and Almond and Currie (2011a).

${ }^{20}$ For contrast, the positive effects observed for secondary schooling in later childhood, discussed later on in the paper, implicate access to labor markets and public services.
} 
where the intertemporal elasticity of substitution in human capital investments is low, it may be very difficult to recover from early shocks to the human capital endowment. Remediation, then, is a matter for empirical study. However, the evidence base to date on the substitutability and complementarity of investments across periods is both limited and mixed (see reviews in Douglas Almond and Bhashkar Mazumder (2013), Valentina Duque, et al. (2017), and Maya Rossin-Slater and Miriam Wüst (2017)). The 1930s famously saw the rollout of a series of New Deal-related spending programs — such as cash assistance, farm loans, and the building of schools, hospitals, and roads - that may have provided relief to Dust Bowl-stricken households. This raises an important question: although the results thus far make it clear that the Dust Bowl did have a statistically significant and economically meaningful adverse impact on the human capital of exposed individuals, could things have been even worse? Put another way, is there empirical support for the possibility of remediation in this setting? To examine this question, I test for whether New Deal spending attenuated Dust Bowl impacts.

I interact measures of total state-level per capita public spending over the period, taken from Price Fishback et al. (2003), with the measure of treatment as follows:

$$
\begin{aligned}
h_{i b s t}=\alpha & +\beta_{1} \times \text { treated }_{b} \times \text { erosion }_{s}+\beta_{2} \times \text { publicspending }_{s} \times \text { treated }_{b} \times \text { erosion }_{s} \\
& +\beta_{3} \times \text { publicspending }_{s} \times \text { treated }_{b}+x_{i b s t} \psi \psi+\theta_{s}+\lambda_{b}+\eta_{t}+\gamma_{b s}+u_{i b s t}
\end{aligned}
$$

Depending on the specification, the public spending variable above takes one of three values. The first is relief expenditure, which includes Works Progress Administration, Federal Emergency Relief Administration, and Public Assistance grants; the second is loans, which includes loans made in aid of farms and housing; and the third encompasses all New Deal expenditures, including additional expenditures such as those on the construction of roads and public buildings. ${ }^{22}$ Evidence suggests that these state-level measures of New Deal-related spending may be treated as plausibly exogenous to Dust Bowl severity. For instance, I find these public spending variables to be largely uncorrelated with observable birth-state characteristics such as erosion. Additionally, panel regressions using annual state-level spending data for a variety of highly granular New Deal programs (Fishback 2015; Fishback and Kachanovskaya 2015) indicate no significant relationship between spending

\footnotetext{
${ }^{22}$ See Fishback et al. (2003) for details of the variables' construction, sources of the underlying data, and discussion of New Deal-era programs.
} 
and contemporaneous or lagged values of state drought or income per capita, except in the case of a few very narrow categories of relief spending (not reported).The apparent exogeneity of New Deal allocations to statelevel need during the 1930s is consistent with Price Fishback et al. (2007) and Fishback et al. (2003), who suggest that funding may not have been allocated purely to severely-affected regions; rather, such spending may have in part been used to curry political favor. Although we might expect states that were more politically engaged, civic-minded, or public goods-oriented to receive more funding (and so, to enjoy different returns to or takeup of remediation efforts), the evidence on this is mixed. State-level spending appears to be weakly to moderately positively correlated with turnout in the 1928 and 1932 presidential elections, weakly to moderately negatively correlated with pre-existing healthcare provision, and strongly positively correlated with pre-existing educational provision.

The results from these regressions are reported in Table 5 (for men) and Table 6 (for women). Public expenditure associated with the New Deal is found to ameliorate the adverse effects of Dust Bowl exposure in large and statistically significant ways. Relief spending in particular appears to mitigate the damage caused by Dust Bowl exposure: a one standard deviation increase in per capita relief spending reduces exposed men's welfare income by $\$ 60.13$, and lowers the probability of work disability, vision and hearing disability, and selfcare and independent living disability by $0.89,4.49$, and 2.05 percentage points, respectively. Per capita loans similarly ameliorate adverse impacts on male college completion and female work disability, albeit to a smaller degree: a one standard deviation increase in per capita loans is associated with a 0.66 percentage point greater chance of completing college, and the same increase in spending contributes to 0.52 percentage point lower rates of work disability amongst exposed women.

Broader New Deal expenditures, meanwhile, are associated with higher probabilities of high school completion among both exposed men (5.93 percentage points for a one standard deviation increase in spending) and exposed women (3.26 percentage points). Given that loans and broader New Deal spending are associated with higher probabilities of high school completion amongst the exposed, but the subset of New Deal spending focused on direct relief has the opposite effect, perhaps spending was most effective on improving secondary schooling outcomes where it was targeted at agricultural recovery and infrastructural investment. Clearly, state 
spending aimed at Depression and Dust Bowl recovery appears to have been effective in compensating for earlylife insults and diminishing the worst Dust Bowl impacts on human capital, in particular those on disability and schooling. These results are consistent with some recent studies in modern developing countries, in which positive shocks to income have been shown to partially or even fully mitigate early-life deprivation (Gunnsteinsson, et al. 2016; Adhvaryu, et al. 2016). Importantly, relative to these comparatively short-run studies, I show that the effects of childhood remediation efforts persist well into adulthood.

\section{ROBUSTNESS}

The results discussed thus far refer to coefficients that are statistically significant at the standard levels. However, many results, particularly those for college completion and disability, also survive the much stricter standards imposed by the Bonferroni correction for multiple comparisons. ${ }^{24}$ Specifications including controls for age (to account for life cycle effects) and veteran status (to account for possible G.I. Bill benefit effects on postsecondary education and income/wealth) produce similar results to those in the baseline (not reported). Results are also robust to the removal of trends, ${ }^{25}$ controls for place of residence and birth-residence migration paths,${ }^{26}$ alternate approaches to the standard errors, ${ }^{27}$ alternate definitions of treated cohorts, ${ }^{28}$ and alternate

\footnotetext{
${ }^{24}$ Tables 2-6 use daggers to denote the strength of a coefficient's Bonferroni-corrected significance.

${ }^{25}$ Motivated by the non-linear trend in fertility, I re-estimate the key results for the children ever born outcome using quadratic state trends. The use of quadratic rather than linear trends makes coefficients smaller in magnitude, but generally raises their statistical significance. For instance, the core statistically significant effects on this outcome continue to be negative and to occur in the ages 1-9 exposure bands, although the size of the effect is roughly halved (not reported).

${ }^{26}$ Studies such as James Heckman, et al. (1995) suggest that estimates of the long term effects of human capital inputs may be sensitive to the place of residence in adulthood, or to selection into specific migration paths, thus conflating the early-life input with selection or with the subsequent environment. Accordingly, in one robustness check, I add controls for the census region of enumeration, and in another, I replace birth-state fixed effects with dummies for birth-state-region-of-enumeration pairs. Both approaches produce results virtually identical to those presented in the main results (not reported), suggesting that these confounders are not a major issue in this analysis.

${ }^{27}$ I find that two-way clustering in this manner produces very similar standard errors to those obtained by clustering on birth state alone, or by using a wild cluster bootstrap approach (not reported).

${ }^{28}$ The results presented in the baseline, where cohorts aged -1 to 12 are deemed treated by the Dust Bowl, are generally very similar to those obtained when restricting treated status to just those either aged -1 to 5 at any time during the Dust Bowl, or whose entire -1 to 5 period occurred during the Dust Bowl (not reported). Where there may be differences, they are generally small, and are consistent with the results presented in Tables 3 and 4 on the impact of the Dust Bowl by developmental stage at exposure. That is,
} 
definitions of Dust Bowl severity (not reported). Clearly, the Dust Bowl was a meaningful shock that severely influenced the human capital and later-life welfare of those exposed.

Nevertheless, there are four major phenomena that could be said to have confounded effects that I attribute here to Dust Bowl exposure: the Great Depression, which could have affected childhood incomes independently of the Dust Bowl; migration from the Great Plains to the West, which could have affected duration of treatment and sample selection; and selection into the sample (fertility) or out of the sample (mortality). Below I provide evidence to suggest that these issues are unlikely to undermine my analysis and findings. ${ }^{29}$

\section{The Great Depression}

First, the difference-in-differences approach is designed to test the effect of differences in severity of Dust Bowl exposure even within cohorts in which all individuals were exposed to the Depression. Thus, as long as Depression severity is not systematically correlated with erosion (which does not appear to be the case), $\beta_{l}$ isolates the treatment effect of the Dust Bowl above and beyond the effects of the Great Depression. ${ }^{30}$

Second, I control for several fixed effects and trends that account for variation beyond that due to the Dust Bowl. These include birth-year fixed effects, which control for nationwide macroeconomic shocks; birthstate fixed effects, which take into account a state's level of economic development; and state trends, which capture trends in state economic performance and public spending over time. Only if the Depression's effects varied dramatically within a state (for instance, spatially or demographically) might the latter two controls be insufficient to approximate the Depression's effect on individuals. ${ }^{31}$ While controls for an individual's actual

where Tables 3 and 4 identify outcomes as being impacted by very early-childhood exposure, these -1-to-5 restrictions amplify the baseline result, while where Tables 3 and 4 suggest older ages at exposure matter, the exclusion from treatment of children exposed to the Dust Bowl at older ages yields coefficients smaller than in the baseline.

${ }^{29}$ Sources used exclusively in analysis appearing in the Online Appendix are not included in the main paper's references; instead, they are given only in the Online Appendix's reference list.

${ }^{30}$ Furthermore, Depression severity (which I measure by the ratio of state per capita income at various stages of the Depression to 1929 baselines) appears to be relatively similar across the states in the sample (Bureau of Economic Analysis 2012).

${ }^{31}$ Examination of county-level retail sales per capita for 1929, 1933, 1935, and 1939, a proxy for local economic conditions, (Fishback et al. 2005) suggests that intra-state, inter-county variation in these circumstances was non-negligible (the standard deviation in county retail sales per capita ranges from roughly 20-50 percent of the mean at its peak, with urban and resource-rich 
household income in childhood would be ideal, these figures are not available in the census.

Lastly, in the absence of information on actual childhood household circumstances, I control for statelevel childhood income per capita, meant to proxy for Great Depression effects (Fishback and Thomasson 2014). ${ }^{32}$ Although, consistent with Fishback and Thomasson (2014), childhood income has an intuitive and significant impact on outcomes such as disability, results on Dust Bowl exposure are robust to the inclusion of these controls (reported in the Section 3 of the Online Appendix), which include real state per capita personal income in the birth year, in the year before birth, and averaged over childhood (ages -1 to 12). These results suggest the Dust Bowl had adverse effects above and beyond those due to the Depression; indeed, it is likely that the Dust Bowl, and not just macroeconomic shocks, contributed to the low incomes experienced in this period in the Great Plains.

\section{Migration}

First, since migration status during childhood is unknown, equation (1) proceeds as an intent-to-treat analysis, meaning that the adverse effects estimated here are likely a lower bound on the true treatment effects of the Dust Bowl. Indeed, regressions disaggregating adult outcomes by (eventual) migrant status indicate that migrants had wellbeing outcomes similar to or better than non-migrants. This could be because Dust Bowl exposure was cut short by childhood out-migration, because the destination state offered better conditions to remediate early-life insults, or because migrants were positively selected on health or other related observables. In the first two cases, my analysis would, by conflating plausible migrants and non-migrants, actually understate the adverse effects experienced by exposed non-migrants (methods and results reported in Section 3 of the Online Appendix). If, however, the better outcomes of migrants are exclusively a function of positive selection, then the Dust Bowl effects estimated here are neither under- nor over-estimates. I find little evidence of selection into migration when looking

\footnotetext{
states the most spatially unequal), but that this variation dropped considerably during the trough of the Depression as counties' fates became more uniformly poor. When accounting for the spatial distribution of population, however, this intra-state variation becomes much less pronounced.

${ }^{32}$ It should be noted that even some measure of the observed Depression severity, as traditionally captured in variables such as state per capita personal income or per capita retail sales, is likely to reflect agricultural damage wrought by the Dust Bowl. As an environmental event and as measured by erosion, the Dust Bowl was more clearly exogenous.
} 
for socioeconomic-status gradients in the probability of migration during childhood (see Table A4). Although the data do not allow me to fully rule out selection into post-childhood migration, the baseline results are unchanged after adding controls for the state of adult residence and the birth-state-residence-state migration path. Finally, I find that childhood Dust Bowl severity has no significant effect on eventual migration status as an adult (see Section 3 of the Online Appendix).

Second, migration is unlikely to have affected childhood treatment. Even individuals migrating as children are unlikely to have escaped the phase in which I find the strongest adverse impacts of exposure: the -1 to 0 age band, a narrow and vulnerable timeframe in a child's life. This, added to the fact that interstate migration rates were actually "unusually" low during the 1930s (Rosenbloom and Sundstrom 2004; Long and Siu 2016), suggests migration during the treatment window is unlikely to influence exposure measures.

Third, I find little evidence of migrant selectivity. Neither Dust Bowl severity nor measures of household income and socioeconomic status, conditional on Dust Bowl treatment, are significant in determining the likelihood of migration in childhood (methods and results reported in Sections 1 and 3 of the Online Appendix). The only significant difference is found in Dust Bowl-exposed children from farm households, who were if anything less likely to have migrated before age 12 than the non-farm exposed, consistent with Long and Siu (2016), who find that farmers were the least likely to have moved during the Dust Bowl. Secondary literature, too, suggests an ambiguous (or even non-existent) relationship between migrant status and individual/household characteristics, such as wealth, which one might expect to affect both treatment and the response to the shock (Lord 1938; Wallace 1938; Worster 1979; Nealand 2008; Burns et al. 2012; Long and Siu 2016). Together, these findings suggest no systematic difference in migrant and non-migrant characteristics in this setting.

\section{Fertility selection}

Work on crisis events such as famine and macroeconomic busts indicates that often in such periods, only those who can afford to provide for children will choose to continue bearing them (Dehejia and Lleras-Muney 2004; Ó Gráda 2011). If such a phenomenon were at play during the Dust Bowl, I would expect that the individuals most resilient to and best able to compensate for the shock would disproportionately enter my sample, while many of the most vulnerable would never been born at all. This would tend to understate the adverse effects of the shock. 
Similarly, any involuntary reductions in fertility amongst Dust Bowl mothers (for instance, due to malnutrition- or stress-related amenorrhea) would also raise the average health status of the Dust Bowl cohort in ways that would lead me to underestimate the event's damage to later-life human capital (Ladurie 1969).

I test for such fertility selection into my sample and find no statistically significant differences in fertility in response to the Dust Bowl by maternal socioeconomic status (methods and results reported in Sections 1 and 3 of the Online Appendix). Analysis of vital statistics shows that the timing and severity of erosion did not drive change in birth rates: indeed, states experienced no significant change in birth rates during the Dust Bowl period, consistent with Cutler et al. (2007) and Fishback et al. (2007). As a further check, regressions inferring Dust Bowl-era fertility adjustments from 1920-50 Census cohort size in single-year age bands indicate no significant effect of childhood exposure to the Dust Bowl on cohort size (not reported). ${ }^{34}$

\section{Mortality selection}

Given that the individuals in the Dust Bowl cohort are aged anywhere from 39-82 by the time I observe them as adults in 1980-2000, survivorship bias may be a concern. That is, many of the individuals in poorest health as a result of Dust Bowl exposure may have died before being observed as adults, a "culling" effect that would bias the wellbeing of individuals in my sample upwards. If such an effect existed, my results would underestimate the true adverse effects of the Dust Bowl on health.

I find no significant change by Dust Bowl exposure in yearly state-level stillbirth rates and infant mortality rates (reported in Section 3 of the Online Appendix). Similarly, I test for whether the Dust Bowl cohort had significantly higher mortality rates than the unexposed at any stage in their life-course, up to and including my observation period. I find no significant difference in mortality rates, except in the 5-14 and 55-64 age bins, during which males in the Dust Bowl cohort experienced marginally lower mortality rates than their unexposed

\footnotetext{
${ }^{34}$ When exposure timing is narrowed to the year before birth, however, 1940 and 1936 birth cohorts are found to have significantly smaller cohort sizes than their untreated age 0 and age 4 counterparts, respectively. Although reductions in cohort size may conflate reductions in fertility with increases in mortality, or may be influenced by mothers' migration, I interpret these cohort size reductions, in light of the other fertility, mortality, and migration results, as evidence of likely voluntary decisions on the part of exposed mothers to forgo or defer childbearing.
} 
counterparts (methods and results reported in Sections 1 and 3 of the Online Appendix). These findings indicate that mortality selection and survivorship bias are unlikely to influence my results.

\section{DISCUSSION}

Taken as a whole, the results presented in this study not only suggest that the Dust Bowl had permanent consequences for health, but they also hint at when and how certain capabilities are developed. In this way, they shed light on the technology of human capital formation. For instance, the finding that health outcomes like disability are determined within the first year of life is reasonably intuitive, given that the fetal programming literature suggests that earlier developmental stages tend to disproportionately influence many health outcomes. However, it is striking that this early-life development pathway would also be responsible for outcomes like college completion and poverty, which one might expect to be associated with deficits in schooling and labormarket preparation resulting from shocks at school-going age. Indeed, given that high school completion rates rise amongst the exposed, why did not college completion rise as well, and poverty levels fall with this acquisition of education? Why does college completion behave like a health outcome? The answer might be that cognitive and physical impairments accrued in utero as a result of maternal poverty and ill-health influenced individuals' ability to enter and complete college, to hold down jobs, and to earn income as adults. That these impairments were not fully remediated by adulthood is consistent with dynamic models of capability formation, such as that in Heckman (2007), in which investments made further in time from a shock are less productive. ${ }^{35}$

For contrast, increases in high school completion among the exposed (a notable exception to the infant exposure pattern more generally observed) suggest that secondary schooling outcomes may depend less on innate ability than on access to opportunity and questions of time use. As discussed briefly with respect to the results using the change in farm value, these increases in high school completion rates are substantial: for instance, men exposed between the ages of 7 and 12 see a 3.42 to 3.61 percentage point greater chance of finishing high school; for women, the figures are even higher, ranging from an extraordinary 4.89 to 6.39 percentage point increase. An

\footnotetext{
35 The results presented in this study are broadly consistent with Heckman's (2007) model of human capability formation where human capital inputs (say, investments or adverse shocks) at different stages of development have nonlinear effects, and where inputs may be complementary rather than perfectly substitutable across time. For more, see Almond and Currie (2011a).
} 
analysis of the short-term impact of the Dust Bowl on school attendance corroborates this finding: 1940 teenagers born in more highly eroded states and counties were statistically significantly likelier to be attending school than their counterparts in 1930 (see Online Appendix and Tables A9-10 for more). Although the idea that a shock at schooling age would affect schooling is intuitive, finding positive outcomes on schooling may appear less intuitive at first glance. Here, the devastation of farming livelihoods may have played a role.

In particular, these findings suggest a tradeoff between secondary schooling and child labor in agriculture. Prior to the Dust Bowl's destruction of farms, child farm labor was prevalent. Robert Whaples (2005) shows that in 1930, 74.5 percent of boys and 61.5 percent of girls aged 10-15 were employed in agriculture, and Clay et al. (2012) indicate that child labor was extensive even in the face of compulsory schooling laws, which were not strictly enforced. Laws restricting child labor, such as the 1938 Fair Labor Standards Act, contained many exemptions for child labor in agriculture, especially on family farms (U.S. Department of Labor, 2007 and 2013). Thus, the collapse of agriculture in the Great Plains may have reduced opportunities for child labor. Child labor and schooling have been shown to be closely related (McNay et al. 2005; Bhalotra 2007; Clay et al. 2012; Baker 2015). For instance, in present-day India, Sonia Bhalotra (2007) finds that lowering the opportunity cost of schooling through cash transfers meant to offset the child's wages is essential to reducing child labor and increasing schooling. Poverty may have remained an issue for Dust Bowl households, but for them, the lack of opportunities for labor in agriculture may have caused a drop in the opportunity cost of schooling. Indeed, Kirsty McNay et al. (2005) find this phenomenon at play where higher rates of girls' schooling in nineteenth-century Britain are found in regions where opportunities for girls' employment were few. Richard Baker (2015) finds a similar effect in the twentieth-century U.S. South, where the boll weevil, a cotton pest, raised the school enrollment of black children, who were unusually active in agricultural work.

Together, the timing of the surge and the fact that farm population-weighting raises the magnitude of the Dust Bowl's high school completion effect suggest that a reduction in the need for child labor in agriculture following the destruction of farms may have lowered the opportunity cost of secondary schooling for school-age (i.e., working-age) children who now had no more profitable way to spend their time. Of course, increased high school completion may also reflect increased public spending — for instance, on school-building — as a response to 
the disaster. Most importantly to our understanding of human capital formation, despite both being educational outcomes, the fact that high school and college completion are associated with exposure in very different developmental stages suggests that these outcomes may in fact have very different inputs and production processes. For instance, childhood time allocation concerns appear to be important to pre-tertiary school attendance decisions (Moehling 1999; McNay et al. 2005; Clay et al. 2012; Baker 2015), while intellectual capability appears to be crucial to to college completion (Heckman 2007). While for present-day households, credit constraints have been found less important than child ability in determining college enrollment (Heckman 2007), it should be noted that the same low incomes that may have played a role in producing poor college outcomes through fetal malnutrition, and thus, cognitive impairments in utero, may also have produced poor college outcomes through constraints on a Dust Bowlstricken parent's ability to afford college.

The results also shed light on the recovery process. Specifically, they show that public spending through New Deal and related programs helped mitigate the Dust Bowl's adverse effects. Thus, these findings provide striking evidence of the capacity for remediation through compensatory investments. Furthermore, they suggest that the New Deal was especially long-reaching through its beneficial effects on individuals' life-course wellbeing. Although these results indicate that some measure of recovery may in fact be possible, the findings that recovery is incomplete, and that those exposed in earlier stages suffer worse outcomes than those struck later on in life, nevertheless suggest that investments in human capital cannot be perfectly substituted across periods in a child's development. Thus, as Heckman (2007) and Douglas Almond and Janet Currie (2011a) discuss, the assumption that investments have linear effects across childhood is likely an unrealistic one.

\section{CONCLUSION}

Through this analysis, I use variation in childhood Dust Bowl exposure to show that this natural disaster had meaningful long-term human capital costs for those exposed as children. For women, fertility and college completion rates fell, while poverty rates rose. For men, poverty rates, welfare receipts, and disability rates rose. Notably, these adverse effects were most severe for those exposed in utero and in early childhood, implicating an indirect health pathway - that is, poor prenatal nutrition and health, and through it, disrupted capability development —in the production of these impacts. 
For all, but especially for women, high school completion rates rose. In contrast to the sensitive periods implicated in the bulk of the outcomes studied here, the impact on secondary schooling was greatest on children who experienced the Dust Bowl in late childhood and early adolescence, when the tradeoff between child farm labor and formal schooling likely dictated time use. In these outcomes (unlike in college completion, which suffered as a result of the Dust Bowl), family income and student cognitive ability were unlikely to be barriers to entry. Results like these offer suggestive and policy-relevant evidence on when and how different capabilities are formed-for example, substantiating the hypothesis that college-readiness may be strongly determined in utero and in early childhood, and suggesting that postsecondary educational interventions should be targeted accordingly. Finally, New Deal-related expenditure is found to have attenuated the Dust Bowl's adverse effects, demonstrating the capacity for remediation even where private investment in recovery may have been constrained in light of large income shocks.

As intent-to-treat rather than treatment-on-the-treated estimates, my results represent the lower bounds on the actual later-life effects of childhood Dust Bowl exposure. This intent-to-treat design stems from a limitation in census data: the absence of information on individuals' circumstances as children. Although adult outcomes cannot be linked to childhood erosion below the state level, making it difficult to accurately gauge an individual's actual Dust Bowl exposure, true erosion exposure may not be as strongly tied to birth county erosion as expected, meaning that the state-level construction of erosion exposure may actually yield two advantages over county-level construction. First, a less localized measure reflects the reality of the considerable intra-state, inter-county migration documented within the Dust Bowl region (Long and Siu 2016), and second, a state-level measure is likelier to capture downwind externalities (Hansen and Libecap 2004). Nevertheless, I do take steps to account for the likely level, timing, and duration of exposure. First, I weight erosion by county population, allowing for a more realistic measure of the severity of human exposure within a state. Second, I disaggregate exposure by developmental stage. Finally, since these data do not allow for analysis of the effects of differences in parental or household characteristics in childhood, I include state-level proxies for childhood economic circumstances.

These results represent an important contribution to our understanding of the Dust Bowl's impacts; namely, they show quantitatively that exposed children suffered long-term and meaningful damage to health and 
human capital. Perhaps more important, however, is the finding that such harm can be overcome through timely and substantial policy intervention.

\section{REFERENCES}

Adhvaryu, Achyuta, Teresa Molina, Anant Nyshadham, and Jorge Tamayo. 2016. "Helping Children Catch Up: Early Life Shocks and the Progresa Experiment." Mimeo.

Almond, Douglas. 2006. "Is the 1918 Influenza Pandemic Over? Long-Term Effects of In Utero Influenza Exposure in the Post-1940 U.S. Population.” Journal of Political Economy, 114(4) 672-712.

Almond, Douglas and Janet Currie. 2011. "Human Capital Development Before Age Five." pp. 1315-486 in Handbook of Labor Economics, Vol.4B, O. Ashenfelter and D. Card, ed., Amsterdam: North-Holland, 2011.

--. 2011. "Killing Me Softly: The Fetal Origins Hypothesis.” Journal of Economic Perspectives, 25(3)153-172.

Almond, Douglas, Lena Edlund, Hongbin Li, and Junsen Zhang. 2007. "Long-Term Effects of the 1959-1961 China Famine: Mainland China and Hong Kong." NBER Working Paper 13384.

Almond, Douglas, Lena Edlund, and Marten Palme. 2009. "Chernobyl's Subclinical Legacy: Prenatal Exposure to Radioactive Fallout and School Outcomes in Sweden.” Quarterly Journal of Economics, 124(4)1729-1772.

Almond, Douglas and Bhashkar Mazumder. 2013. "Fetal Origins and Parental Responses." Annual Review of Economics 5(1):37-56.

Banerjee, Abhijit, Esther Duflo, Gilles Postel-Vinay, and Tim Watts. 2010. "Long-Run Health Impacts of Income Shocks: Wine and Phylloxera in Nineteenth Century France.” Review of Economics and Statistics, 92(4)714-728.

Baker, Richard. 2015. "From the Field to the Classroom: The Boll Weevil's Impact on Education in Rural Georgia." Journal of Economic History, 75(4): 1128-1160.

Barker, David and Clive Osmond. 1986. "Infant Mortality, Childhood Nutrition, and Ischaemic Heart Disease in England and Wales.” The Lancet, 321, pp. 1077-1081.

Bennett, Hugh Hammond. Soil Conservation, London: McGraw-Hill, 1939.

Bhalotra, Sonia. 2007. “Is Child Work Necessary?” Oxford Bulletin of Economics and Statistics, 69(1) 29-55.

Bhalotra, Sonia and Atheendar Venkataramani. 2012. "Shadows of the Captain of the Men of Death: Early Life Health Interventions, Human Capital Investments, and Institutions." Mimeo.

Bonnifield, Paul. The Dust Bowl: Men, Dirt, and Depression, Albuquerque: University of New Mexico Press, 1979.

Bureau of Economic Analysis. 2012. "State Personal Income, 1929-2011.” Accessed 1 Jul 2013 at <http://bea.gov>.

Burns, Ken, Dayton Duncan, and Julie Dunfey, The Dust Bowl: A Film By Ken Burns, 2012. 
Carlson, Avis. 1935. "Dust.” The New Republic, pp. 332-333.

Clay, Karen, Jeff Lingwall, and Melvin Stephens, Jr. 2012. "Do Schooling Laws Matter? Evidence from the Introduction of Compulsory Attendance Laws in the United States.” NBER Working Paper 18477.

Cunfer, Geoff. On the Great Plains: Agriculture and Environment, College Station: Texas A \& M Press, 2005.

Cunha, Flavio and James Heckman. 2008. "Formulating, Identifying and Estimating the Technology of Cognitive and Noncognitive Skill Formation.”J Journal of Human Resources, 43(4) 738-781.

Cutler, David, Grant Miller, and Douglas Norton. 2007. "Evidence on Early-Life Income and Late-Life Health from America's Dust Bowl Era." Proceedings of the National Academy of Sciences, 104, pp. 13244-13249.

Dehejia, Rajeev, and Adriana Lleras-Muney. 2004. “Booms, Busts, and Babies’ Health.” Quarterly Journal of Economics, 119(3)1091-1130.

Duque, Valentina, Maria Rosales, and Fabio Sanchez. 2017. "Integrating Early Life Shocks and Human Capital Investments on Educational Outcomes." Mimeo.

Egan, Timothy. The Long Darkness: Surviving the Great American Dust Bowl, Stroud: Tempus, 2006.

Fishback, Price. 2015. "New Deal Funding: Estimates of Federal Grants and Loans Across States by Year, 1930-1940." Research in Economic History vol 31, ed. Chris Hanes and Susan Wolcott, Emerald Publishing Group.

Fishback, Price, Michael Haines, and Shawn Kantor. 2007. "Births, Deaths, and New Deal Relief During the Great Depression." Review of Economics and Statistics, 89(1) 1-14.

Fishback, Price, William Horrace, and Shawn Kantor. 2005. "The Impact of New Deal Expenditures on Local Economic Activity: An Examination of Retail Sales, 1929-1939." Journal of Economic History, pp. 36-71.

--. 2006. "The Impact of New Deal Expenditures on Mobility During the Great Depression." Explorations in Economic History, 43(2)179-222.

Fishback, Price and Valentina Kachanovskaya. 2015. "The Multiplier for Federal Spending in the States During the Great Depression.” Journal of Economic History, 75(01):125-162.

Fishback, Price, Shawn Kantor, and John Wallis. 2003. "Can the New Deal's Three R's Be Rehabilitated? A Program-byProgram, County-by-County Analysis.” Explorations in Economic History, 40(3) 278-307.

Fishback, Price and Melissa Thomasson. 2014. "Hard Times in the Land of Plenty: The Effect on Income and Disability Later in Life for People Born During the Great Depression.” Explorations in Economic History, 54:64-78.

Fishback, Price, Werner Troesken, Trevor Kollmann, Michael Haines, Paul Rhode, and Melissa Thomasson. 2011. "Information and the Impact of Climate and Weather on Mortality Rates During the Great Depression." The Economics of Climate Change, ed. Gary Libecap and Rick Steckel. Chicago, IL: University of Chicago Press, 
pp. 131-168.

Goldin, Claudia and Lawrence Katz. 2002. "The Power of the Pill: Oral Contraceptives and Women's Career and Marriage Decisions." Journal of Political Economy, 110(4) 730-70.

--. 2011. "Mass Secondary Schooling an the State: the Role of State Compulsion in the High School Movement." in Understanding Long-Run Economic Growth: Geography, Institutions, and the Knowledge Economy (ed. Dora Costa and Naomi Lamoreaux). Chicago, IL: University of Chicago Press, pp. 275-310.

Gunnsteinsson, Snaebjorn., Achyuta. Adhvaryu, Paul Christian, Alain Labrique, Jonathan Sugimoto, Abu Ahmed Shamim, Keith P. West, Jr. 2016. "Resilience to Early Life Shocks: Evidence from the Interaction of a Natural Experiment and a Randomized Control Trial.” Mimeo.

Hansen, Zeynep and Gary Libecap. 2004. "Small Farms, Externalities, and the Dust Bowl of the 1930s." Journal of Political Economy, 112(3) 665-694.

Heckman, James. 2007. “The Economics, Technology, and Neuroscience of Human Capability Formation.” Proceedings of the National Academy of Sciences, 104(33) 1-6.

Heckman, James, Anne Layne-Farrar, and Petra Todd. 1995. "Does Measured School Quality Really Matter? An Examination of the Earnings-Quality Relationship.” NBER Working Paper \#5274.

Helms, J. Douglas, George Pavelis, Scott Argabright, Roger Cronshey, and H. Raymond Sinclair, Jr. 1996. "National Soil Conservation Policies: A Historical Case Study of the Driftless Area.” Agricultural History, 70(2) 377-394.

Hornbeck, Richard. 2012. "The Enduring Impact of the American Dust Bowl: Short- and Long-Run Adjustments to Environmental Catastrophe." American Economic Review, 102(4) 1477-1507.

Hurt, R. Douglas. The Dust Bowl: An Agricultural and Social History, Chicago: Nelson-Hall, 1981.

Ladurie, Emmanuel Le Roy. 1969. Amenorrhea During the Famines of the 17th-20th Centuries. Annales. 24(6)1589-1601.

Lleras-Muney, Adriana. 2002. "Were Compulsory Attendance and Child labor Laws Effective? An Analysis from 19151939.” Journal of Law and Economics, 45(2):401-435.

Long, J. and H. Siu. 2016. "Refugees From Dust and Shrinking Lands: Tracking the Dust Bowl Migrants" NBER Working Paper \#22108.

Lord, Russell. To Hold This Soil: Misc. Publication No. 321, United States Dept. of Agriculture, Washington, D.C.: USGPO, 1938.

McNay, Kirsty, Jane Humphries, and Stephen Klasen. 2005. 'Excess Female Mortality in Nineteenth-Century England and Wales: A Regional Analysis." Social Science History, 29(4) 649-681.

Moehling, Carolyn. 1999. "State Child Labor Laws and the Decline of Child Labor.” Explorations in Economic History, 
36, pp. 72-106.

Nealand, Daniel. 2008. “Archival Vintages for The Grapes of Wrath.” Prologue, 40(4).

Ó Gráda, Cormac. 2011. "Fetal Origins, Childhood Development, and Famine: A Bibliography and Literature Review." UCD CER Working Paper 11/28.

Rosenbloom, Joshua and William Sundstrom. 2004. "The Decline and Rise of Interstate Migration in the United States: Evidence from the IPUMS, 1850-1990.” in Research in Economic History, Vol. 22. Emerald Group Publishing Limited, pp. 289-325.

Rossin-Slater, Maya and Miriam Wüst. 2017. "What is the Added Value of Preschool? Long-Term Impacts and Interactions with an Infant Health Intervention.” Mimeo.

Ruggles, Steven, J. Trent Alexander, Katie Genadek, Ronald Goeken, Matthew Schroeder, and Matthew Sobek, Integrated Public Use Microdata Series: v5.0, Minneapolis, MN: Minnesota Population Center, 2010.

Soil Conservation Service, Soil Erosion: A Critical Problem in American Agriculture, Washington, DC: USGPO, 1935.

Steinbeck, John. The Grapes of Wrath, New York: Viking Press, 1939.

Stephens, Philip. 1937. “Why the Dust Bowl?”J Journal of Farm Eeconomics, 19(3) 750-757.

U.S. Census Bureau. 2002. "Race and Hispanic Origin: 1790 to 1990 by State." Accessed 29 Dec 2013 at 〈http://www.census.gov/population/www/documentation/twps0056/tabs15-65.pdf〉.

U.S. Census Bureau. 2013. "State and County QuickFacts." Accessed 29 Dec 2013 at <http://quickfacts.census.gov/qfd/index.html>.

U.S. Dept. of Labor. 2013. "Child Labor Provisions for Nonagricultural Occupations Under the Fair Labor Standards Act." Child Labor Bulletin 101, pp. 1-26.

U.S. Dept. of Labor. 2007. "Child Labor Requirements in Agricultural Occupations Under the Fair Labor Standards Act." Child Labor Bulletin 102, pp. 1-9.

Vandenbroucke, Guillaume. 2015. "Lifetime Benefits of an Education Have Never Been So High." Federal Reserve Bank of St. Louis: The Regional Economist, pp. 10-11.

Wallace, Henry. Soils and Men:Yearbook of Agriculture 1938, Washington, D.C.: USGPO, 1938.

Whaples, Robert. 2005. "Child Labor in the United States" in EH.Net Encyclopedia, ed. Robert Whaples, Accessed 29 Dec 2013 at <http://eh.net/encyclopedia/article/whaples/ childlabor>.

Worster, Donald. Dust Bowl: The Southern Plains in the 1930s, New York: Oxford University Press, 1979. 
Table 1 - Summary Statistics

\begin{tabular}{|c|c|c|c|c|c|c|c|}
\hline Panel A: Dust Bowl Severity & & Mean & Min & Max & $\mathrm{SD}$ & $N$ & \\
\hline Erosion (Pop-weighted) & & 0.15 & 0.00 & 0.67 & 0.21 & 15 & \\
\hline Erosion (Farm pop-weighted) & & 0.13 & 0.00 & 0.42 & 0.15 & 15 & \\
\hline$\Delta$ Farm Values (Pop-weighted) & & 0.33 & 0.00 & 0.92 & 0.27 & 15 & \\
\hline \multirow[t]{2}{*}{ Panel B: Adult Outcomes } & & \multicolumn{2}{|c|}{ All } & \multicolumn{2}{|c|}{ Men } & \multicolumn{2}{|c|}{ Women } \\
\hline & & Mean & $N$ & Mean & $N$ & Mean & $N$ \\
\hline \multirow[t]{2}{*}{ Children ever born } & Unweighted & 2.40 & $1,601,986$ & & & 2.40 & $1,601,986$ \\
\hline & Weighted & 2.37 & $31,377,111$ & & & 2.37 & $31,377,111$ \\
\hline \multirow[t]{2}{*}{ Probability of completing high school } & Unweighted & 0.70 & $1,590,689$ & 0.70 & 760,484 & 0.70 & 830,205 \\
\hline & Weighted & 0.70 & $31,813,820$ & 0.70 & $15,209,720$ & 0.70 & $16,604,100$ \\
\hline \multirow[t]{2}{*}{ Probability of completing college } & Unweighted & 0.15 & $1,590,689$ & 0.18 & 760,484 & 0.12 & 830,205 \\
\hline & Weighted & 0.15 & $31,813,820$ & 0.18 & $15,209,720$ & 0.12 & $16,604,100$ \\
\hline \multirow[t]{2}{*}{ Welfare income } & Unweighted & 101.08 & $4.256,983$ & 73.56 & $1,997,206$ & 125.41 & $2,259,777$ \\
\hline & Weighted & 101.00 & $82,669,561$ & 72.70 & $38,846,949$ & 126.09 & $43,822,612$ \\
\hline \multirow[t]{2}{*}{ Probability of poverty } & Unweighted & 0.12 & $4,256,983$ & 0.10 & $1,997,206$ & 0.14 & $2,259,777$ \\
\hline & Weighted & 0.12 & $82,669,561$ & 0.10 & $38,846,949$ & 0.14 & $43,822,612$ \\
\hline \multirow[t]{2}{*}{ Probability of cognitive disability } & Unweighted & 0.08 & $4,256,983$ & 0.07 & 568,197 & 0.09 & 657,791 \\
\hline & Weighted & 0.08 & $23,175,971$ & 0.07 & $10,730,470$ & 0.08 & $12,445,501$ \\
\hline \multirow[t]{2}{*}{ Probability of physical disability } & Unweighted & 0.19 & $1,225,988$ & 0.17 & 568,197 & 0.21 & 657,791 \\
\hline & Weighted & 0.19 & $23,175,971$ & 0.17 & $10,730,470$ & 0.20 & $12,445,501$ \\
\hline \multirow[t]{2}{*}{ Probability of vision \& hearing difficulty } & Unweighted & 0.08 & $1,225,988$ & 0.09 & 568,197 & 0.08 & 657,789 \\
\hline & Weighted & 0.08 & $23,175,971$ & 0.09 & $10,730,470$ & 0.07 & $12,445,501$ \\
\hline \multirow{2}{*}{$\begin{array}{l}\text { Probability of self-care \& independent mobility } \\
\text { difficulty }\end{array}$} & Unweighted & 0.12 & $2,666,294$ & 0.10 & $1,236,722$ & 0.14 & $1,429,572$ \\
\hline & Weighted & 0.12 & $50,855,741$ & 0.10 & $23,637,229$ & 0.14 & $27,218,512$ \\
\hline
\end{tabular}

Note: Panel A reports summary statistics for state-level Dust Bowl severity measures, calculated from data in Hornbeck (2012). Erosion (pop-weighted) refers to the proportion of individuals in the state living in high-erosion counties in 1930. Erosion (farm pop-weighted) refers to the proportion of farm population in the state living in high-erosion counties in 1930. Change in farm values refers to the proportion of individuals in the state living in counties in 1930 that experienced high loss in farm values between 1930 and 1940. Panel B reports average values of human capital outcome variables by IPUMS observation (unweighted) and by IPUMS observation weighted by the IPUMS variable PERWT (weighted); the latter yields the average value of the human capital outcome variables for the entire population represented by the observations included. Panel B data come from the 5\% IPUMS 1980, 1990, and 2000 samples for individuals born in 1900-1959, inclusive, in the 15 sample states given in Figure 1. 
Table 2 - Impact of Childhood Exposure to the Dust Bowl on Later-Life Outcomes

\begin{tabular}{|c|c|c|c|c|c|c|}
\hline & \multicolumn{2}{|c|}{$\begin{array}{c}\text { Erosion } \\
\text { (Pop-weighted) }\end{array}$} & \multicolumn{2}{|c|}{$\begin{array}{c}\text { Erosion } \\
\text { (Farm pop-weighted) }\end{array}$} & \multicolumn{2}{|c|}{$\begin{array}{l}\Delta \text { Farm Values } \\
\text { (Pop-weighted) }\end{array}$} \\
\hline & (1) & (2) & (3) & $(4)$ & (5) & (6) \\
\hline & Men & Women & Men & Women & Men & Women \\
\hline Children ever born & & $\begin{array}{l}-0.2061 \\
(0.1323)\end{array}$ & & $\begin{array}{l}-0.3450 * \\
(0.1990)\end{array}$ & & $\begin{array}{c}0.0659 \\
(0.1150)\end{array}$ \\
\hline Probability of completing high school & $\begin{array}{c}0.0169 \\
(0.0152)\end{array}$ & $\begin{array}{c}0.0307 \\
(0.0192)\end{array}$ & $\begin{array}{c}0.0318 \\
(0.0211)\end{array}$ & $\begin{array}{c}0.0473 \\
(0.0297)\end{array}$ & $\begin{array}{c}0.0236 \\
(0.0165)\end{array}$ & $\begin{array}{l}0.0371 * * \\
(0.0176)\end{array}$ \\
\hline Probability of completing college & $\begin{array}{l}-0.0107 \\
(0.0075)\end{array}$ & $\begin{array}{c}-0.0117 * * \\
(0.0054)\end{array}$ & $\begin{array}{l}-0.0153 \\
(0.0120)\end{array}$ & $\begin{array}{c}-0.0209 * * *, \dagger \dagger \\
(0.0074)\end{array}$ & $\begin{array}{l}-0.0000 \\
(0.0091)\end{array}$ & $\begin{array}{l}-0.0068 \\
(0.0055)\end{array}$ \\
\hline Welfare income & $\begin{array}{c}15.05^{*} \\
(9.1470)\end{array}$ & $\begin{array}{c}16.54 \\
(10.2027)\end{array}$ & $\begin{array}{c}21.47 \\
(15.2200)\end{array}$ & $\begin{array}{c}23.26 \\
(17.2300)\end{array}$ & $\begin{array}{l}22.83 * * *,+\uparrow \dagger \\
(6.8840)\end{array}$ & $\begin{array}{l}15.37 * * \\
(6.4140)\end{array}$ \\
\hline Probability of poverty & $\begin{array}{l}0.0080^{*} \\
(0.0042)\end{array}$ & $\begin{array}{l}0.0047 * \\
(0.0028)\end{array}$ & $\begin{array}{l}0.0127 * \\
(0.0070)\end{array}$ & $\begin{array}{l}0.0077 * \\
(0.0043)\end{array}$ & $\begin{array}{l}0.0111^{*} \\
(0.0058)\end{array}$ & $\begin{array}{c}0.0036 \\
(0.0065)\end{array}$ \\
\hline Probability of cognitive disability & $\begin{array}{c}0.0065 \\
(0.0069)\end{array}$ & $\begin{array}{l}-0.0054 \\
(0.0062)\end{array}$ & $\begin{array}{c}0.0114 \\
(0.0107)\end{array}$ & $\begin{array}{l}-0.0083 \\
(0.0102)\end{array}$ & $\begin{array}{c}0.0030 \\
(0.0102)\end{array}$ & $\begin{array}{l}0.0145^{* *} \\
(0.0066)\end{array}$ \\
\hline Probability of physical disability & $\begin{array}{l}0.0110 * * *, \dagger \\
(0.0041)\end{array}$ & $\begin{array}{l}-0.0021 \\
(0.0110)\end{array}$ & $\begin{array}{l}0.0173 * * *, \dagger \\
\quad(0.0062)\end{array}$ & $\begin{array}{l}-0.0035 \\
(0.0187)\end{array}$ & $\begin{array}{c}0.0069 \\
(0.0102)\end{array}$ & $\begin{array}{l}-0.0144 \\
(0.0091)\end{array}$ \\
\hline Probability of vision $\&$ hearing difficulty & $\begin{array}{l}-0.0027 \\
(0.0066)\end{array}$ & $\begin{array}{l}-0.0023 \\
(0.0050)\end{array}$ & $\begin{array}{c}0.0010 \\
(0.0106)\end{array}$ & $\begin{array}{l}-0.0046 \\
(0.0084)\end{array}$ & $\begin{array}{c}0.0080 \\
(0.0067)\end{array}$ & $\begin{array}{c}0.0094 * *, \dagger \\
(0.0037)\end{array}$ \\
\hline Probability of self-care \& independent mobility difficulty & $\begin{array}{l}-0.0003 \\
(0.0039)\end{array}$ & $\begin{array}{l}-0.0015 \\
(0.0029)\end{array}$ & $\begin{array}{l}-0.0012 \\
(0.0061)\end{array}$ & $\begin{array}{l}-0.0022 \\
(0.0048)\end{array}$ & $\begin{array}{l}0.0112 * \\
(0.0048)\end{array}$ & $\begin{array}{c}0.0129 * * *, \dagger \dagger \\
(0.0043)\end{array}$ \\
\hline
\end{tabular}

$* * * \mathrm{p}<0.01, * * \mathrm{p}<0.05, * \mathrm{p}<0.1$ uncorrected; $\dagger \dagger \dagger \mathrm{p}<0.01, \dagger \dagger \mathrm{p}<0.05, \dagger \mathrm{p}<0.1$ Bonferroni-corrected; Note: Table reports treated $\times$ <erosion coefficients. Each row in the left-hand column refers to the regression's dependent variable, while the remaining column headings indicate the definition of Dust Bowl severity (i.e. erosion $_{s}$ ) used. All regressions are estimated by OLS and include controls for race; birth year, birth state, and census year fixed effects; and state trends. Standard errors, two-way clustered by birth state and birth year, are reported in parentheses below each coefficient. Erosion and farm value data are calculated from Hornbeck (2012), while human capital outcome data come from the 5\% IPUMS 1980, 1990, and 2000 samples for individuals born in 1900-1959, inclusive, in the 15 sample states given in Figure 1.Treated cohorts are those born 1918-1941. 
Table 3 - Impact of Exposure to the Dust Bowl by Development Stage on Later-Life Outcomes: Men

\begin{tabular}{|c|c|c|c|c|c|}
\hline & \multicolumn{5}{|c|}{ Men } \\
\hline & $\begin{array}{c}-1 \text { to } 0 \\
(1)\end{array}$ & $\begin{array}{l}1 \text { to } 3 \\
\text { (2) }\end{array}$ & $\begin{array}{c}4 \text { to } 6 \\
(3)\end{array}$ & $\begin{array}{c}7 \text { to } 9 \\
(4)\end{array}$ & $\begin{array}{c}10 \text { to } 12 \\
(5)\end{array}$ \\
\hline Probability of completing high school & $\begin{array}{l}-0.0052 \\
(0.0139)\end{array}$ & $\begin{array}{c}0.0105 \\
(0.0133)\end{array}$ & $\begin{array}{c}0.0188 \\
(0.0124)\end{array}$ & $\begin{array}{c}0.0342 * * *, \dagger \\
(0.0127)\end{array}$ & $\begin{array}{c}0.0361 * * \\
(0.0167)\end{array}$ \\
\hline Probability of completing college & $\begin{array}{l}-0.0110 \\
(0.0103)\end{array}$ & $\begin{array}{l}-0.0088 \\
(0.0082)\end{array}$ & $\begin{array}{l}-0.0072 \\
(0.0065)\end{array}$ & $\begin{array}{c}-0.0022 \\
(0.0058)\end{array}$ & $\begin{array}{l}-0.0024 \\
(0.0063)\end{array}$ \\
\hline Welfare income & $\begin{array}{l}16.29 * * \\
(6.7940)\end{array}$ & $\begin{array}{c}14.15^{*} \\
(8.3700)\end{array}$ & $\begin{array}{c}5.76 \\
(7.6730)\end{array}$ & $\begin{array}{c}8.37 \\
(8.3060)\end{array}$ & $\begin{array}{c}5.42 \\
(8.6060)\end{array}$ \\
\hline Probability of poverty & $\begin{array}{c}0.0039 \\
(0.0032)\end{array}$ & $\begin{array}{c}0.0031 \\
(0.0037)\end{array}$ & $\begin{array}{c}0.0040 \\
(0.0037)\end{array}$ & $\begin{array}{c}0.0043 \\
(0.0036)\end{array}$ & $\begin{array}{c}0.0065 \\
(0.0040)\end{array}$ \\
\hline Probability of cognitive disability & $\begin{array}{c}0.0116 \\
(0.0076)\end{array}$ & $\begin{array}{c}0.0026 \\
(0.0083)\end{array}$ & $\begin{array}{l}-0.0059 \\
(0.0073)\end{array}$ & $\begin{array}{l}-0.0114 \\
(0.0076)\end{array}$ & $\begin{array}{l}-0.0121 \\
(0.0095)\end{array}$ \\
\hline Probability of physical disability & $\begin{array}{c}0.0169 * * *, \dagger \dagger \\
(0.0042)\end{array}$ & $\begin{array}{c}0.0189 * * *,+1 \dagger \\
(0.0045)\end{array}$ & $\begin{array}{l}0.0062 * * \\
(0.0027)\end{array}$ & $\begin{array}{l}-0.0054 \\
(0.0084)\end{array}$ & $\begin{array}{c}-0.0164 * * \\
(0.0082)\end{array}$ \\
\hline Probability of vision $\&$ hearing difficulty & $\begin{array}{c}0.0067 \\
(0.0054)\end{array}$ & $\begin{array}{c}0.0081 \\
(0.0068)\end{array}$ & $\begin{array}{l}-0.0010 \\
(0.0080)\end{array}$ & $\begin{array}{l}-0.0114 \\
(0.0080)\end{array}$ & $\begin{array}{c}-0.0154 * \\
(0.0086)\end{array}$ \\
\hline Probability of self-care \& independent mobility difficulty & $\begin{array}{c}0.0025 \\
(0.0041)\end{array}$ & $\begin{array}{l}-0.0024 \\
(0.0041)\end{array}$ & $\begin{array}{c}-0.0078 * * \\
(0.0038)\end{array}$ & $\begin{array}{l}-0.0057 \\
(0.0042)\end{array}$ & $\begin{array}{l}-0.0051 \\
(0.0043)\end{array}$ \\
\hline
\end{tabular}

$* * * \mathrm{p}<0.01, * * \mathrm{p}<0.05, * \mathrm{p}<0.1$ uncorrected; $\dagger \dagger \dagger \mathrm{p}<0.01, \dagger \dagger \mathrm{p}<0.05, \dagger \mathrm{p}<0.1$ Bonferroni-corrected; Note: Table reports treated ${ }_{b} \times$ erosion coefficients. Each row in the left-hand column refers to the regression's dependent variable, while the remaining column headings indicate the developmental stage that defines treated $_{b, .}$ Treated $_{b}$ here is a duration-weighted measure that gives the proportion of time an individual born 1918-1941 spent in the given age band during the Dust Bowl years of 1930-1940 (see Appendix WA2 for details). All regressions are estimated by OLS and include controls for race; birth year, birth state, and census year fixed effects; and state trends. Standard errors, twoway clustered by birth state and birth year, are reported in parentheses below each coefficient. Erosion data are calculated from Hornbeck (2012), while human capital outcome data come from the 5\% IPUMS 1980, 1990, and 2000 samples for individuals born in 1900-1959, inclusive, in the 15 sample states given in Figure 1. 
Table 4 - Impact of Exposure to the Dust Bowl by Development Stage on Later-Life Outcomes: Women

\begin{tabular}{|c|c|c|c|c|c|}
\hline & \multicolumn{5}{|c|}{ Women } \\
\hline & $\begin{array}{c}-1 \text { to } 0 \\
\text { (1) }\end{array}$ & $\begin{array}{l}1 \text { to } 3 \\
\text { (2) }\end{array}$ & $\begin{array}{l}4 \text { to } 6 \\
\text { (3) }\end{array}$ & $\begin{array}{l}7 \text { to } 9 \\
\text { (4) }\end{array}$ & $\begin{array}{c}10 \text { to } 12 \\
(5)\end{array}$ \\
\hline Children ever born & $\begin{array}{l}-0.1650 \\
(0.1030)\end{array}$ & $\begin{array}{l}-0.2410^{*} \\
(0.1310)\end{array}$ & $\begin{array}{l}-0.2680 * \\
(0.1380)\end{array}$ & $\begin{array}{c}-0.2380 * \\
(0.1320)\end{array}$ & $\begin{array}{l}-0.1840^{*} \\
(0.1110)\end{array}$ \\
\hline Probability of completing high school & $\begin{array}{l}-0.0128 \\
(0.0090)\end{array}$ & $\begin{array}{l}-0.0007 \\
(0.0129)\end{array}$ & $\begin{array}{c}0.0203 \\
(0.0178)\end{array}$ & $\begin{array}{c}0.0489 * * \\
(0.0221)\end{array}$ & $\begin{array}{c}0.0639^{* *} \\
(0.0278)\end{array}$ \\
\hline Probability of completing college & $\begin{array}{c}-0.0154 * * *,+\dagger \dagger \\
(0.0040)\end{array}$ & $\begin{array}{c}-0.0136^{* * *,+\dagger \dagger T} \\
(0.0035)\end{array}$ & $\begin{array}{c}-0.0144 * * \\
(0.0063)\end{array}$ & $\begin{array}{l}-0.0104 \\
(0.0065)\end{array}$ & $\begin{array}{l}-0.0048 \\
(0.0064)\end{array}$ \\
\hline Welfare income & $\begin{array}{l}14.90^{* *} \\
(7.1030)\end{array}$ & $\begin{array}{c}14.19 \\
(9.3610)\end{array}$ & $\begin{array}{c}10.85 \\
(9.0000)\end{array}$ & $\begin{array}{c}13.47 \\
(11.0700)\end{array}$ & $\begin{array}{c}12.00 \\
(11.3800)\end{array}$ \\
\hline Probability of poverty & $\begin{array}{c}0.0073 * * *, \dagger \\
(0.0028)\end{array}$ & $\begin{array}{l}0.0051^{*} \\
(0.0028)\end{array}$ & $\begin{array}{c}0.0010 \\
(0.0031)\end{array}$ & $\begin{array}{c}0.0023 \\
(0.0024)\end{array}$ & $\begin{array}{c}0.0005 \\
(0.0033)\end{array}$ \\
\hline Probability of cognitive disability & $\begin{array}{c}0.0082 \\
(0.0053)\end{array}$ & $\begin{array}{c}0.0000 \\
(0.0060)\end{array}$ & $\begin{array}{l}-0.0070 \\
(0.0049)\end{array}$ & $\begin{array}{c}-0.0153 * * * ; \dagger \dagger \dagger \\
(0.0043)\end{array}$ & $\begin{array}{c}-0.0208 * * *,+\dagger \dagger \\
(0.0023)\end{array}$ \\
\hline Probability of physical disability & $\begin{array}{l}0.0128^{*} \\
(0.0071)\end{array}$ & $\begin{array}{c}0.0054 \\
(0.0079)\end{array}$ & $\begin{array}{l}-0.0119 \\
(0.0095)\end{array}$ & $\begin{array}{c}-0.0191^{* *} \\
(0.0094)\end{array}$ & $\begin{array}{c}-0.0252^{* *} \\
(0.0100)\end{array}$ \\
\hline Probability of vision \& hearing difficulty & $\begin{array}{l}0.0011 \\
(0.0042)\end{array}$ & $\begin{array}{c}0.0029 \\
(0.0038)\end{array}$ & $\begin{array}{l}-0.0008 \\
(0.0040)\end{array}$ & $\begin{array}{l}-0.0043 \\
(0.0050)\end{array}$ & $\begin{array}{l}-0.0051 \\
(0.0058)\end{array}$ \\
\hline Probability of self-care \& independent mobility difficulty & $\begin{array}{l}0.0057^{*} \\
(0.0032)\end{array}$ & $\begin{array}{c}-0.0002 \\
(0.0030)\end{array}$ & $\begin{array}{c}-0.0075 * * \\
(0.0032)\end{array}$ & $\begin{array}{c}-0.0104 * * \\
(0.0049)\end{array}$ & $\begin{array}{l}-0.0099^{*} \\
(0.0060)\end{array}$ \\
\hline
\end{tabular}

*** $\mathrm{p}<0.01, * * \mathrm{p}<0.05, * \mathrm{p}<0.1$ uncorrected; $\dagger \dagger \mathrm{p}<0.01$, $\dagger \mathrm{p}<0.05, \dagger \mathrm{p}<0.1$ Bonferroni-corrected; Note: Table reports treated $_{b} \times$ erosion $_{s}$ coefficients. Each row in the left-hand column refers to the regression's dependent variable, while the remaining column headings indicate the developmental stage that defines treated $_{b .}$ Treated $_{b}$ here is a duration-weighted measure that gives the proportion of time an individual born 19181941 spent in the given age band during the Dust Bowl years of 1930-1940 (see Appendix WA2 for details). All regressions are estimated by OLS and include controls for race; birth year, birth state, and census year fixed effects; and state trends. Standard errors, two-way clustered by birth state and birth year, are reported in parentheses below each coefficient. Erosion data are calculated from Hornbeck (2012), while human capital outcome data come from the 5\% IPUMS 1980, 1990, and 2000 samples for individuals born in 1900-1959, inclusive, in the 15 sample states given in Figure 1. 
Table 5 - Impact of Exposure to the Dust Bowl by Mechanism: Public Spending - Men

\begin{tabular}{|c|c|c|c|c|c|c|}
\hline & \multicolumn{2}{|c|}{ New Deal } & \multicolumn{2}{|c|}{ Relief } & \multicolumn{2}{|c|}{ Loans } \\
\hline & (1a) & (1b) & $(2 \mathrm{a})$ & $(2 b)$ & $(3 a)$ & $(3 b)$ \\
\hline & Treated $\times$ Erosion & $\begin{array}{c}\text { New Deal } \times \text { Treated } \\
\times \text { Erosion }\end{array}$ & Treated $\times$ Erosion & $\begin{array}{c}\text { Relief } \times \text { Treated } \times \\
\text { Erosion }\end{array}$ & Treated $\times$ Erosion & $\begin{array}{c}\text { Loams } \times \text { Treated } \times \\
\text { Erosion }\end{array}$ \\
\hline Probability of completing high school & $\begin{array}{c}-0.1510 * * *, \dagger \dagger \\
(0.0309)\end{array}$ & $\begin{array}{c}0.00125 * * *, \dagger \dagger \\
(0.00025)\end{array}$ & $\begin{array}{c}0.3260 * * *, \dagger \\
(0.1110)\end{array}$ & $\begin{array}{c}-0.00422 * * *, \dagger \\
(0.00146)\end{array}$ & $\begin{array}{c}-0.0880 * * *, \dagger \dagger \\
(0.0250)\end{array}$ & $\begin{array}{c}0.00148 * * *, \dagger \dagger \\
(0.00031)\end{array}$ \\
\hline Probability of completing college & $\begin{array}{l}-0.0227 \\
(0.0162)\end{array}$ & $\begin{array}{c}0.00010 \\
(0.00010)\end{array}$ & $\begin{array}{c}0.0012 \\
(0.0889)\end{array}$ & $\begin{array}{l}-0.00017 \\
(0.00115)\end{array}$ & $\begin{array}{c}-0.0313 * * \\
(0.0148)\end{array}$ & $\begin{array}{l}0.00028^{*} \\
(0.00016)\end{array}$ \\
\hline Welfare income & $\begin{array}{c}7.18 \\
(20.9600)\end{array}$ & $\begin{array}{c}0.07430 \\
(0.17400)\end{array}$ & $\begin{array}{c}202.80 * * *, \dagger \dagger \\
(54.6100)\end{array}$ & $\begin{array}{c}-2.58600 * * *, \dagger \dagger \\
(0.73700)\end{array}$ & $\begin{array}{c}1.79 \\
(21.3600)\end{array}$ & $\begin{array}{c}0.26000 \\
(0.26000)\end{array}$ \\
\hline Probability of poverty & $\begin{array}{l}-0.0154 \\
(0.0124)\end{array}$ & $\begin{array}{l}0.00018 * \\
(0.00009)\end{array}$ & $\begin{array}{c}0.0768 \\
(0.0536)\end{array}$ & $\begin{array}{l}-0.00095 \\
(0.00071)\end{array}$ & $\begin{array}{l}-0.0070 \\
(0.0121)\end{array}$ & $\begin{array}{c}0.00024 \\
(0.00017)\end{array}$ \\
\hline Probability of cognitive disability & $\begin{array}{c}0.0075 \\
(0.0265)\end{array}$ & $\begin{array}{c}0.00000 \\
(0.00020)\end{array}$ & $\begin{array}{c}0.0987 \\
(0.0676)\end{array}$ & $\begin{array}{l}-0.00126 \\
(0.00088)\end{array}$ & $\begin{array}{c}0.0080 \\
(0.0145)\end{array}$ & $\begin{array}{l}-0.00004 \\
(0.00011)\end{array}$ \\
\hline Probability of physical disability & $\begin{array}{l}0.0377 * \\
(0.0226)\end{array}$ & $\begin{array}{l}-0.00020 \\
(0.00018)\end{array}$ & $\begin{array}{c}0.0132 \\
(0.0676)\end{array}$ & $\begin{array}{l}-0.00003 \\
(0.00093)\end{array}$ & $\begin{array}{c}0.0404 * * *, \dagger \dagger \\
(0.0138)\end{array}$ & $\begin{array}{c}-0.00041 * * \\
(0.00017)\end{array}$ \\
\hline Probability of vision \& hearing difficulty & $\begin{array}{l}-0.0178 \\
(0.0289)\end{array}$ & $\begin{array}{c}0.00013 \\
(0.00022)\end{array}$ & $\begin{array}{l}0.1350 * \\
(0.0721)\end{array}$ & $\begin{array}{c}-0.00191 * * \\
(0.00096)\end{array}$ & $\begin{array}{l}-0.0060 \\
(0.0195)\end{array}$ & $\begin{array}{c}0.00007 \\
(0.00024)\end{array}$ \\
\hline $\begin{array}{l}\text { Probability of self-care \& independent mobility } \\
\text { difficulty }\end{array}$ & $\begin{array}{c}0.0205 \\
(0.0140)\end{array}$ & $\begin{array}{l}-0.00014 \\
(0.00011)\end{array}$ & $\begin{array}{l}0.0631 * * \\
(0.0256)\end{array}$ & $\begin{array}{c}-0.00088 * *, \dagger \\
(0.00035)\end{array}$ & $\begin{array}{c}0.0080 \\
(0.0059)\end{array}$ & $\begin{array}{l}-0.00007 \\
(0.00008)\end{array}$ \\
\hline
\end{tabular}

$* * * \mathrm{p}<0.01, * * \mathrm{p}<0.05, * \mathrm{p}<0.1$ uncorrected; $\dagger \dagger \uparrow \mathrm{p}<0.01, \dagger \dagger \mathrm{p}<0.05, \dagger \mathrm{p}<0.1$ Bonferroni-corrected; Note: Tables report treated ${ }_{b} \times$ erosion $_{s}$ coefficients (columns a) and interaction $\times$ treated $_{b} \times$ erosion $_{s}$ coefficients (columns b) for specifications that interact the baseline treatment term with the relevant measure of the state's total per capita New Deal and related spending. All regressions are estimated by OLS and include two-way interactions and controls for race; birth year, birth state, and census year fixed effects; and state trends. Standard errors, two-way clustered by birth state and birth year, are reported in parentheses below each coefficient. Public spending variables are continuous; to aid in interpreting the interaction coefficient for these regressions, the minimum, maximum, and standard deviation for the relevant variables in the full sample are as follows: New Deal (104.351, 289.141, 47.396); Relief (41.708, 128.980, 23.143); Loans (58.462, 167.357, 23.787). Erosion data are calculated from Hornbeck (2012),spending data are calculated from Fishback, et al. (2003), and human capital outcome data come from the 5\% IPUMS 1980, 1990, and 2000 samples for individuals born in 1900-1959, inclusive, in the 15 sample states given in Figure 1.Treated cohorts are those born 1918-1941. 
Table 6 - Impact of Exposure to the Dust Bowl by Mechanism: Public Spending - Women

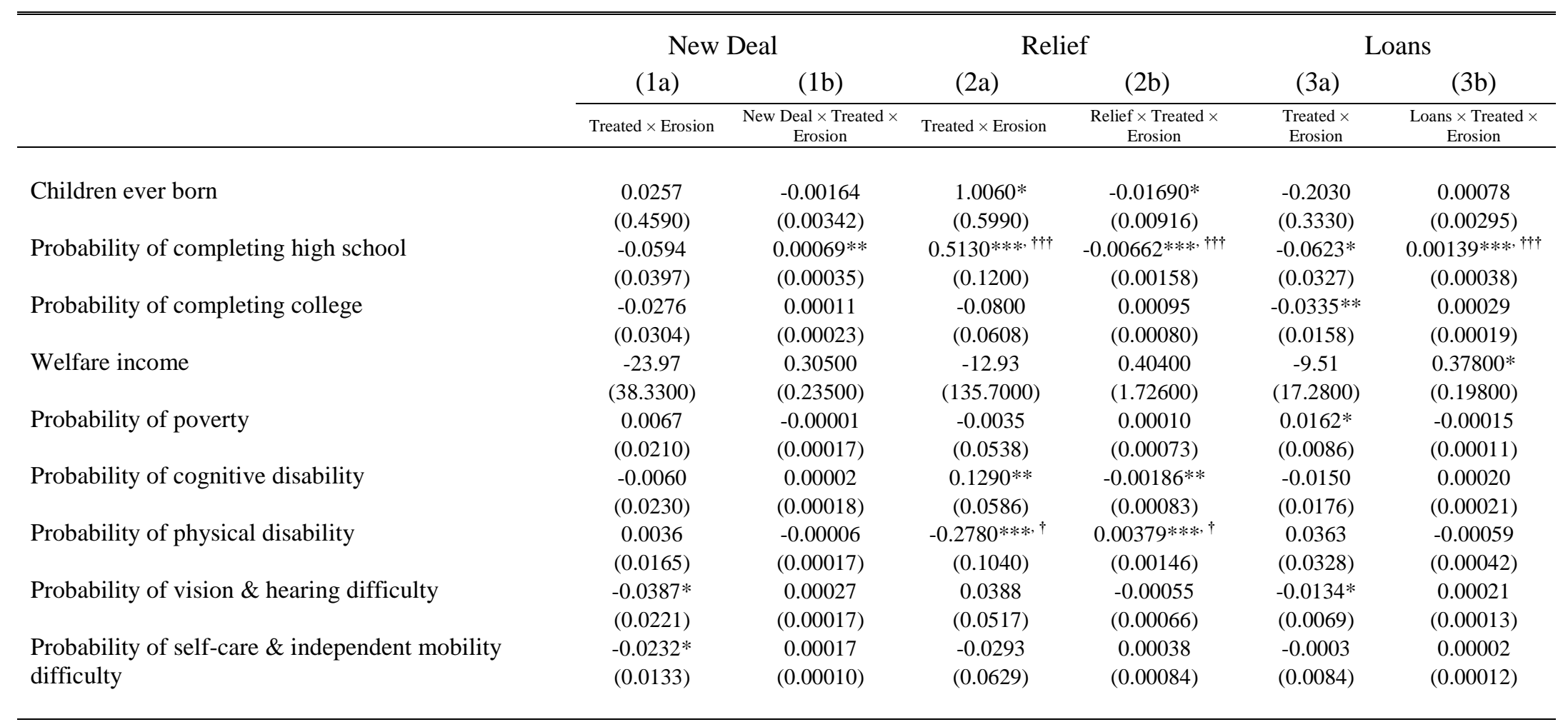

$* * * \mathrm{p}<0.01, * * \mathrm{p}<0.05, * \mathrm{p}<0.1$ uncorrected; $\uparrow \dagger \uparrow \mathrm{p}<0.01, \dagger \dagger \mathrm{p}<0.05, \dagger \mathrm{p}<0.1$ Bonferroni-corrected; Note: Tables report treated $\times$ erosion $n_{s}$ coefficients (columns a) and interaction $\times$ treated $_{b} \times$ erosion $_{s}$ coefficients (columns b) for for specifications that interact the baseline treatment term with the relevant measure of the state's total per capita New Deal and related spending. All regressions are estimated by OLS and include two-way interactions and controls for race; birth year, birth state, and census year fixed effects; and state trends. Standard errors, two-way clustered by birth state and birth year, are reported in parentheses below each coefficient. Public spending variables are continuous; to aid in interpreting the interaction coefficient for these regressions, the minimum, maximum, and standard deviation for the relevant variables in the full sample are as follows: New Deal (104.351, 289.141, 47.396); Relief $(41.708,128.980,23.143)$; Loans $(58.462,167.357,23.787)$. Erosion data are calculated from Hornbeck (2012),spending data are calculated from Fishback, et al. (2003), and human capital outcome data come from the 5\% IPUMS 1980, 1990, and 2000 samples for individuals born in 1900-1959, inclusive, in the 15 sample states given in Figure 1.Treated cohorts are those born 1918-1941. 
Figure 1 - Dust Bowl Severity
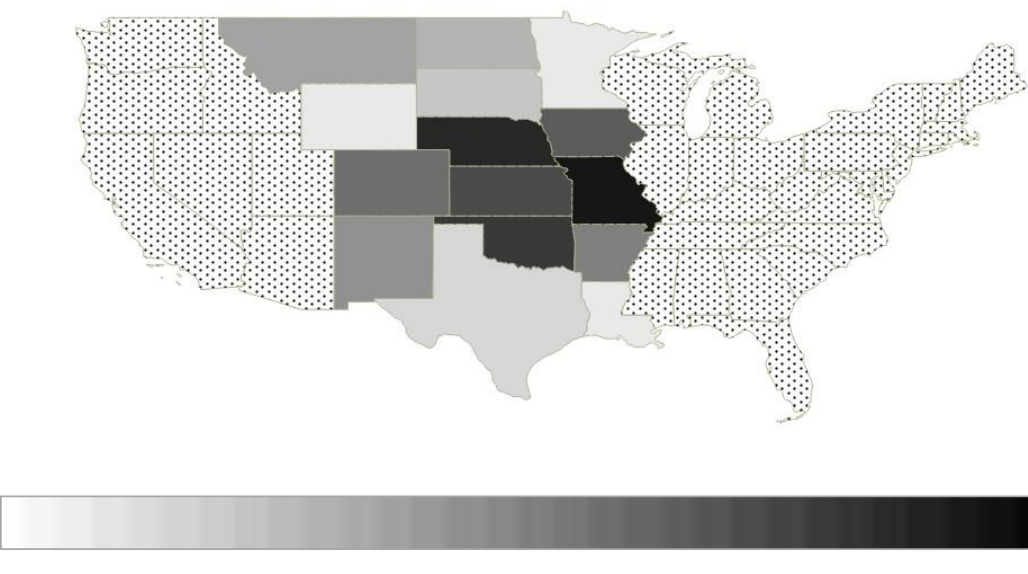

0.00

0.67

Figure 1a: Proportion of state population living in high erosion areas

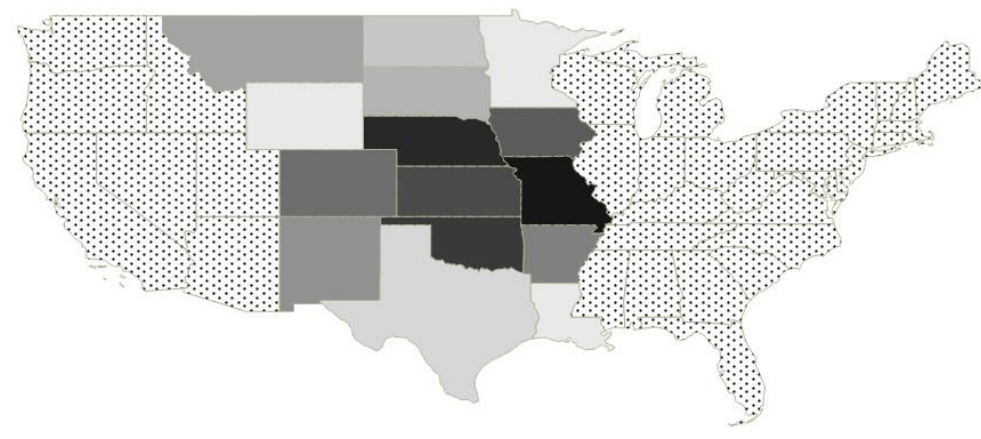

0.00

0.42

Figure 1b: Proportion of state farm population living in high erosion areas

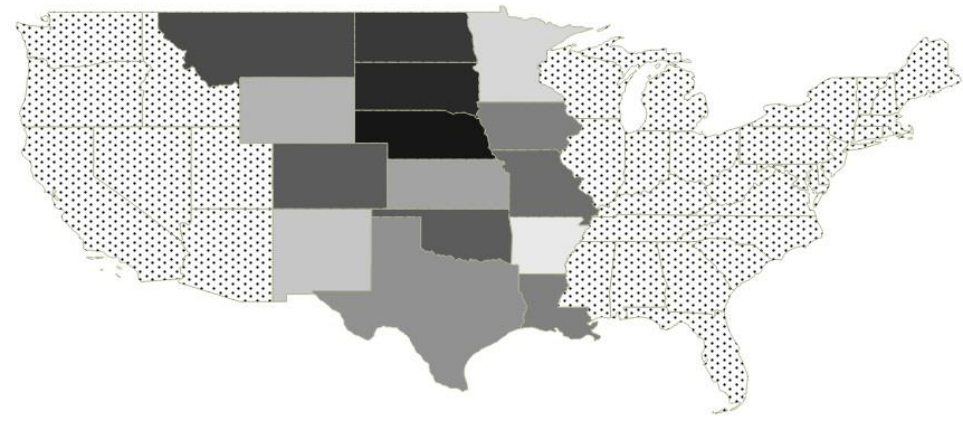

0.00

0.92

Figure 1c: Proportion of state population living in high farm value loss areas 
FOR ONLINE PUBLICATION

APPENDIX 


\section{METHODOLOGY APPENDIX}

\section{Methodology: Eventual Migration}

I use the data from my baseline analysis to test whether eventual migrants exposed to the Dust Bowl (that is, individuals found in adulthood to be living in a state other than their birth state; see Data Appendix for a discussion of this variable and its interpretation) have statistically significantly different later-life outcomes than their exposed counterparts enumerated as adults in their birth state. I also test for the effect of Dust Bowl exposure on the likelihood of being such an eventual migrant.

To test for differences in adult outcomes by migrant status, I estimate the following regression, by OLS:

$$
\begin{aligned}
h_{i b s t} & =\alpha+\beta_{1} \times \text { treated }_{b} \times \text { erosion }_{s}+\beta_{2} \times \text { migrant }_{i b s t} \times \text { treated }_{b} \times \text { erosion }_{s} \\
& +\beta_{3} \times \text { migrant }_{i b s t} \times \text { treated }_{b}+\beta_{4} \times \text { migrant }_{i b s t} \times \text { erosion }_{s}+\beta_{5} \times \text { migrant }_{i} \\
& +x_{i b s t} \psi+\theta_{s}+\lambda_{b}+\eta_{t}+\gamma_{b s}+u_{i b s t}
\end{aligned}
$$

where $h_{i b s t}$, as in the baseline equation (1), is the individual-level human capital outcome of interest for the individual $i$ born in year $b$ in state $s$ and enumerated in year $t$.

Treated $_{b}$ is a binary dummy which takes the value of 1 if the individual was born between 1918 and 1941, inclusive.

Erosion $_{s}$ is, as in the baseline regressions, a population-weighted measure of erosion severity in the individual's birth state.

Migrantibst is a binary dummy that takes the value of 1 if the individual is enumerated (as an adult) in a state other than their birth state.

$x_{i b s t}$ represents a vector of controls, including race.

$\theta_{s,}, \lambda_{b}$, and $\eta_{t}$ represent birth state fixed effects, birth year fixed effects, and census year fixed effects, while $\gamma_{b s}$ represents state trends. Standard errors are clustered at the birth state and birth year levels.

Each equation is estimated separately for men and women.

I also estimate the effect of Dust Bowl exposure on the likelihood of being a migrant, by OLS:

$$
\operatorname{migrant}_{i b s t}=\alpha+\beta_{1} \times \text { treated }_{b} \times \text { erosion }_{s}+x_{i b s t} t \psi+\theta_{s}+\lambda_{b}+\eta_{t}+\gamma_{b s}+u_{i b s t}
$$

All details of this regression are as specified for (WA1) above.

Results are reported in Section 3 of the Online Appendix. 


\section{Methodology: Childhood Migration by Household Characteristics}

I use data on children (that is, individuals aged 12 and under only) born in my 15 states of interest in the 1\% IPUMS samples of the 1920, 1930, 1940, and 1950 US Censuses (Ruggles et al. 2010) to test for whether Dust Bowl exposure and/hour household characteristics influenced a child's likelihood to have migrated before the age of 12. Similar to the method employed in baseline specification (1), I test for whether children born between 1918 and 1941, inclusive (that is, children aged -1 to 12 during the Dust Bowl) were likelier to be enumerated before age 12 in a state other than their birth state. I interact the Dust Bowl treatment term with measures of household income, socioeconomic status, and farm status to test whether certain household characteristics were associated with patterns in who migrated during childhood.

To test for differences in likelihood of having migrated out of the birth state as a child, I estimate the following regression, by OLS:

$$
\begin{aligned}
k_{\text {ibst }}= & \alpha+\beta_{1} \times \text { treated }_{b} \times \text { erosion }_{s} \\
& +\beta_{2} \times \text { householdcharacteristic }_{i b s t} \times \text { treated }_{b} \times \operatorname{erosion}_{s} \\
& +\beta_{3} \times \text { householdcharacteristic }_{i b s t} \times \text { treated }_{b} \\
& +\beta_{4} \times \text { householdcharacteristic }_{i b s t} \times \operatorname{erosion}_{s} \\
& +\beta_{5} \times \text { householdcharacteristic }_{i b s t}+x_{i b s t} \psi+\theta_{s}+\lambda_{b}+\eta_{t}+\gamma_{b s}+u_{i b s t}
\end{aligned}
$$

where $k_{i b s t}$ is a binary dummy which takes the value of 1 if child $i$ was enumerated in a state other than its birth state.

Treated $_{b}$ is a binary dummy which takes the value of 1 if the child was born between 1918 and 1941, inclusive.

Erosion $_{s}$ is, as in the baseline regressions, a population-weighted measure of erosion severity in the child's birth state.

Householdcharacteristic ibst $_{\text {is }}$ a measure of the child's household income or socioeconomic circumstances; several alternative versions of socioeconomic and household status are used, including Occscore, SEI, PRESGL, and farm status. See Data Appendix for a discussion of these variables. Results are reported in Section 3 of the Online Appendix, with the column headers referring to which of these interacted variables has been used in the specification.

$x_{i b s t}$ represents a vector of individual- and household-level controls, including sex, race, age, household farm status (for regressions using income variables and where, thus, farm status has not already been included as a control), and income (for regressions using farm status, where income has not already been included as a control). In regressions on farm status, the income variable control chosen is Occscore. 
$\theta_{s,}, \lambda_{b}$, and $\eta_{t}$ represent birth state fixed effects, birth year fixed effects, and census year fixed effects, while $\gamma_{b s}$ represents state trends. Standard errors are clustered at the birth state and birth year levels.

The specification above is also estimated and reported in the table under the header of "Dust Bowl" as follows:

$$
k_{\mathrm{ibst}}=\alpha+\beta_{1} \times \text { treated }_{b} \times \operatorname{erosion}_{s}+x_{i b s t} \psi+\theta_{s}+\lambda_{b}+\eta_{t}+\gamma_{b s}+u_{i b s t}
$$

As above for farm status regressions, here, Occscore is the income control used.

Results are reported in Section 3 of the Online Appendix.

\section{Methodology: Fertility by Maternal Characteristics}

I use data on ever-married women enumerated in my 15 states of interest in the 1\% IPUMS samples of the 1920,1930, 1940, and 1950 US Censuses (Ruggles et al. 2010) to test for fertility selection into my sample. Similar to the method employed in baseline specification (1), I test for whether ever-married women enumerated in 1940 had a lower probability of having had children in the preceding 10 years (that is, that women in 1940, for whom the preceding 10 years coincided with the Dust Bowl period), than those ever-married women for whom the past 10 years were not spend in the Dust Bowl. I interact the Dust Bowl treatment term with measures of household income, socioeconomic status, and farm status to test whether certain maternal characteristics were associated with changes in childbearing patterns.

To test for differences in likelihood of having borne children in the past 10 years across time, I estimate the following regression, by OLS:

$$
\begin{aligned}
p_{i b s t}= & \alpha+\beta_{1} \times \text { treated }_{b} \times \text { erosion }_{s} \\
& +\beta_{2} \times \text { householdcharacteristic }_{i b s t} \times \operatorname{treated}_{b} \times \operatorname{erosion}_{s} \\
& +\beta_{3} \times \text { householdcharacteristic }_{i b s t} \times \operatorname{treated}_{b} \\
& +\beta_{4} \times \text { householdcharacteristic }_{i b s t} \times \operatorname{erosion}_{s} \\
& +\beta_{5} \times \text { householdcharacteristic }_{i b s t}+x_{i b s t} \psi+\theta_{s}+\lambda_{b}+\eta_{t}+\gamma_{b s}+u_{i b s t}
\end{aligned}
$$

where $p_{i b s t}$ is a binary dummy which takes the value of 1 if woman $i$ reported having any children aged 10 or under.

Treated $_{b}$ is a binary dummy which takes the value of 1 if the census year is 1940.

Erosion $_{s}$ is, as in the baseline regressions, a population-weighted measure of erosion severity in the state in which the woman is enumerated. 
Householdcharacteristic ibst $_{\text {is }}$ a measure of the woman's household income or socioeconomic circumstances; several alternative versions of socioeconomic and household status are used, including Occscore, SEI, PRESGL, and farm status. See Data Appendix for a discussion of these variables. Results are reported in Section 3 of the Online Appendix, with the column headers referring to which of these interacted variables has been used in the specification.

$x_{i b s t}$ represents a vector of individual- and household-level controls, including race, age, household farm status (for regressions using income variables and where, thus, farm status has not already been included as a control), and income (for regressions using farm status, where income has not already been included as a control). In regressions on farm status, the income variable control chosen is Occscore.

$\theta_{s,}, \lambda_{b}$, and $\eta_{t}$ represent census state fixed effects, birth year fixed effects, and census year fixed effects, while $\gamma_{b s}$ represents state trends. Standard errors are clustered at the census state and birth year levels.

Results are reported in Section 3 of the Online Appendix.

\section{Methodology: Birth Rates}

I use yearly state-level crude birth rates over the period 1915-1960 from US Vital Statistics (Public Health Service 1947; National Center for Health Statistics 1968) for each of the 15 states in my sample to test for whether the Dust Bowl cohort had significantly different (for instance, lower) birth rates than those not exposed.

To test for differences in birth rates across cohorts, I estimate the following regression, by OLS:

$$
c_{s t}=\alpha+\beta_{1} \times \text { treated }_{t} \times \operatorname{erosion}_{s}+\theta_{s}+\lambda_{t}+\gamma_{s t}+u_{s t}
$$

where $c_{s t}$ is the crude birth rate in state $s$ in year $t$.

Treated $_{t}$ is a binary dummy which takes the value of 1 if the year is 1930-40, inclusive. In order to test when birth rates may have begun to respond to Dust Bowl conditions, treated ${ }_{t}$ is also alternatively defined as 1 if the year is 1931-40, 1932-40, and on until treated $t_{t}$ takes the value of

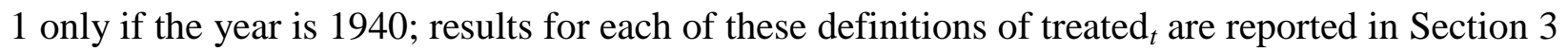
of the Online Appendix under column headers referring to how treated ${ }_{t}$ has been defined in that specification.

Erosion $_{s}$ is, as in the baseline regressions, a population-weighted measure of erosion severity in state $s$.

As in the baseline, $\theta_{s,}$ and $\lambda_{t}$ represent state fixed effects and year fixed effects, while $\gamma_{s t}$ represents state trends. Standard errors are clustered at the state level. 
Results are reported in Section 3 of the Online Appendix.

\section{Methodology: Stillbirths}

I use yearly state-level stillbirth rates over the period 1915-1960 from US Vital Statistics (Public Health Service 1947; National Center for Health Statistics 1968) for each of the 15 states in my sample to test for whether the Dust Bowl cohort had significantly higher stillbirth rates than those not exposed.

To test for differences in stillbirth rates across cohorts, I estimate the following regression, by OLS:

$$
b_{s t}=\alpha+\beta_{1} \times \text { treated }_{t} \times \operatorname{erosion}_{s}+\theta_{s}+\lambda_{t}+\gamma_{s t}+u_{s t}
$$

where $b_{s t}$ is the stillbirth rate in state $s$ in year $t$.

Treated $_{t}$ is a binary dummy which takes the value of 1 if the year is 1930-40, inclusive. In order to test when stillbirth rates may have begun to respond to Dust Bowl conditions, treated ${ }_{t}$ is also alternatively defined as 1 if the year is 1931-40, 1932-40, and on until treated $t_{t}$ takes the value of 1 only if the year is 1940; results for each of these definitions of treated $_{t}$ are reported in Section 3

of the Online Appendix under column headers referring to how treated thas $_{t}$ been defined in that specification.

Erosion $_{s}$ is, as in the baseline regressions, a population-weighted measure of erosion severity in state $s$.

As in the baseline, $\theta_{s}$, and $\lambda_{t}$ represent state fixed effects and year fixed effects, while $\gamma_{s t}$ represents state trends. Standard errors are clustered at the state level.

Results are reported in Section 3 of the Online Appendix.

\section{Methodology: Infant Mortality}

I use yearly state-level infant mortality rates over the period 1915-1960 from US Vital Statistics (Public Health Service 1947; National Center for Health Statistics 1968) for each of the 15 states in my sample to test for whether the Dust Bowl cohort had significantly higher infant mortality rates than those not exposed.

To test for differences in infant mortality rates across cohorts, I estimate the following regression, by OLS:

$$
i_{s t}=\alpha+\beta_{1} \times \operatorname{treated}_{t} \times \operatorname{erosion}_{s}+\theta_{s}+\lambda_{t}+\gamma_{s t}+u_{s t}
$$


where $i_{s t}$ is the infant mortality rate in state $s$ in year $t$.

Treated $_{t}$ is a binary dummy which takes the value of 1 if the year is 1930-40, inclusive. In order to test when infant mortality rates may have begun to respond to Dust Bowl conditions, treated $_{t}$ is also alternatively defined as 1 if the year is $1931-40,1932-40$, and on until treated $t_{t}$ takes the value of 1 only if the year is 1940; results for each of these definitions of treated ${ }_{t}$ are reported in Section 3 of the Online Appendix under column headers referring to how treated $t_{t}$ has been defined in that specification.

Erosion $_{s}$ is, as in the baseline regressions, a population-weighted measure of erosion severity in state $s$.

As in the baseline, $\theta_{s,}$ and $\lambda_{t}$ represent state fixed effects and year fixed effects, while $\gamma_{s t}$ represents state trends. Standard errors are clustered at the state level.

Results are reported in Section 3 of the Online Appendix.

\section{Methodology: Mortality Across Life-Course}

I use decadal state-level mortality rates from US Vital Statistics 1930-2000 (Public Health Service 1947; National Center for Health Statistics 1968, 1974, 1985, \& 1994; Centers for Disease Control and Prevention 2000, 2003, \& 2013; National Bureau of Economic Research 2006) for each of the 15 states in my sample to test for whether the Dust Bowl cohort had significantly higher mortality rates at any life stage (under age 1, 1-4, 5-14, 15-24, 25-34, 45-54, 55-64, 65-74, and 74-85) up to and including my observation period, than those not exposed.

To test for differences in age-specific mortality rates, I estimate the following regression, by OLS:

$$
m_{\text {gast }}=\alpha+\beta_{1} \times \text { treated }_{t} \times \text { erosion }_{s}+\theta_{s}+\lambda_{t}+\gamma_{s t}+u_{\text {gast }}
$$

where $m_{\text {gast }}$ is the mortality rate for gender $g$ in age bin $a$ in state $s$ in year $t$.

Treated $_{t}$ is a binary dummy which takes the value of 1 if in a given census year, the age bin for which the regression is being run is populated only by individuals who were aged -1 to 12 during the Dust Bowl (that is, the age bin contains only 1918-41 births in the given census year). Regressions using this version of treated $_{t}$ are referred to in the tables as "age bins narrowly defined" since an age bin only counts as containing the Dust Bowl cohort if all the age bins members were children during the Dust Bowl. In the specifications labeled "age bins broadly defined", treated $_{t}$ takes the value of 1 if any individual in that age bin was a child during the Dust Bowl, even if the age bin also contains individuals not exposed to the Dust Bowl as children. For instance, an age bin containing people born 1915-1920 would be categorized as 
broadly rather than narrowly defined treated, since it contains people born 1918-1920, who belong to the Dust Bowl cohort, but also contains people born 1915-1917 who were not part of the Dust Bowl cohort.

Erosion $_{s}$ is, as in the baseline regressions, a population-weighted measure of erosion severity in state $s$.

As in the baseline, $\theta_{s}$, and $\lambda_{t}$ represent state fixed effects and year fixed effects, while $\gamma_{s t}$ represents state trends. Standard errors are clustered at the state level.

The regression is estimated separately for each gender and age bin; results are reported in Section 3 of the Online Appendix.

\section{Methodology: Contemporaneous Schooling}

To test whether short-term information on human capital outcomes can corroborate the long-term findings in the main analysis, I test whether the Dust Bowl affected contemporaneous school attendance in a sample of children and teenagers taken from the 1930 and 1940 censuses. The "SCHOOL" variable, which is the only reasonable one available to test the Dust Bowl cohort's contemporaneous health or education outcomes in IPUMS, asked respondents whether they had attended any school at any point during a given reference period prior to the census day. In the 1930 census, the reference period was the 6 months prior to April 1, 1930, while in the 1940 census, the reference period was the 1 month prior to April 1, 1940. (Note that because the reference periods are not perfectly comparable, it is possible that the rate of school attendance in 1930 respondents may be mechanically higher.) I drop observations for which school attendance is unknown, but the results are nearly identical whether these observations are dropped or coded as non-attendance.

For parallelism with the main analysis, I first test this effect using state-level measures of erosion on a sample of children aged 5-20 who were born in the states in my main analysis sample and enumerated in 1930 or 1940 . Children enumerated in 1940 are considered to have been treated by the Dust Bowl. I also take advantage of the availability of county-of-enumeration information to develop more granular measures of Dust Bowl exposure. In the county-level analysis, my sample consists of children who were enumerated in one of the states in my main analysis sample, who were aged 5-20 in the census in question (1930 or 1940). I assume the county of enumeration is also the county of birth for those children living in the same state as the birth state, and I drop the remaining $17 \%$ of children who were born outside of the state of residence. (Since this is a short-term rather than later-life or adult analysis, here it is less problematic than in the main analysis to assume that the county of enumeration is also the county of birth.) I then assign these children as their Dust Bowl exposure measure the share of county area deemed to be high erosion. As in the main analysis, in both these approaches, I include a race control, birth 
state dummies, birth year dummies, linear birth trends, and two-way cluster standard errors by birth state and birth year. Here, I also control by age (omitting census wave dummies since these are collinear with age when birth year dummies are also included).

The regression is estimated separately for girls and boys; results are reported in Section 3 of the Online Appendix. 


\section{DATA APPENDIX}

\section{Outcome Variables}

As discussed in Section 2.1, all data on adult outcomes are taken from the 5\% samples of the 1980, 1990, and 2000 US Censuses, available through IPUMS (Ruggles et al. 2010). The sample is restricted to individuals born between the years 1900 and 1959, inclusive, in the 15 Great Plains and adjacent states: Arkansas, Colorado, Iowa, Kansas, Louisiana, Minnesota, Missouri, Montana, Nebraska, New Mexico, North Dakota, Oklahoma, South Dakota, Texas, and Wyoming.

Individual-level outcomes are as follows:

Children Ever Born - The total number of children born to the individual, excluding stillbirths, adopted children, and stepchildren (reported only for female respondents in the census; "CHBORN" in IPUMS). IPUMS "Not applicable" values have been excluded, and regressions on children ever born are restricted to women where the number of children born is known.

Probability of Completing High School - 1 if the individual completed high school, and 0 if not (Constructed based on "HIGRADE" in IPUMS, such that individuals with 13 or more years of schooling [HIGRADE $\geq 15]$ are deemed to have completed high school).

Probability of Completing College - 1 if the individual completed college, and 0 if not (Constructed based on "HIGRADE" in IPUMS, such that individuals with 17 or more years of schooling [HIGRADE $\geq 19$ ] are deemed to have completed college).

Welfare Income - The contemporary dollar amount of pre-tax income, if any, the individual received through public assistance programs including federal/state Supplemental Security Income, Aid to Families with Dependent Children, and General Assistance, but excluding private charitable sources of income ("INCWELFR" in IPUMS).

Probability of Poverty - 1 if the individual is living at or below the official federal poverty threshold designated for their household size and structure, and 0 if not (Constructed based on "POVERTY" in IPUMS, such that individuals for whom POVERTY $\leq 100$ are deemed to be living in poverty).

Probability of Cognitive Disability - 1 if the individual has cognitive difficulties such as those involved in learning, decision-making, concentrating, or remembering; and 0 if not (Constructed based on "DIFFREM" in IPUMS such that individuals experiencing any sort of cognitive impairment are deemed to suffer from cognitive disability).

Probability of Physical Disability - 1 if the individual suffers from conditions that significantly limits one or more essential day-to-day physical activities, such as walking, lifting, climbing, etc.; and 0 if not (Constructed based on "DIFFPHYS" in IPUMS such that individuals experiencing any sort of ambulatory difficulty are deemed to suffer from physical disability). 
Probability of Vision \& Hearing Difficulty - 1 if the individual has long-lasting blindness, deafness, or other severe vision or hearing difficulty; and 0 if not (Constructed based on "DIFFSENS" in IPUMS such that individuals experiencing any sort of vision or hearing impairment are deemed to suffer from cognitive disability).

Probability of Self-Care \& Independent Mobility Difficulty - 1 if the individual has lasting (i.e. non-temporary) conditions that cause difficulty in performing basic personal activities either within or outside the home (e.g. bathing, dressing, shopping, visiting the doctor); and 0 if not (Constructed based on "DIFFCARE" and "DIFFMOB" in IPUMS such that individuals experiencing any sort of impairment in either variable are deemed to suffer from self-care and independent mobility difficulty).

\section{Dust Bowl Exposure Variables}

Erosion (Population-Weighted) - The proportion of the state population in 1930 living in higherosion counties in the individual's birth state (constructed using 1930 county population figures and county-level erosion classifications from the U.S. Census) (Hornbeck 2012). This variable may be interpreted as the probability that an individual in a given state experienced high erosion. Census data, through which only birth state, rather than birth county or birth city is known, does not allow me to pinpoint the actual Dust Bowl severity experienced by an individual in childhood. I attempt to overcome these limitations by constructing this variable such that it accounts for the distribution of population over space. By incorporating county-level information on human geography, I arrive at a measure of Dust Bowl severity more appropriate to a study of the human costs of the disaster than those not "weighted" by population, such as those weighted by county area.

Erosion (Farm Population-Weighted) - replaces erosion ${ }_{s}$ in equation (1); The proportion of the state's farm population in 1930 living in high-erosion counties in the individual's birth state (constructed using 1930 county farm population figures and county-level erosion classifications from the U.S. Census; Hornbeck 2012). This variable may be interpreted as the probability that those engaged in agriculture in a given state experienced high erosion, and thus, as a measure of the severity of the Dust Bowl for agriculture-dependent communities.

Change in Farm Values - The proportion of the state population in 1930 living in high-farm value-loss counties in the individual's birth state (constructed using 1930 county population figures and 1930 and 1940 county-level farm values from the U.S. Census of Agriculture; Hornbeck 2012). To construct this figure, I calculate for each county the percentage change in farm values over the Dust Bowl period, that is, between 1930 and 1940. I then classify the tercile of counties in my sample that experienced the greatest drop in farm values over the period as experiencing "high" farm value loss. I then calculate the proportion of the 1930 population in each state living in high farm value loss counties. By accounting for farm values prior to the Dust Bowl, this variable overcomes the weaknesses in erosion data, for which pre-Dust Bowl baselines do not exist (Soil Conservation Service 1935; Hornbeck 2012). Furthermore, farm values may capture Dust Bowl effects - for instance, economic ones - that erosion alone does not. 
Drought - The sum of drought magnitudes for all official drought events occurring between 1930 and 1940 in the individual's birth state. Drought figures are calculated using monthly climate station-level NOAA data on historical rainfall collected from 1910 to 2010 (National Climatic Data Center of the National Oceanic and Atmospheric Administration 2013); the 100year span of data used exceeds the minimum roughly 50-year sample recommended to establish state baselines (McKee et al. 1993; Wu et al. 2004). Since not all states had climate stations in every county in the early- to mid- $20^{\text {th }}$ Century, it is not possible to gather county-level drought data nor is it possible to weight drought by county-level population as in the erosion and farm value measures of Dust Bowl severity. Instead, I summed the precipitation levels of each climate station within a state in a given month and divided it by the number of climate stations in that state in that month to create monthly state-level precipitation averages. To normalize the rainfall data to allow comparability both across states and across time within a state, these raw precipitation figures were converted to a monthly Standardized Precipitation Index (SPI) figure using a 12-month timescale to capture both short- and longer-term drought effects. The SPI method is preferred by climatologists to other common drought indices, such as the Palmer Drought Index, because of its simplicity and its incorporation of climatological timescales (McKee et al. 1993; Guttman 1999; Wu et al. 2004; World Meteorological Organization 2009). Per McKee et al. (1993), the monthly state-level SPI figures were used to identify official drought events (McKee et al. 1993), and the magnitudes of these events (which capture both severity and duration of drought) were summed over the 1930 to 1940 period to create a single state-level variable representing the total severity of drought in a state during the Dust Bowl timeframe, relative to the state's own historic rainfall baseline.

Treated (Baseline) - 1 if the individual was aged -1 to 12 at any point during the Dust Bowl period of 1930 to 1940, and 0 if not. This age span represents childhood, here defined as the time in utero to the onset of puberty. This variable denotes whether an individual was a child during the Dust Bowl, and thus may plausibly have been exposed to Dust Bowl shocks such as dust storms.

Treated (Developmental Stage) - The proportion of the given age range (-1 to 0,1 to 3, 4 to 6, 7 to 9 , and 10 to 12) spent in (i.e., that coincides with) the Dust Bowl period of 1930 to 1940. For example, an individual born in 1941 spent $50 \%$ of the -1 to 0 age range in the Dust Bowl, while an individual born in 1940 spent $100 \%$ of the same age range in the Dust Bowl, and an individual born in 1942 spent $0 \%$ of this age range in the Dust Bowl. Similarly, an individual born in 1919 would have spent $66.7 \%$ of the 10 to 12 age range but $0 \%$ of the 7 to 9 age range in the Dust Bowl timeframe. This variable is thus a measure of the developmental stage or age at plausible exposure to the Dust Bowl, weighted more heavily for those that spent a greater proportion of the developmental stage during the Dust Bowl period.

\section{Individual \& Household Characteristics}

Sex -1 if the individual is female, 0 if male. 
Race - 1 if the individual is non-white, 0 if white. (Constructed based on "RACE" in IPUMS such that all individuals not identifying exclusively as "white" are deemed non-white).

Veteran Status - 1 if the individual has ever served in the US armed forces on active duty, 0 if not (Constructed based on "VETSTAT" in IPUMS such that only individuals explicitly listed as veterans are deemed veterans; those where veteran status is unknown are counted as nonveterans). For all the census waves used in this study, women are included in this definition of military service.

Migrant Status (Adult) - 1 if the individual is living in a state other than the birth state at the time of the census, 0 if not (Constructed based on "BPL" and "STATEFIP" in IPUMS such that individuals for whom BPL $\neq$ STATEFIP are deemed migrants.) Although the age at which migration took place is unknown, and although it is possible that even those who are currently found living in their birth state migrated out at some point before returning, this variable serves as a rough proxy for individuals who may have migrated out of the sample during childhood.

Migrant Status (Child) - 1 if the individual, currently (in the 1920-50 Censuses) aged 12 or below, is living in a state other than the birth state at the time of the census, 0 if not (Constructed based on "BPL" and "STATEFIP" in IPUMS such that individuals for whom BPL $\neq$ STATEFIP are deemed migrants.) This allows for testing the impact of dust on children's likelihood of migration, as well as that of household characteristics on determining who may have migrated out of the sample during childhood.

Income in Childhood - per capita personal income in the birth year and birth state (Income in Birth Year), per capita personal income in birth state and year before birth (Income In Utero), or per capita personal income in the birth state averaged across the years in which the child was aged -1 to 12, inclusive (Average Income Across Childhood). Income figures are all in 1982-4 dollars (Sahr 2007). Yearly per capita personal income by state is taken from the Bureau of Economic Analysis (2012) for 1929 to 1971; from Easterlin (1957) for 1920; from Klein (2009) for 1890, 1900, and 1910; and is exponentially interpolated from the known data for 1899, 19019, 1911-9, and 1921-8.

Occscore - A continuous variable proxying household income before income was recorded in the Census, constructed by IPUMS (Ruggles et al. 2010) as the median salary attached to the household head's stated occupation. (The variables SEI and PRESGL are also used to proxy for household income and socioeconomic status; see IPUMS for further details of these variables' construction.)

Farm - In regressions using the 1920-50 Censuses (Ruggles et al. 2010), 1 if the household is listed as a farm household in the Census, i.e. the household is engaged in agricultural occupations; and 0 if not.

\section{Fixed Effects \& Trends}


Birth State - The individual's state of birth (identified using "BPL" in IPUMS). Note that in censuses from 1940 onwards, no detail below birth state (such as birth county) is available. In this paper, only those born in Arkansas, Colorado, Iowa, Kansas, Louisiana, Minnesota, Missouri, Montana, Nebraska, New Mexico, North Dakota, Oklahoma, South Dakota, Texas, and Wyoming are included in the sample. These states are selected for being states in the Great Plains region or states neighboring the Great Plains. Studies using Dust Bowl erosion to explain agricultural and environmental phenomena have used a similar if slightly smaller set of states (Hansen \& Libecap 2004; Hornbeck 2012); my sample adds states like Missouri and Arkansas that the qualitative literature suggests may have also suffered from the Dust Bowl (Nealand 2008). The use of states beyond those strictly in the Great Plains/those hardest hit by the Dust Bowl allows me to exploit a greater degree of variation in shock severity. Such variation is necessary for differences-in-differences analysis.

Birth Year — The individual's year of birth (identified using "BIRTHYR" in IPUMS). In this paper, only those born in the years 1900 to 1959, inclusive, are included in the sample. Since individuals born between 1918 and 1941, inclusive, are the cohort of interest, the inclusion of individuals born before and after this period allows for differences-in-differences estimation against those who could not possibly have been exposed to the Dust Bowl.

Census Year - The census year in which the individual's data is reported (identified using "YEAR" in IPUMS). In this paper, the 5\% sample of the US census for 1980, 1990, and 2000 are used. These census waves are chosen in part for the specific variables they report which other censuses do not (such as the highest grade achieved, or a standardized veteran status), as well as to enable capture adult outcomes that are relatively stable (such as those for schooling and fertility, which an individual may not yet have completed if using earlier censuses) (Bhalotra \& Venkataramani 2012).

State Trends - A linear time trend for each birth state in the sample (constructed using "BPL" and "BIRTHYR" in IPUMS).

\section{Public Spending}

New Deal - total per capita New Deal expenditure in the individual's birth state; for further detail, see Fishback et al. (2003) and http://www.u.arizona.edu/ fishback/ Published_Research_Datasets.html.

Relief - total per capita relief expenditure in the individual's birth state as a part of New Deal and related programs; for further detail, see Fishback et al. (2003) and http://www.u.arizona.edu/ fishback/Published_Research_Datasets.html.

Loans - total per capita loan expenditure in the individual's birth state as a part of New Deal and related programs; for further detail, see Fishback et al. (2003) and http://www.u.arizona.edu/ fishback/ Published_Research_Datasets.html. 


\section{REFERENCES FOR METHODOLOGY \& DATA APPENDICES ${ }^{1}$}

Bhalotra, Sonia, and Atheendar Venkataramani, 'Shadows of the Captain of the Men of Death: Early Life Health Interventions, Human Capital Investments, and Institutions', Manuscript, (2012), pp. 1-59.

Bureau of Economic Analysis, 'State Personal Income, 1929-2011', (2012), Accessed 1 July 2013 at 〈http://bea.gov>.

Centers for Disease Control and Prevention, National Center for Health Statistics. Compressed Mortality File 1968-1978, CDC WONDER Online Database, compiled from Compressed Mortality File CMF 1968-1988, Series 20, No. 2A, (2000), Accessed 13 February 2014 at <http://wonder.cdc.gov/cmf-icd8.html>.

Centers for Disease Control and Prevention, National Center for Health Statistics. Compressed Mortality File 1979-1998, CDC WONDER On-line Database, compiled from Compressed Mortality File CMF 1968-1988, Series 20, No. 2A, 2000 and CMF 1989-1998, Series 20, No. 2E, (2003), Accessed 13 February 2014 at 〈http://wonder.cdc.gov/cmf-icd9.html〉.

Centers for Disease Control and Prevention, National Center for Health Statistics. Compressed Mortality File 1999-2010 on CDC WONDER Online Database, released January 2013. Data are compiled from Compressed Mortality File 1999-2010 Series 20 No. 2P, (2013), Accessed 13 February 2014 at <http://wonder.cdc.gov/cmf-icd10.html>.

Easterlin, Richard, 'State Income Estimates', in Population Redistribution and Economic Growth United States,1870-1950, Volume I: Methodological Considerations and Reference Tables, Lee, Everett, Ann Miller, C.P. Brainerd, and Richard Easterlin, ed., Philadelphia: American Philosophical Society, 1957.

Fishback, Price, Shawn Kantor, and John Wallis, 'Can the New Deal's Three R's Be Rehabilitated? A Program-by-Program, County-by-County Analysis', Explorations in Economic History, 40:3 (2003), pp. 278-307.

Guttman, Nathaniel, 'Accepting the Standardized Precipitation Index: A Calculation Algorithm', Journal of the American Water Resources Association, 35.2 (1999), pp. 31122.

Hansen, Zeynep. and Gary Libecap, 'Small Farms, Externalities, and the Dust Bowl of the 1930s',

\footnotetext{
${ }^{1}$ Note: This list contains references to data sources used in analysis exclusive to the Online Appendix and thus not included in main paper; as such, these sources do not appear in the main paper's references.
} 
Journal of Political Economy, 112.3 (2004), pp. 665-94.

Hornbeck, Richard, 'The Enduring Impact of the American Dust Bowl: Short- and Long-Run Adjustments to Environmental Catastrophe', American Economic Review, 102:4 (2012), pp. 1477-507.

Klein, Alexander, 'Personal Income of U.S. States: Estimates for the Period 1880-1910', Warwick Economic Research Papers \#916, (2009), pp. 1-60.

McKee, Thomas, Nolan Doesken, and John Kliest, 'The Relationship of Drought Frequency and Duration to Time Scales', Proceedings of the Eighth Conference on Applied Climatology, (1993), pp. 179-84.

National Bureau of Economic Research, US Census Intercensal Population Estimates Data File pop7099s, Released April 2006, Accessed 13 February 2014 at < http://www.nber.org/data/census-intercensal-population/>.

National Climatic Data Center of the National Oceanic and Atmospheric Administration, 'Annual Climatological Summary Data Extracts for 1910-2010', Accessed 27 September 2013 at $<$ http://www.ncdc.noaa.gov/>.

National Center for Health Statistics, Vital Statistics of the United States 1970: Mortality, Washington, D.C.: Public Health Service, 1974.

National Center for Health Statistics, Vital Statistics of the United States 1980: Mortality, Washington, D.C.: Public Health Service, 1985.

National Center for Health Statistics, Vital Statistics of the United States 1990: Mortality, Washington, D.C.: Public Health Service, 1994.

National Center for Health Statistics, Vital Statistics Rates in the United States 1940-1960, Washington, D.C.: Public Health Service, 1968.

Nealand, Daniel, 'Archival Vintages for The Grapes of Wrath', Prologue Magazine, 40.4 (2008), $\begin{array}{lllll}\text { Accessed } & 25 & \text { February } & 2013\end{array}$ <http://www.archives.gov/publications/prologue/2008/winter/grapes.html.>

Public Health Service, Vital Statistics Rates in the United States 1900-1940, Washington, D.C.: U.S. Government Printing Office, 1947.

Ruggles, Steven, J. Trent Alexander, Katie Genadek, Ronald Goeken, Matthew Schroeder, and Matthew Sobek, Integrated Public Use Microdata Series: Version 5.0 [Machine-readable database], Minneapolis, MN: Minnesota Population Center [producer and distributor], 
2010.

Sahr, Robert, 'Inflation Conversion Factors for Years 1665 to Estimated 2017', (2007), Accessed 18 March 2014 at <http://oregonstate.edu/cla/polisci/facultyresearch/sahr/infcf16652007.pdf>.

Soil Conservation Service, Soil Erosion: A Critical Problem in American Agriculture, Washington, DC: United States Government Printing Office, 1935.

World Meteorological Organization, 'Experts Agree on a Universal Drought Index to Cope With Climate Risks', Press Release No. 872, (2009), p. 1.

Wu, Hong, Michael J. Hayes, Donald A. Wilhite, and Mark D. Svoboda, 'The Effect of the Length of Record on the Standardized Precipitation Index Calculation', International Journal of Climatology, 25 (2005), pp. 505-20. 


\section{TABLE APPENDIX}

Table A1 - Impact of Exposure to the Dust Bowl on Later-life Outcomes: Depression Controls - Men

\begin{tabular}{|c|c|c|c|c|c|c|}
\hline & \multicolumn{2}{|c|}{$\begin{array}{l}\text { Income in Year of Birth } \\
\text { (1) }\end{array}$} & \multicolumn{2}{|c|}{$\begin{array}{l}\text { Income In Utero } \\
\text { (2) }\end{array}$} & \multicolumn{2}{|c|}{$\begin{array}{c}\text { Average Income Across } \\
\text { Childhood } \\
\text { (3) }\end{array}$} \\
\hline & Treated $\times$ Erosion & PC Income & Treated $\times$ Erosion & $\mathrm{PC}$ Income & Treated $\times$ Erosion & $\begin{array}{c}\mathrm{PC} \\
\text { Income }\end{array}$ \\
\hline Probability of Completing High School & $\begin{array}{c}0.0185 \\
(0.0138)\end{array}$ & $\begin{array}{c}-7.81 \mathrm{E}-06 \\
(0.0000)\end{array}$ & $\begin{array}{c}0.0184 \\
(0.0140)\end{array}$ & $\begin{array}{c}-6.87 \mathrm{E}-06 \\
(0.0000)\end{array}$ & $\begin{array}{c}0.0184 \\
(0.0115)\end{array}$ & $\begin{array}{c}-3.11 \mathrm{e}-05^{* * * *} \\
(0.0000)\end{array}$ \\
\hline Probability of Completing College & $\begin{array}{l}-0.0105 \\
(0.0075)\end{array}$ & $\begin{array}{c}-1.33 \mathrm{E}-06 \\
(0.0000)\end{array}$ & $\begin{array}{l}-0.0102 \\
(0.0075)\end{array}$ & $\begin{array}{c}-2.52 \mathrm{E}-06 \\
(0.0000)\end{array}$ & $\begin{array}{l}-0.0107 \\
(0.0071)\end{array}$ & $\begin{array}{c}-1.18 \mathrm{E}-06 \\
(0.0000)\end{array}$ \\
\hline Welfare Income & $\begin{array}{c}15.92 * \\
(8.3350)\end{array}$ & $\begin{array}{c}-0.00438 * * \\
(0.0020)\end{array}$ & $\begin{array}{l}16.29 * * \\
(8.1360)\end{array}$ & $\begin{array}{l}-0.00583 * * * \\
(0.0019)\end{array}$ & $\begin{array}{l}15.48^{*} \\
(8.3170)\end{array}$ & $\begin{array}{c}-0.0143 * * * \\
(0.0055)\end{array}$ \\
\hline Probability of Poverty & $\begin{array}{c}0.00898 * * * \\
(0.0034)\end{array}$ & $\begin{array}{l}-4.82 \mathrm{e}-06^{* * * *} \\
(0.0000)\end{array}$ & $\begin{array}{c}0.00874 * * \\
(0.0036)\end{array}$ & $\begin{array}{c}-3.38 \mathrm{e}-06^{*} \\
(0.0000)\end{array}$ & $\begin{array}{c}0.00840^{* *} \\
(0.0033)\end{array}$ & $\begin{array}{l}-1.26 \mathrm{e}-05^{* * *} \\
(0.0000)\end{array}$ \\
\hline Probability of Cognitive Disability & $\begin{array}{l}0.00735 \\
(0.0068)\end{array}$ & $\begin{array}{c}-4.64 \mathrm{E}-06 \\
(0.0000)\end{array}$ & $\begin{array}{l}0.00716 \\
(0.0068)\end{array}$ & $\begin{array}{c}-3.42 \mathrm{E}-06 \\
(0.0000)\end{array}$ & $\begin{array}{l}0.00647 \\
(0.0062)\end{array}$ & $\begin{array}{c}-9.52 \mathrm{e}-06 * \\
(0.0000)\end{array}$ \\
\hline Probability of Physical Disability & $\begin{array}{c}0.0116^{* *} \\
(0.0050)\end{array}$ & $\begin{array}{c}-3.75 \mathrm{e}-06^{*} \\
(0.0000)\end{array}$ & $\begin{array}{c}0.0112 * * \\
(0.0049)\end{array}$ & $\begin{array}{c}-9.96 \mathrm{E}-07 \\
(0.0000)\end{array}$ & $\begin{array}{c}0.0109 * * \\
(0.0046)\end{array}$ & $\begin{array}{c}-1.47 \mathrm{e}-05^{*} \\
(0.0000)\end{array}$ \\
\hline Probability of Vision \& Hearing Difficulty & $\begin{array}{c}-0.00234 \\
(0.0060)\end{array}$ & $\begin{array}{c}-2.26 \mathrm{E}-06 \\
(0.0000)\end{array}$ & $\begin{array}{l}-0.0024 \\
(0.0061)\end{array}$ & $\begin{array}{c}-1.79 \mathrm{E}-06 \\
(0.0000)\end{array}$ & $\begin{array}{c}-0.00279 \\
(0.0057)\end{array}$ & $\begin{array}{c}-9.04 \mathrm{e}-06 * * \\
(0.0000)\end{array}$ \\
\hline $\begin{array}{l}\text { Probability of Self- Care \& Independent Mobility } \\
\text { Difficulty }\end{array}$ & $\begin{array}{l}5.73 \mathrm{E}-05 \\
(0.0031)\end{array}$ & $\begin{array}{c}-1.75 \mathrm{e}-06^{*} \\
(0.0000)\end{array}$ & $\begin{array}{c}0.000239 \\
(0.0030)\end{array}$ & $\begin{array}{l}-2.52 \mathrm{e}-06^{* * * *} \\
(0.0000)\end{array}$ & $\begin{array}{l}-0.00021 \\
(0.0033)\end{array}$ & $\begin{array}{l}-4.57 \mathrm{e}-06^{*} \\
(0.0000)\end{array}$ \\
\hline
\end{tabular}

*** $\mathrm{p}<0.01, * * \mathrm{p}<0.05, * \mathrm{p}<0.1$; Note: Table reports, for each regression, the treated $_{b} \times$ erosion $_{s}$ and per capita income coefficients. Column headers refer to the measure of birth state-birth year per capita income used. All regressions are estimated by OLS and include additional controls for race; birth year, birth state, and census state fixed effects; and state trends. Standard errors, clustered by birth state, are reported in parentheses below each coefficient. To aid in interpreting the coefficients of the per capita income variables, the minimum, maximum, and standard deviation are as follows: Income in Year of Birth (988.636, 7842.472, 1686.206); Income In Utero (854.516, 7610.116, 1650.102); Average Income Across Childhood (1292.224, 8893.168, 1878.751). 
Table A2 - Impact of Exposure to the Dust Bowl on Later-life Outcomes: Depression Controls - Women

Income in Year of Birth

(1)
Income In Utero

(2)
Average Income Across Childhood

$* * * \mathrm{p}<0.01, * * \mathrm{p}<0.05, * \mathrm{p}<0.1$; Note: Table reports, for each regression, the treated $_{b} \times$ erosion $_{s}$ and per capita income coefficients. Column headers refer to the measure of birth state-birth year per capita income used. All regressions are estimated by OLS and include additional controls for race; birth year, birth state, and census state fixed effects; and state trends. Standard errors, clustered by birth state, are reported in parentheses below each coefficient. To aid in interpreting the coefficients of the per capita income variables, the minimum, maximum, and standard deviation are as follows: Income in Year of Birth (988.636, 7842.472, 1677.844); Income In Utero (854.516, 7610.116, 1640.673); Average Income Across Childhood (1292.224, 8893.168, 1883.209). 
Table A3 - Impact of Exposure to the Dust Bowl on Later-life Outcomes: Migration Analysis on Adults

\begin{tabular}{|c|c|c|c|c|c|c|}
\hline & $\begin{array}{c}\text { Dust Bowl } \\
\text { (1) }\end{array}$ & \multicolumn{2}{|c|}{$\begin{array}{c}\text { Migrant } \times \text { Erosion } \\
(2)\end{array}$} & $\begin{array}{l}\text { Migrant } \\
\text { (3) }\end{array}$ & \multicolumn{2}{|c|}{$\begin{array}{c}\text { Migrant } \times \text { Erosion } \\
(4)\end{array}$} \\
\hline & \multicolumn{3}{|c|}{ Men } & \multicolumn{3}{|c|}{ Women } \\
\hline & & Main & Interaction & & Main & Interaction \\
\hline Probability of (Eventual) Migration & $\begin{array}{c}0.016 \\
(0.0288)\end{array}$ & & & $\begin{array}{c}0.0194 \\
(0.0292)\end{array}$ & & \\
\hline Children Ever Born & & & & & $\begin{array}{c}-0.243 \\
(0.1650)\end{array}$ & $\begin{array}{c}0.087 \\
(0.1020)\end{array}$ \\
\hline Probability of Completing High School & & $\begin{array}{c}0.0113 \\
(0.0178)\end{array}$ & $\begin{array}{c}-0.00178 \\
(0.0108)\end{array}$ & & $\begin{array}{l}0.0425^{*} \\
(0.0221)\end{array}$ & -0.0373 \\
\hline Probability of Completing College & & $\begin{array}{c}-0.0253 * * \\
(0.0114)\end{array}$ & $\begin{array}{c}0.0179 \\
(0.0141)\end{array}$ & & $\begin{array}{c}-0.0119 * * * \\
(0.0011)\end{array}$ & -0.00232 \\
\hline Welfare Income & & $\begin{array}{l}22.72 * * \\
(9.3270)\end{array}$ & -17.62 & & $\begin{array}{c}21.22 \\
(13.2600)\end{array}$ & $\begin{array}{c}-8.97 \\
(16.1000)\end{array}$ \\
\hline Probability of Poverty & & $\begin{array}{c}0.00811 * * * \\
(0.0029)\end{array}$ & 0.00675 & & 0.00502 & $\begin{array}{l}0.00159 \\
(0.0046)\end{array}$ \\
\hline Probability of Cognitive Disability & & $\begin{array}{l}0.00531 \\
(0.0074)\end{array}$ & $\begin{array}{l}0.00379 \\
(0.0043)\end{array}$ & & $\begin{array}{l}0.00098 \\
(0.0052)\end{array}$ & $\begin{array}{c}-0.0143 * * * \\
(0.0007)\end{array}$ \\
\hline Probability of Physical Disability & & $\begin{array}{c}0.0124 * * * \\
(0.0038)\end{array}$ & $\begin{array}{l}-0.00179 \\
(0.0041)\end{array}$ & & $\begin{array}{l}-0.00295 \\
(0.0141)\end{array}$ & $\begin{array}{l}0.00189 \\
(0.0114)\end{array}$ \\
\hline Probability of Vision \& Hearing Difficulty & & $\begin{array}{c}-0.00126 \\
(0.0066)\end{array}$ & $\begin{array}{r}-0.00391 \\
(0.0078)\end{array}$ & & $\begin{array}{l}0.00361 \\
(0.0047)\end{array}$ & $\begin{array}{c}-0.0125^{* *} \\
(0.0058)\end{array}$ \\
\hline Probability of Self- Care \& Independent Mobility Difficulty & & $\begin{array}{l}0.00265 \\
(0.0060)\end{array}$ & $\begin{array}{l}-0.00538 \\
(0.0082)\end{array}$ & & $\begin{array}{c}0.00479 * * \\
(0.0019)\end{array}$ & $\begin{array}{c}-0.0129 * * \\
(0.0057)\end{array}$ \\
\hline
\end{tabular}

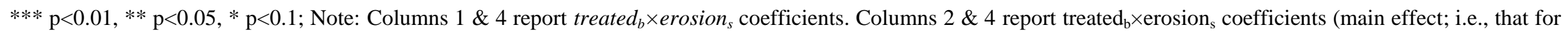
Dust Bowl-exposed non-migrants) and migrant $_{i} \times$ treated $_{b} \times$ erosion $_{s}$ coefficients (interaction effect; i.e., that for Dust Bowl-exposed eventual migrants) for specifications that interact the baseline treatment term with the individual's lifetime migrant status. All regressions are estimated by OLS and include two-way interactions and controls for race; birth year, birth state, and census state fixed effects; and state trends. Standard errors, clustered by birth state and birth year, are reported in parentheses below each coefficient. 
Table A4 - Impact of Household Status on Decision to Migrate During the Dust Bowl: Migration Analysis on Children

\begin{tabular}{|c|c|c|c|c|c|c|c|c|c|c|c|}
\hline & \multirow{3}{*}{$\begin{array}{l}\text { Dust Bowl } \\
\text { (1) }\end{array}$} & \multirow{2}{*}{\multicolumn{2}{|c|}{$\begin{array}{l}\text { Occscore } \times \text { Erosion } \\
\text { (2) }\end{array}$}} & \multicolumn{2}{|c|}{ SEI $\times$ Erosion } & \multirow{2}{*}{\multicolumn{2}{|c|}{$\begin{array}{c}\text { PRESGL } \times \text { Erosion } \\
\text { (4) }\end{array}$}} & \multicolumn{2}{|c|}{ Farm $\times$ Erosion } & \multirow{2}{*}{\multicolumn{2}{|c|}{$\begin{array}{c}\text { Farm } \times \text { Erosion } \\
\text { (with Occscore } \\
\text { control) } \\
(6)\end{array}$}} \\
\hline & & & & & (3) & & & & (5) & & \\
\hline & & Main & Interaction & Main & Interaction & Main & Interaction & Main & Interaction & Main & Interaction \\
\hline $\begin{array}{l}\text { Prob. of } \\
\text { (Childhood) }\end{array}$ & $\begin{array}{l}-0.144 * \\
(0.0857)\end{array}$ & -0.178 & -0.015 & -0.195 & $\begin{array}{l}-0.00454 \\
(0.00951)\end{array}$ & -0.249 & $\begin{array}{l}-0.00363 \\
(0.00768)\end{array}$ & $\begin{array}{l}-0.0242 \\
(0.018)\end{array}$ & $\begin{array}{c}0.021 \\
(0.0189)\end{array}$ & $\begin{array}{c}0.432 * * \\
(0.184)\end{array}$ & $\begin{array}{c}-0.617 * * * \\
(0.135)\end{array}$ \\
\hline
\end{tabular}

Migration

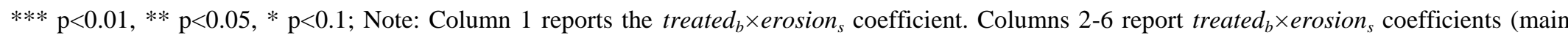
effect) and interaction $\times$ treated $_{b} \times$ erosion $_{s}$ coefficients (interaction effect) for specifications that interact the baseline treatment term with the child's household income/socioeconomic status measure. All regressions are estimated by OLS and include two-way interactions and controls for race, age, sex, farm status, and household income; birth state, birth year, and census year fixed effects; and state trends. Standard errors, clustered by birth state and birth year, are reported in parentheses below each coefficient. Farm status is a binary variable, while the other household status terms are continuous; to aid in interpreting the interaction coefficient for the remaining household status variables, the minimum, maximum, and standard deviation are as follows: Occscore (3, 80, 6.060); SEI (6, 92, 7.494); PRESGL (14.7, 81.5, 6.507). 
Table A5 - Impact of Household Status on Decision to Bear Children During the Dust Bowl

\begin{tabular}{|c|c|c|c|c|c|c|c|c|}
\hline & \multicolumn{2}{|c|}{$\begin{array}{c}\text { Occscore } \times \text { Erosion } \\
\text { (1) }\end{array}$} & \multicolumn{2}{|c|}{$\begin{array}{c}\text { SEI } \times \text { Erosion } \\
(2)\end{array}$} & \multicolumn{2}{|c|}{$\begin{array}{c}\text { PRESGL } \times \text { Erosion } \\
\text { (3) }\end{array}$} & \multicolumn{2}{|c|}{$\begin{array}{c}\text { Farm } \times \text { Erosion } \\
(4)\end{array}$} \\
\hline & Main & Interaction & Main & Interaction & Main & Interaction & Main & Interaction \\
\hline $\begin{array}{l}\text { Probability of Having Had a Child in the } \\
\text { Past } 10 \text { Years }\end{array}$ & $\begin{array}{l}0.0489 * * \\
(0.0221)\end{array}$ & $\begin{array}{r}-0.00069 \\
(0.0008)\end{array}$ & $\begin{array}{c}0.0356 \\
(0.0261)\end{array}$ & $\begin{array}{l}0.000197 \\
(0.0003)\end{array}$ & $\begin{array}{c}0.036 \\
(0.0447)\end{array}$ & $\begin{array}{l}0.000173 \\
(0.0010)\end{array}$ & 0.0454 & $\begin{array}{l}-0.0109 \\
(0.0411)\end{array}$ \\
\hline
\end{tabular}

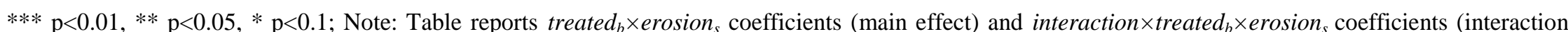
effect) for specifications that interact the baseline treatment term with the woman's household income/socioeconomic status measure. All regressions are estimated by OLS and include two-way interactions and controls for race, age, household farm status, and income; census state, birth year, and census year fixed effects; and state trends. Standard errors, clustered by census state and birth year, are reported in parentheses below each coefficient. Farm status is a binary variable, while the other household status terms are continuous; to aid in interpreting the interaction coefficient for the remaining household status variables, the minimum, maximum, and standard deviation are as follows: Occscore $(3,80,10.081)$; SEI $(4,96,21.632)$; PRESGL $(9.3,81.5,13.327)$.

Table A6 - Impact of Dust Bowl Exposure on State Birth, Stillbirth, and Infant Mortality Rates

\begin{tabular}{|c|c|c|c|c|c|c|c|c|c|c|c|}
\hline & $\begin{array}{c}1930-40 \\
(1)\end{array}$ & $\begin{array}{c}1931-40 \\
(2)\end{array}$ & $\begin{array}{c}1932-40 \\
(3)\end{array}$ & $\begin{array}{c}1933-40 \\
(4)\end{array}$ & $\begin{array}{c}1934-40 \\
(5)\end{array}$ & $\begin{array}{c}1935-40 \\
(6)\end{array}$ & $\begin{array}{c}1936-40 \\
(7)\end{array}$ & $\begin{array}{c}1937-40 \\
(8)\end{array}$ & $\begin{array}{c}1938-40 \\
(9)\end{array}$ & $\begin{array}{c}1939-40 \\
(10)\end{array}$ & $\begin{array}{c}1940 \\
(2)\end{array}$ \\
\hline Crude Birth Rate & $\begin{array}{c}0.0518 \\
(0.4770)\end{array}$ & $\begin{array}{c}0.0455 \\
(0.5430)\end{array}$ & $\begin{array}{c}0.0415 \\
(0.6220)\end{array}$ & $\begin{array}{c}-0.14 \\
(0.7550)\end{array}$ & $\begin{array}{c}-0.361 \\
(0.7450)\end{array}$ & $\begin{array}{c}-0.53 \\
(0.7050)\end{array}$ & $\begin{array}{c}-0.56 \\
(0.7020)\end{array}$ & $\begin{array}{c}-0.546 \\
(0.8570)\end{array}$ & $\begin{array}{c}-0.536 \\
(0.9330)\end{array}$ & $\begin{array}{c}-0.417 \\
(0.9300)\end{array}$ & $\begin{array}{c}-0.489 \\
(1.1290)\end{array}$ \\
\hline Stillbirth Rate & $\begin{array}{c}-0.401 \\
(2.1680)\end{array}$ & $\begin{array}{c}-0.134 \\
(2.1540)\end{array}$ & $\begin{array}{c}0.19 \\
(2.2220)\end{array}$ & $\begin{array}{c}0.497 \\
(2.3170)\end{array}$ & $\begin{array}{c}0.944 \\
(2.2360)\end{array}$ & $\begin{array}{c}1.155 \\
(2.1330)\end{array}$ & $\begin{array}{c}0.617 \\
(2.0910)\end{array}$ & $\begin{array}{c}0.853 \\
(1.5110)\end{array}$ & $\begin{array}{c}0.995 \\
(1.4960)\end{array}$ & $\begin{array}{c}0.355 \\
(1.5420)\end{array}$ & $\begin{array}{l}3.198 * * \\
(1.3750)\end{array}$ \\
\hline Infant Mortality Rate & $\begin{array}{c}-0.952 \\
(3.0420)\end{array}$ & $\begin{array}{c}0.43 \\
(3.1900)\end{array}$ & $\begin{array}{c}0.428 \\
(3.0220)\end{array}$ & $\begin{array}{c}-0.0181 \\
(3.0560)\end{array}$ & $\begin{array}{c}0.0726 \\
(3.5210)\end{array}$ & $\begin{array}{c}-1.436 \\
(3.2890)\end{array}$ & $\begin{array}{c}-0.861 \\
(3.1000)\end{array}$ & $\begin{array}{c}-2.095 \\
(3.1180)\end{array}$ & $\begin{array}{c}-2.619 \\
(3.1670)\end{array}$ & $\begin{array}{c}-2.903 \\
(3.2980)\end{array}$ & $\begin{array}{c}-1.155 \\
(3.8670)\end{array}$ \\
\hline
\end{tabular}

$* * * \mathrm{p}<0.01, * * \mathrm{p}<0.05, * \mathrm{p}<0.1$; Note: Table reports the treated $_{b} \times$ erosion $_{s}$ coefficient. Column headers refer to the way the treated ${ }_{b}$ term is defined (e.g. for Column 1 , treated $_{b}=1$ if the year is 1930-40, inclusive). All regressions are estimated by OLS and include state and year fixed effects and state trends. Standard errors, clustered by state, are reported in parentheses below each coefficient. 
Table A7 — Impact of Dust Bowl Exposure on Age-Specific Mortality Rates - Men

\begin{tabular}{|c|c|c|c|c|c|c|c|c|c|c|}
\hline & $\begin{array}{c}\text { Under } 1 \\
\text { (1) }\end{array}$ & $\begin{array}{l}1-4 \\
(2)\end{array}$ & $\begin{array}{l}5-14 \\
(3)\end{array}$ & $\begin{array}{c}15-24 \\
(4)\end{array}$ & $\begin{array}{c}25-34 \\
(5)\end{array}$ & $\begin{array}{c}35-44 \\
(6)\end{array}$ & $\begin{array}{c}45-54 \\
(7)\end{array}$ & $\begin{array}{c}55-64 \\
(8)\end{array}$ & $\begin{array}{c}65-74 \\
(9)\end{array}$ & $\begin{array}{c}75-84 \\
(10)\end{array}$ \\
\hline Mortality Rate (Age Bin & -16.67 & -0.0812 & $-0.406 * *$ & 0.268 & 0.168 & 0.2 & -0.00796 & 0.628 & -1.009 & \\
\hline Narrowly Defined) & $(15.6200)$ & $(1.2540)$ & $(0.1610)$ & $(0.3920)$ & $(0.5370)$ & $(0.3880)$ & $(0.6670)$ & $(0.9980)$ & $(1.2640)$ & \\
\hline Mortality Rate (Age Bin & -16.67 & -0.0812 & 0.0344 & -0.0902 & 0.325 & 0.0839 & -0.112 & $-3.212 * *$ & -1.719 & -6.228 \\
\hline Broadly Defined) & $(15.6200)$ & $(1.2540)$ & $(0.1040)$ & $(0.4540)$ & $(0.6010)$ & $(0.5020)$ & $(0.4400)$ & $(1.1270)$ & $(2.6260)$ & $(4.0260)$ \\
\hline
\end{tabular}

*** $\mathrm{p}<0.01, * * \mathrm{p}<0.05, * \mathrm{p}<0.1$; Note: Table reports the treated $_{b} \times$ erosion $_{s}$ coefficient, e.g. the effect of Dust Bowl cohort membership on mortality rates within a given age bin, relative to mortality rates in the same age bin for those not exposed to the Dust Bowl. Column headers refer to the age bin for which the regression has been run. Row 1 reports results where treated $b$ has been narrowly defined, i.e., treated $_{b}=1$ only if the age bin contains only Dust Bowlexposed individuals; Row 2 reports results where treated $_{b}$ has been broadly defined, i.e., treated $d_{b}=1$ if the age bin contains any Dust Bowl-exposed individuals. All regressions are estimated by OLS and include state and year fixed effects and state trends. Standard errors, clustered by state, are reported in parentheses below each coefficient.

Table A8 - Impact of Dust Bowl Exposure on Age-Specific Mortality Rates - Women

\begin{tabular}{|c|c|c|c|c|c|c|c|c|c|c|}
\hline & $\begin{array}{c}\text { Under } 1 \\
\text { (1) }\end{array}$ & $\begin{array}{l}1-4 \\
(2)\end{array}$ & $\begin{array}{l}5-14 \\
(3)\end{array}$ & $\begin{array}{c}15-24 \\
(4)\end{array}$ & $\begin{array}{c}25-34 \\
(5)\end{array}$ & $\begin{array}{c}35-44 \\
(6)\end{array}$ & $\begin{array}{c}45-54 \\
(7)\end{array}$ & $\begin{array}{c}55-64 \\
(8)\end{array}$ & $\begin{array}{c}65-74 \\
(9)\end{array}$ & $\begin{array}{c}75-84 \\
(10)\end{array}$ \\
\hline Mortality Rate (Age Bin & -15.16 & -0.883 & -0.275 & 0.17 & 0.502 & 0.138 & 0.144 & 0.439 & 0.552 & \\
\hline Narrowly Defined) & (11.3700) & $(1.2450)$ & $(0.2020)$ & $(0.4120)$ & $(0.4220)$ & $(0.2720)$ & $(0.3350)$ & $(0.8080)$ & $(1.2880)$ & \\
\hline Mortality Rate (Age Bin & -15.16 & -0.883 & -0.0862 & 0.484 & 0.542 & 0.363 & 0.0564 & 0.673 & 0.502 & 0.984 \\
\hline Broadly Defined) & $(11.3700)$ & $(1.2450)$ & $(0.0757)$ & $(0.4530)$ & $(0.4880)$ & $(0.3850)$ & $(0.3890)$ & $(0.9550)$ & $(1.5320)$ & $(2.2290)$ \\
\hline
\end{tabular}

$* * * \mathrm{p}<0.01, * * \mathrm{p}<0.05, * \mathrm{p}<0.1$; Note: Table reports the treated $_{b} \times$ erosion $_{s}$ coefficient, e.g. the effect of Dust Bowl cohort membership on mortality rates within a given age bin, relative to mortality rates in the same age bin for those not exposed to the Dust Bowl. Column headers refer to the age bin for which the regression has been run. Row 1 reports results where treated $_{b}$ has been narrowly defined, i.e., treated $_{b}=1$ only if the age bin contains only Dust Bowlexposed individuals; Row 2 reports results where treated $_{b}$ has been broadly defined, i.e., treated $_{b}=1$ if the age bin contains any Dust Bowl-exposed individuals. All regressions are estimated by OLS and include state and year fixed effects and state trends. Standard errors, clustered by state, are reported in parentheses below each coefficient. 
Table A9 - Impact of Dust Bowl Exposure on Probability of School Attendance - Boys

\begin{tabular}{|c|c|c|c|c|c|c|c|}
\hline & & & & & & & \\
\hline & \multicolumn{7}{|c|}{ BOYS } \\
\hline & (1) & $(2)$ & $(3)$ & (4) & (5) & (6) & (7) \\
\hline & $\begin{array}{c}\text { Probability } \\
\text { of School } \\
\text { Attendance } \\
\text { (Ages 5-20) }\end{array}$ & $\begin{array}{c}\text { Probability } \\
\text { of School } \\
\text { Attendance } \\
\text { (Ages 14-20) }\end{array}$ & $\begin{array}{c}\text { Probability } \\
\text { of School } \\
\text { Attendance } \\
\text { (Ages 15-20) }\end{array}$ & $\begin{array}{c}\text { Probability } \\
\text { of School } \\
\text { Attendance } \\
\text { (Ages 16-20) }\end{array}$ & $\begin{array}{c}\text { Probability } \\
\text { of School } \\
\text { Attendance } \\
\text { (Ages 17-20) }\end{array}$ & $\begin{array}{c}\text { Probability } \\
\text { of School } \\
\text { Attendance } \\
\text { (Ages 18-20) }\end{array}$ & $\begin{array}{c}\text { Probability of } \\
\text { School } \\
\text { Attendance } \\
\text { (Ages 19-20) }\end{array}$ \\
\hline State-Level: Treated x Erosion & $\begin{array}{c}-0.1829 * * * \\
(0.0163)\end{array}$ & $\begin{array}{l}-0.0148 \\
(0.0497)\end{array}$ & $\begin{array}{c}0.0257 \\
(0.0643)\end{array}$ & $\begin{array}{c}0.1463 * \\
(0.0848)\end{array}$ & $\begin{array}{l}0.2035^{*} \\
(0.1177)\end{array}$ & $\begin{array}{c}0.1622 \\
(0.1745)\end{array}$ & $\begin{array}{c}0.1314 \\
(0.3313)\end{array}$ \\
\hline County-Level: Treated x Erosion & $\begin{array}{c}0.0065 \\
(.) \\
\end{array}$ & $\begin{array}{c}0.0547 * * \\
(0.0254) \\
\end{array}$ & $\begin{array}{c}0.0531 * * \\
(0.0263) \\
\end{array}$ & $\begin{array}{l}0.0575 * \\
(0.0326) \\
\end{array}$ & $\begin{array}{c}0.0588 * * * \\
(0.0228)\end{array}$ & $\begin{array}{c}0.0350 * * \\
(0.0161) \\
\end{array}$ & $\begin{array}{c}0.0119 \\
(.)\end{array}$ \\
\hline
\end{tabular}

$* * * \mathrm{p}<0.01, * * \mathrm{p}<0.05, * \mathrm{p}<0.1$; Note: Table reports the treated $_{b} \times$ erosion $_{s}$ coefficient, e.g. the effect of Dust Bowl cohort membership the probability of contemporaneous school attendance, relative to school attendance probability for those not exposed to the Dust Bowl. Sample includes children born in the 15 sample states and enumerated in 1930 (control) or 1940 (treated). Column headers indicate the age range of children in the regression. Row 1 reports results where erosion is assigned at the birth-state level, while row 2 gives the results of analysis using county-of-birth erosion. All regressions are estimated by OLS and include birth state and birth year fixed effects, state trends, and controls for age and race. Standard errors, two-way clustered by state and birth year, are reported in parentheses below each coefficient.

Table A10 - Impact of Dust Bowl Exposure on Probability of School Attendance - Girls

\begin{tabular}{|c|c|c|c|c|c|c|c|}
\hline & \multicolumn{7}{|c|}{ GIRLS } \\
\hline & $(1)$ & $(2)$ & (3) & $(4)$ & $(5)$ & $(6)$ & $(7)$ \\
\hline & $\begin{array}{l}\text { Probability } \\
\text { of School } \\
\text { Attendance } \\
\text { (Ages 5-20) }\end{array}$ & $\begin{array}{c}\text { Probability } \\
\text { of School } \\
\text { Attendance } \\
\text { (Ages 14-20) }\end{array}$ & $\begin{array}{c}\text { Probability } \\
\text { of School } \\
\text { Attendance } \\
\text { (Ages 15-20) }\end{array}$ & $\begin{array}{c}\text { Probability } \\
\text { of School } \\
\text { Attendance } \\
\text { (Ages 16-20) } \\
\end{array}$ & $\begin{array}{c}\text { Probability } \\
\text { of School } \\
\text { Attendance } \\
\text { (Ages 17-20) } \\
\end{array}$ & $\begin{array}{c}\text { Probability } \\
\text { of School } \\
\text { Attendance } \\
\text { (Ages 18-20) }\end{array}$ & $\begin{array}{c}\text { Probability of } \\
\text { School } \\
\text { Attendance } \\
\text { (Ages 19-20) }\end{array}$ \\
\hline \multirow[t]{2}{*}{ State-Level: Treated x Erosion } & $-0.1599 * * *$ & 0.0141 & 0.0757 & $0.1345^{*}$ & $0.2068 *$ & $0.2882 *$ & 0.1589 \\
\hline & $(0.0161)$ & $(0.0482)$ & $(0.0616)$ & $(0.0808)$ & $(0.1127)$ & $(0.1642)$ & $(0.2984)$ \\
\hline \multirow[t]{2}{*}{ County-Level: Treated x Erosion } & -0.0077 & 0.0157 & 0.0157 & 0.0121 & 0.0064 & -0.0027 & -0.0263 \\
\hline & $()$. & $(0.0117)$ & $(0.0120)$ & $(0.0121)$ & $(0.0169)$ & $(0.0231)$ & $()$. \\
\hline
\end{tabular}

*** $\mathrm{p}<0.01, * * \mathrm{p}<0.05, * \mathrm{p}<0.1$; Note: Table reports the treated $_{b} \times$ erosion $_{s}$ coefficient, e.g. the effect of Dust Bowl cohort membership the probability of contemporaneous school attendance, relative to school attendance probability for those not exposed to the Dust Bowl. Sample includes children born in the 15 sample states and enumerated in 1930 (control) or 1940 (treated). Column headers indicate the age range of children in the regression. Row 1 reports results where erosion is assigned at the birth-state level, while row 2 gives the results of analysis using county-of-birth erosion. All regressions are estimated by OLS and include birth state and birth year fixed effects, state trends, and controls for age and race. Standard errors, two-way clustered by state and birth year, are reported in parentheses below each coefficient. 


\section{FIGURE APPENDIX}

Figures A1a-A1i- Summary Statistics: Average Later-Life Outcomes by Birth Year and Sex

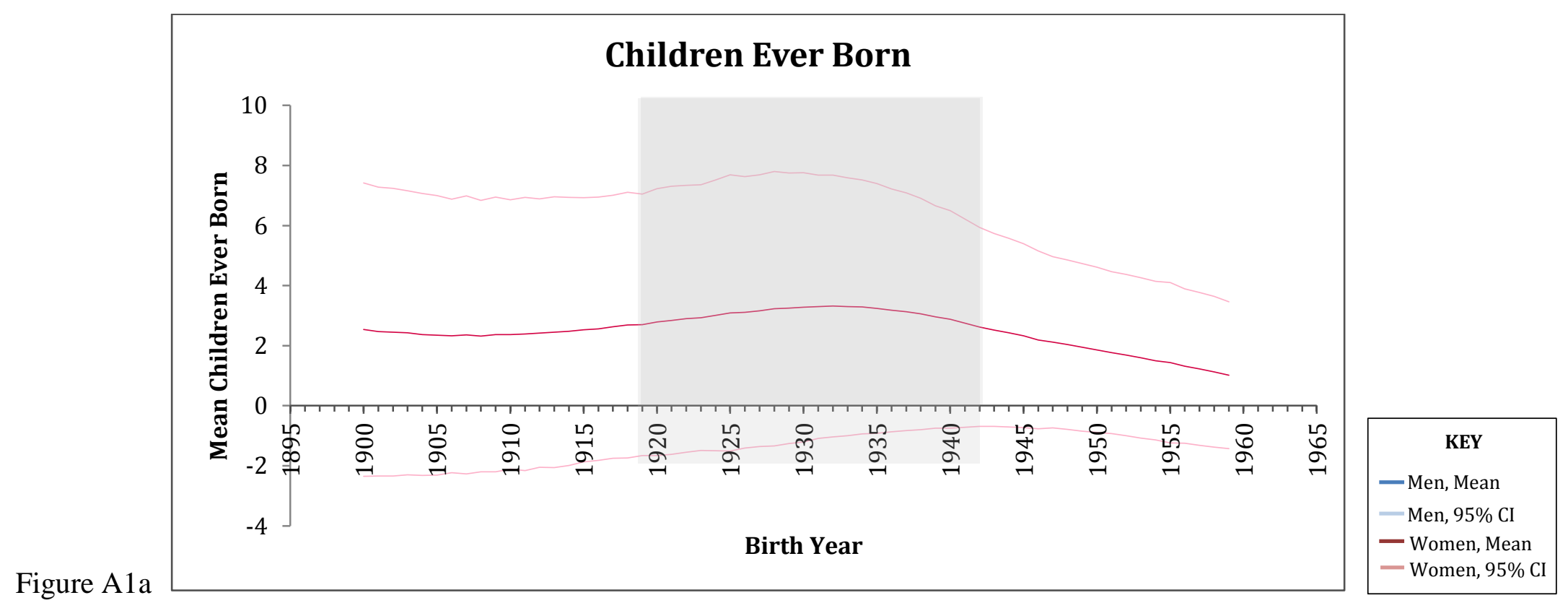




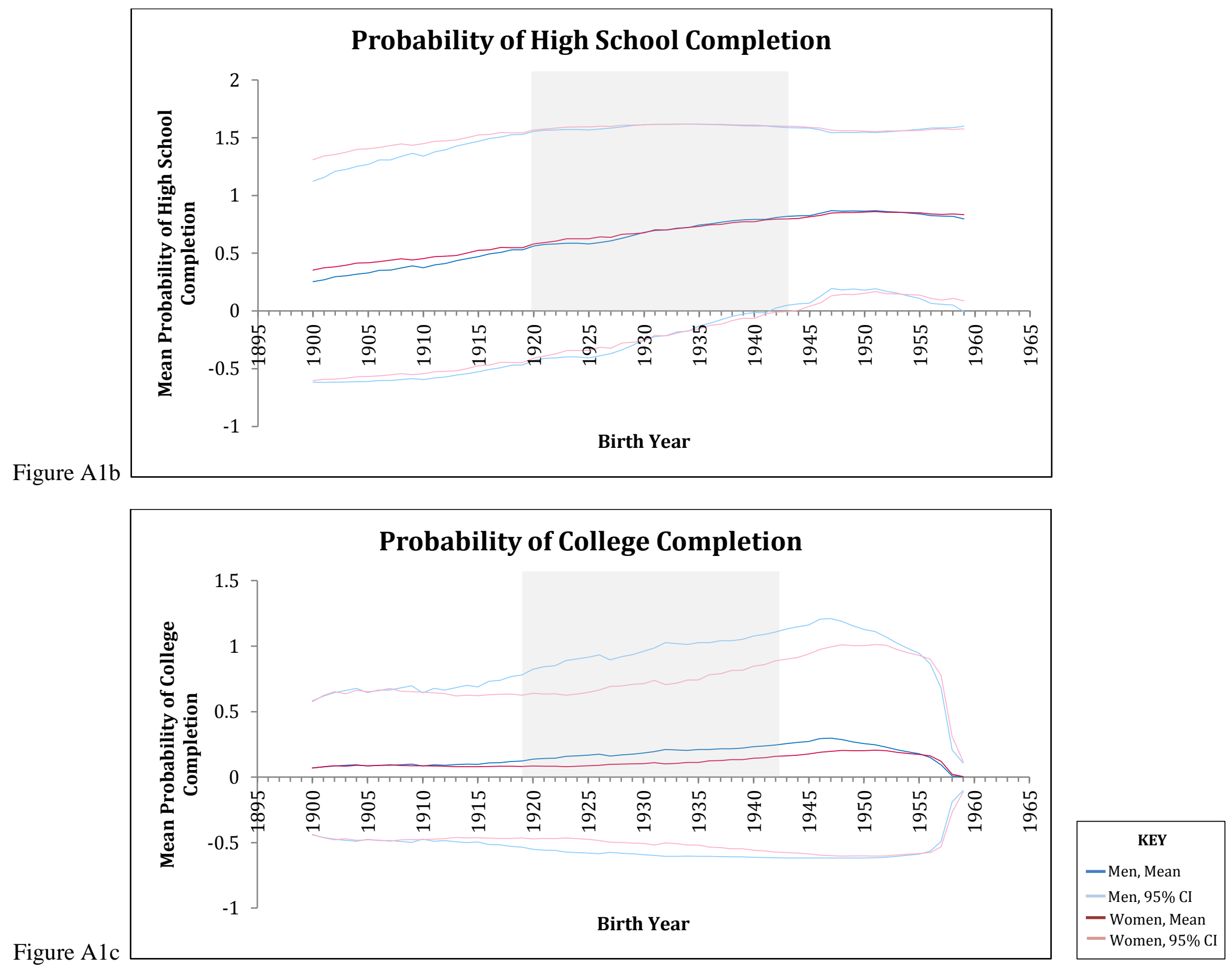



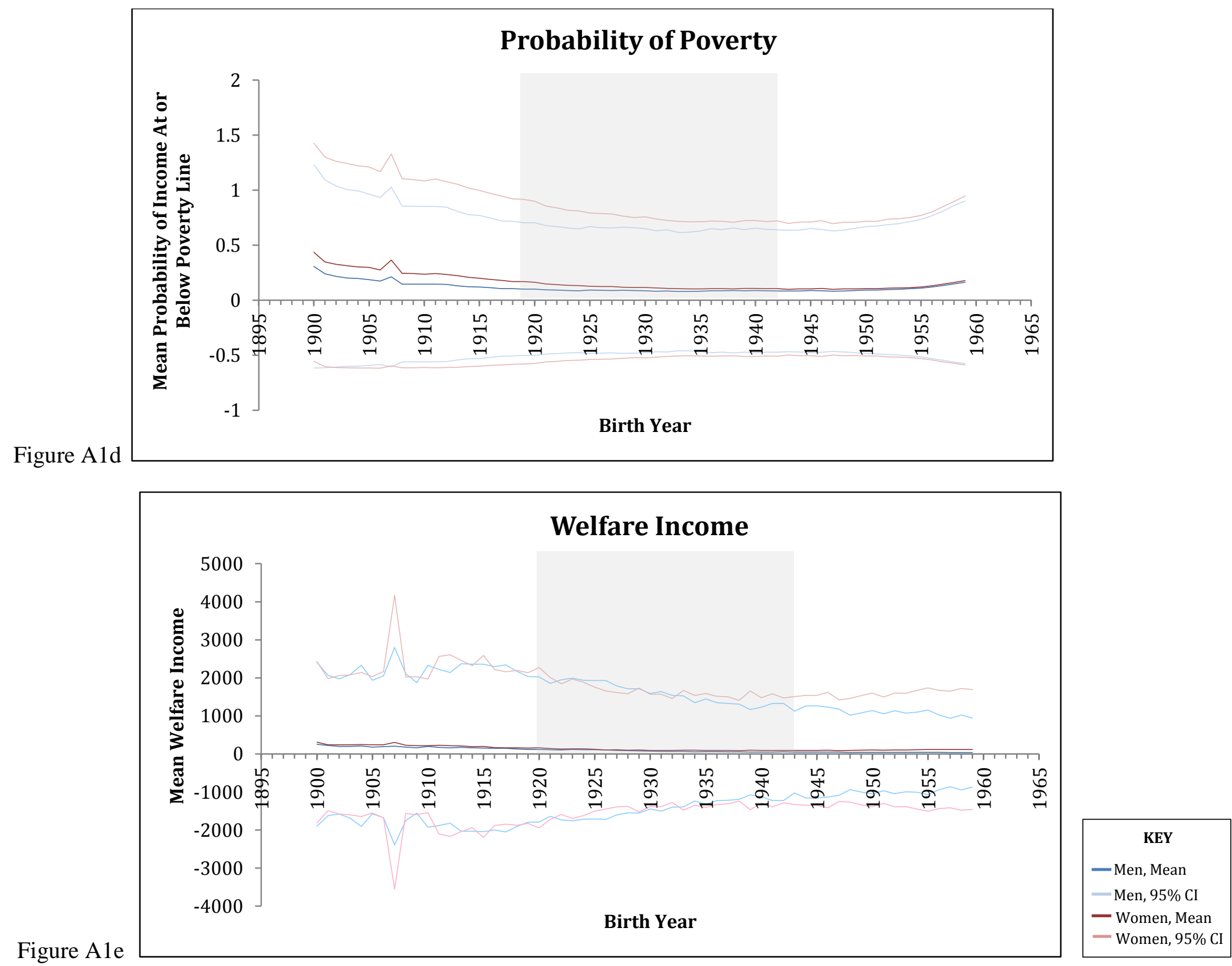

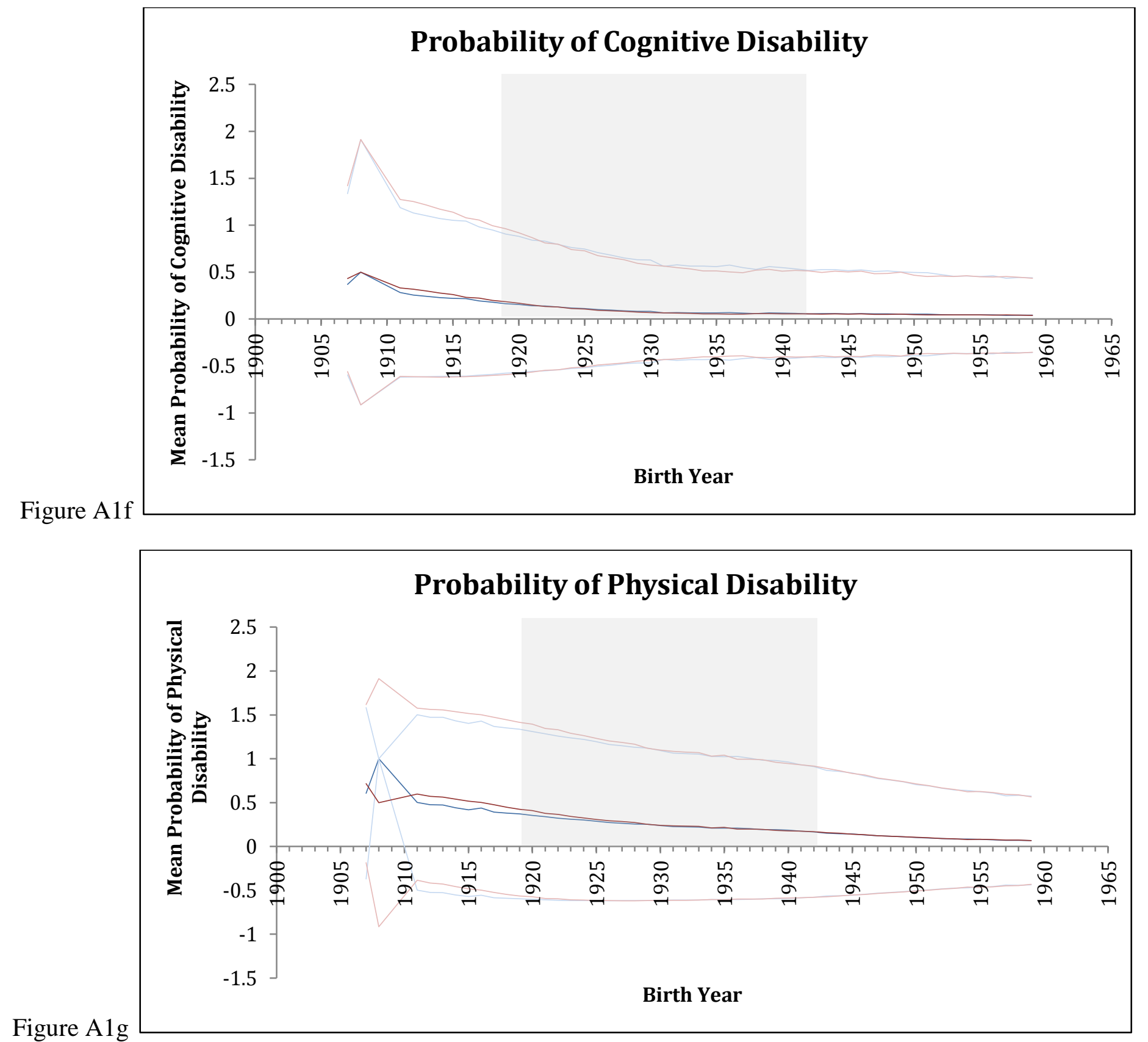

\begin{tabular}{|c|}
\hline \multicolumn{1}{|c|}{ KEY } \\
— Men, Mean \\
- Men, 95\% CI \\
- Women, Mean \\
- Women, 95\% CI \\
\hline
\end{tabular}



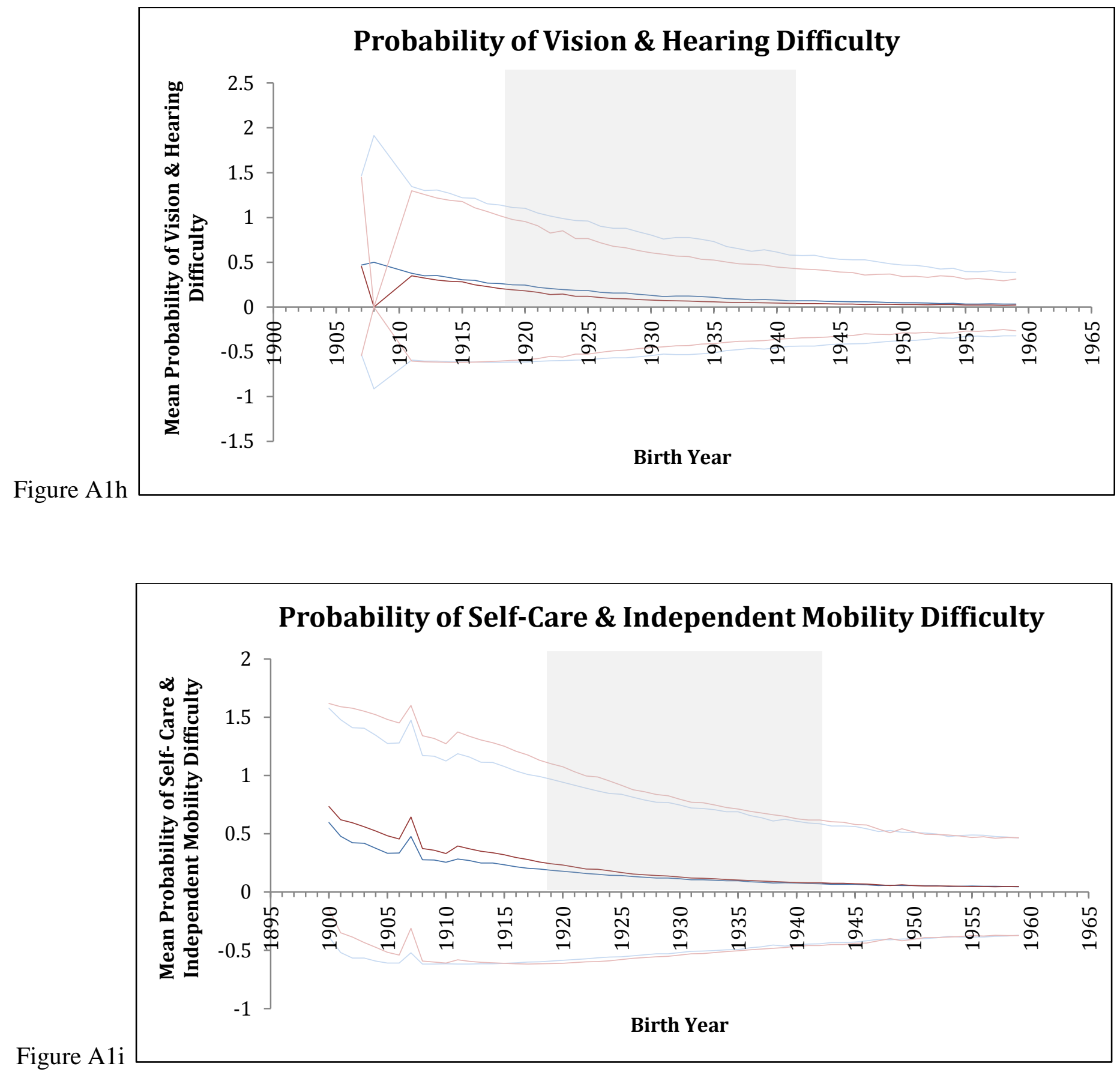
Figures A2-10 - Impact of Exposure to the Dust Bowl by Development Stage on Later-Life Outcomes

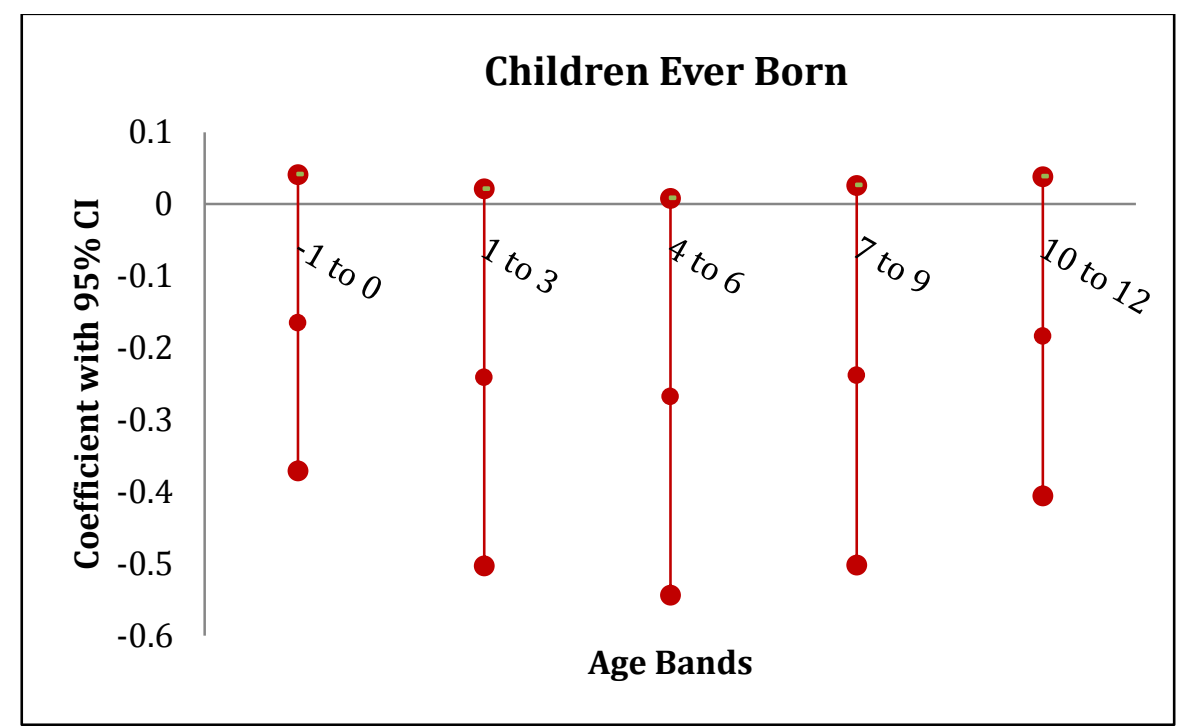

Figure A2: Women
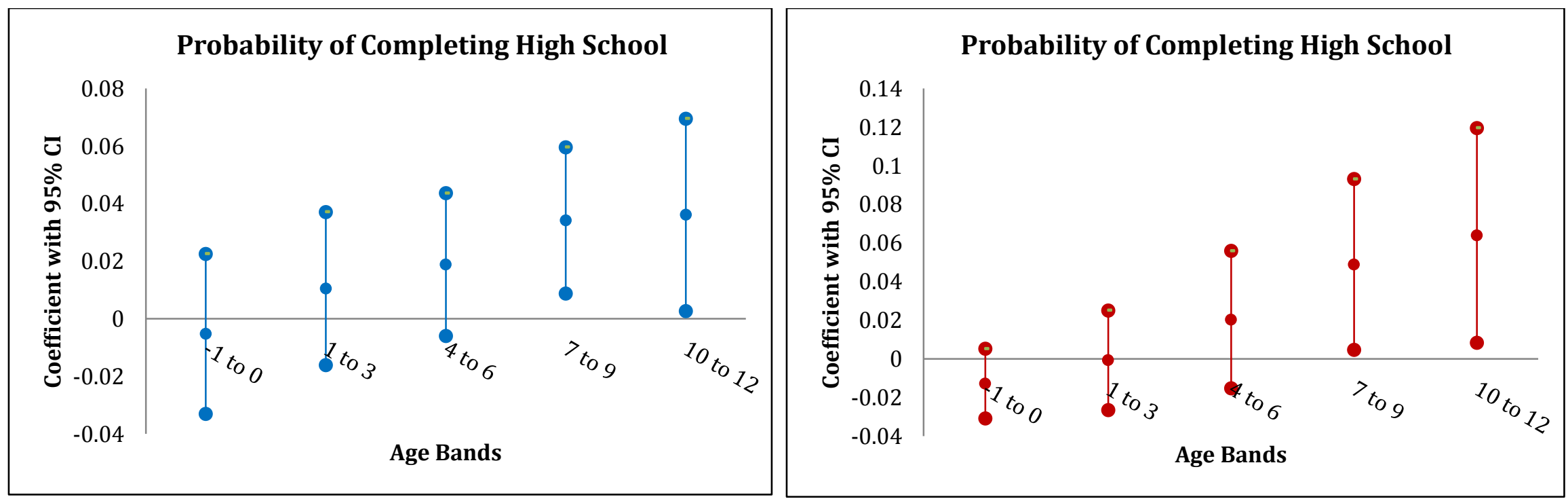

Figure A3a: Men

Figure A3b: Women 

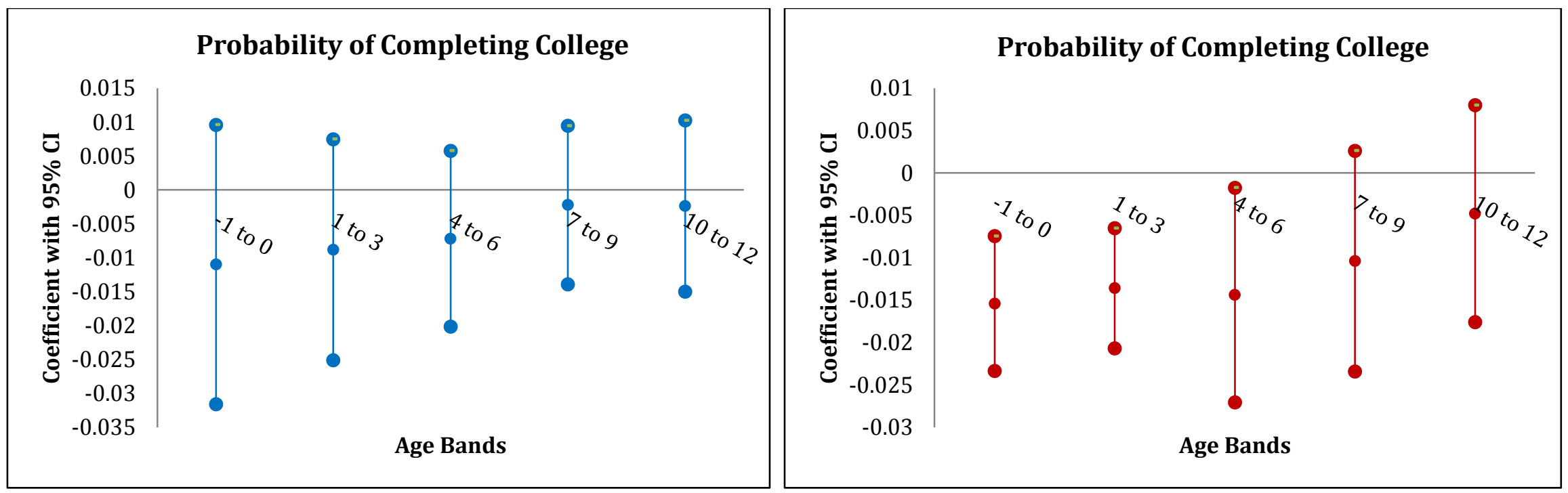

Figure A4a: Men

Figure A4b: Women
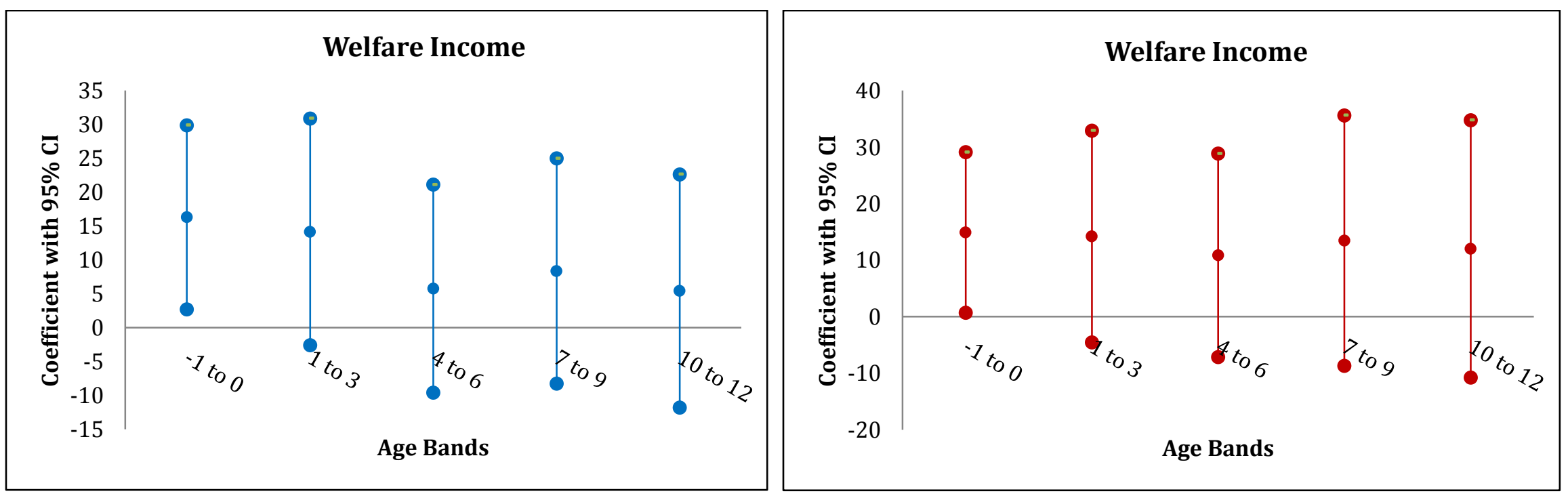

Figure A5a: Men

Figure A5b: Women 


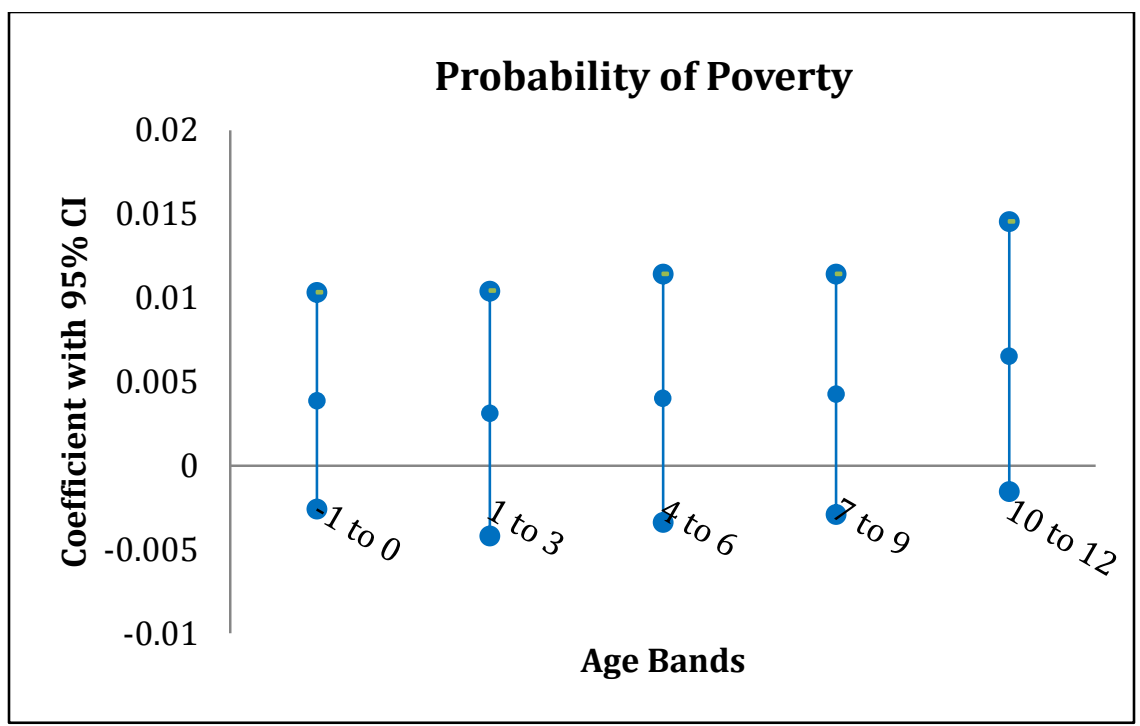

Figure A6a: Men

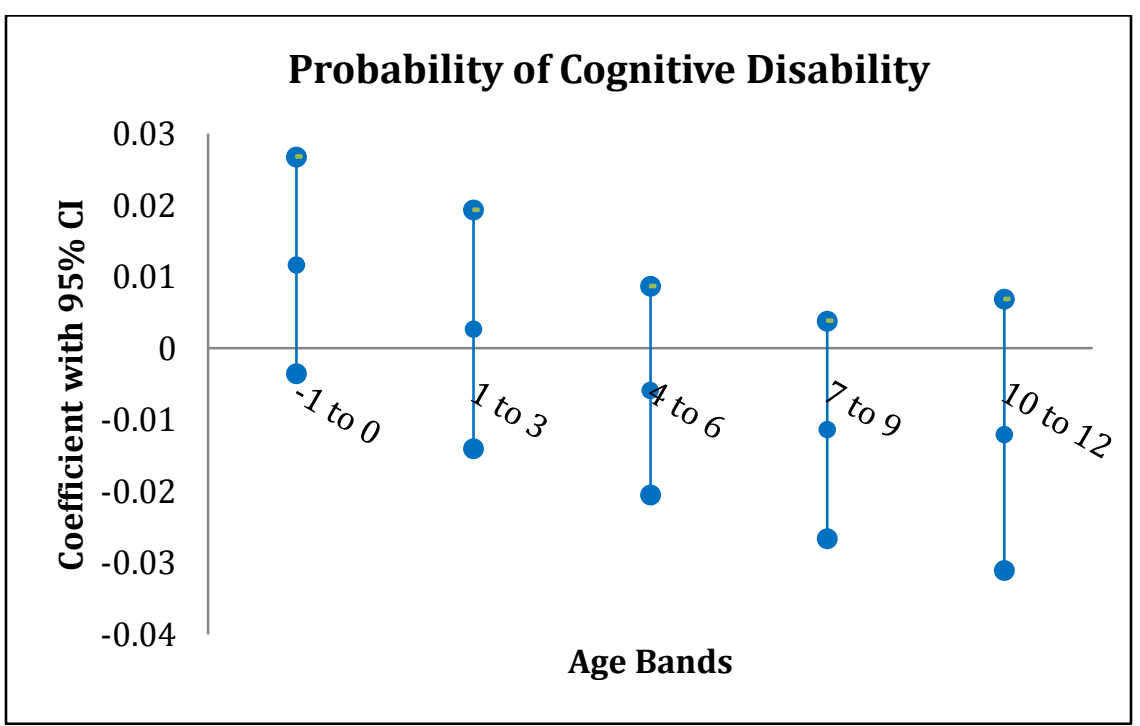

Figure A7a: Men

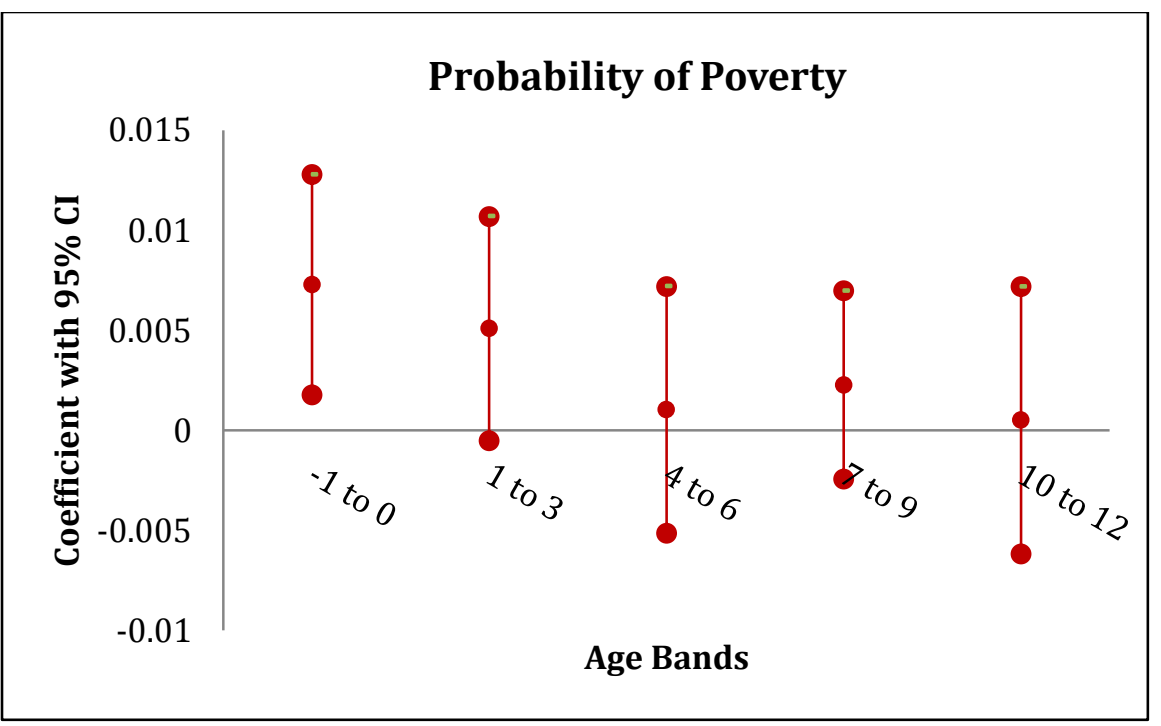

Figure A6b: Women

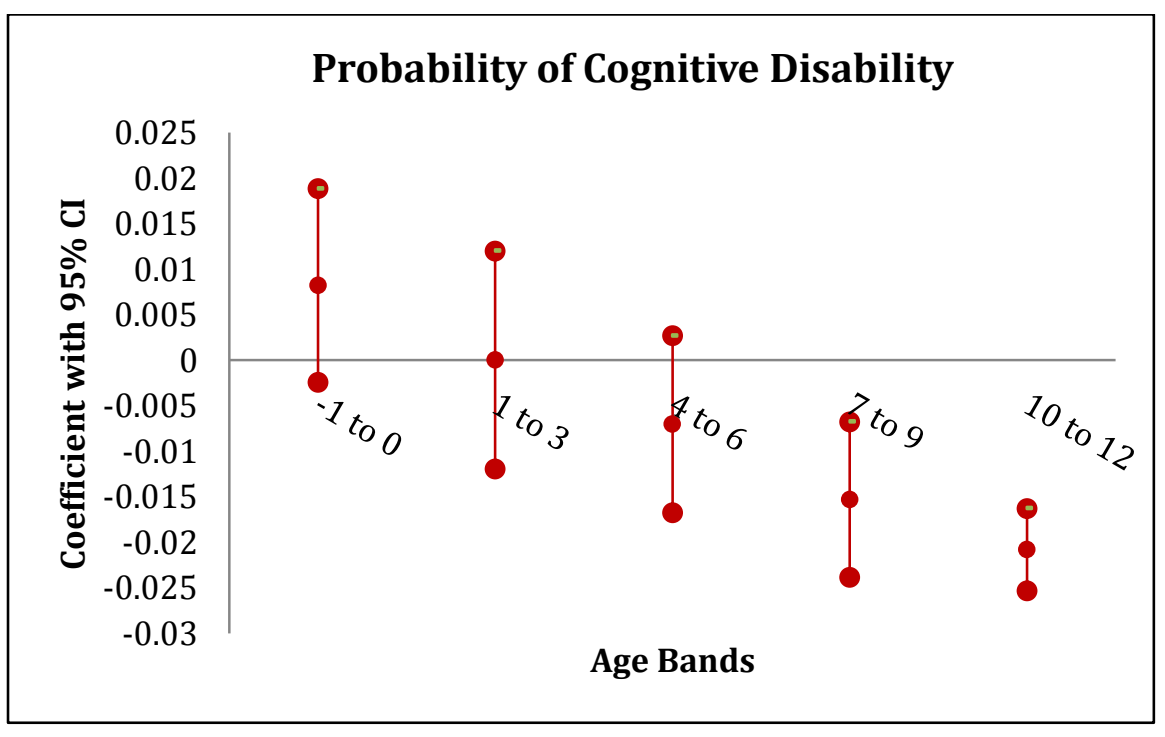

Figure A7b: Women 


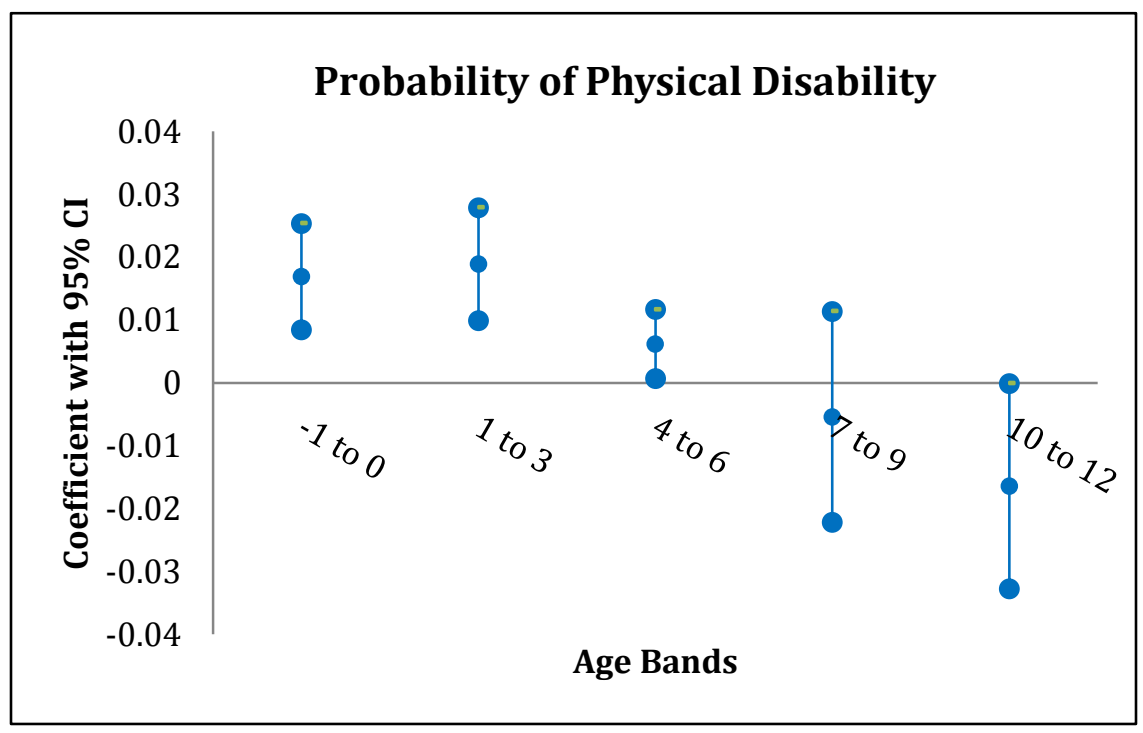

Figure A8a: Men

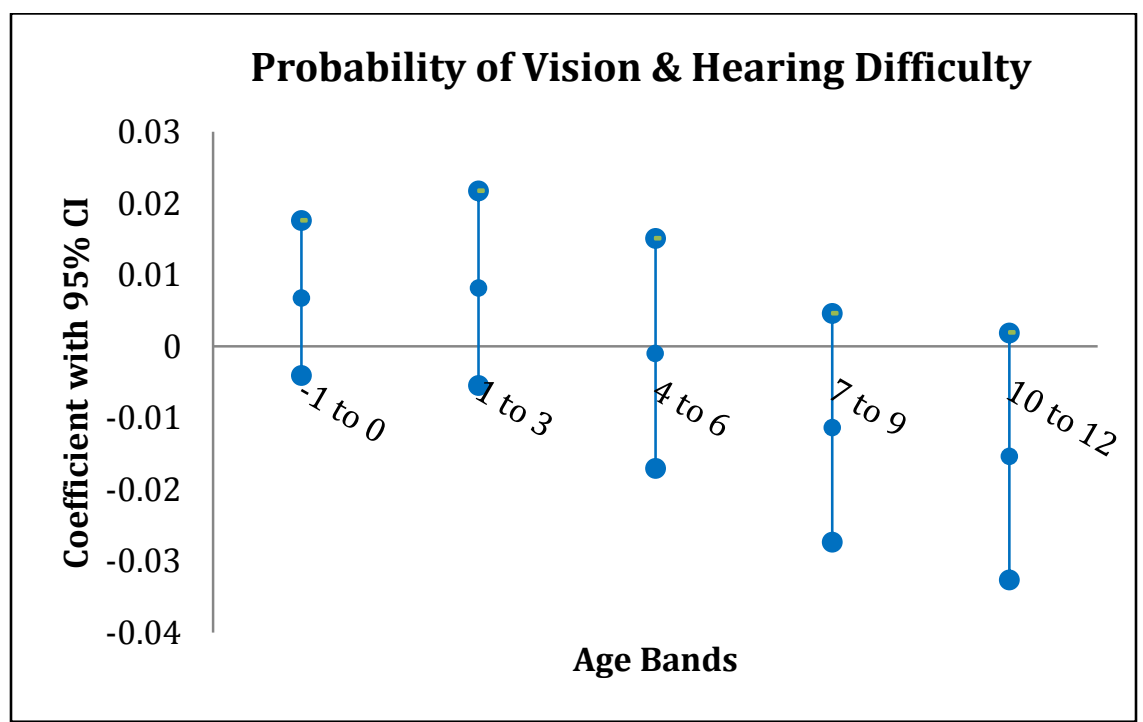

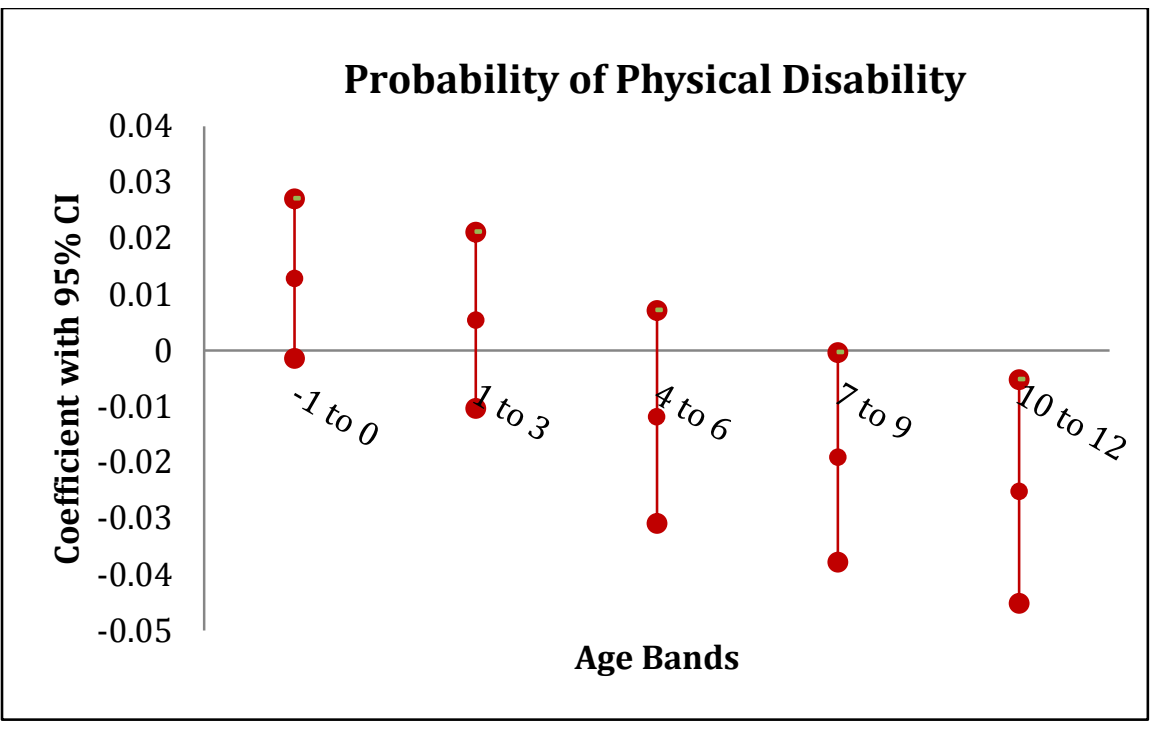

Figure A8b: Women

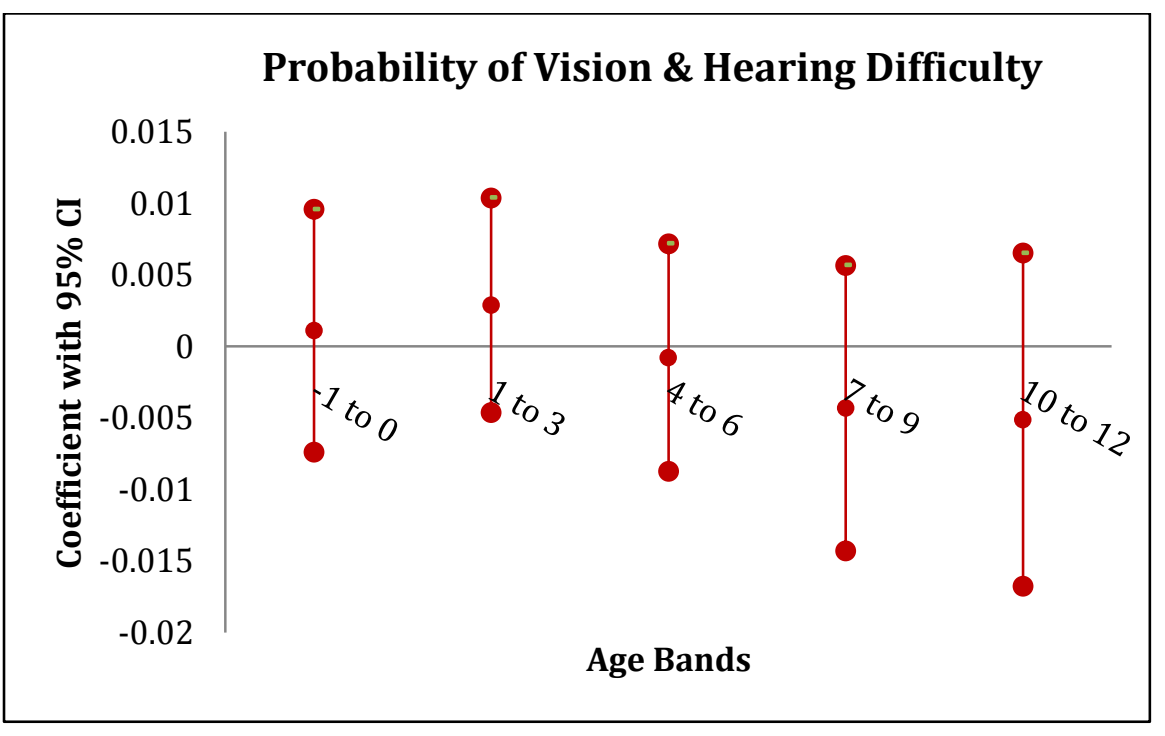

Figure A9b: Women

Figure A9b: Women 

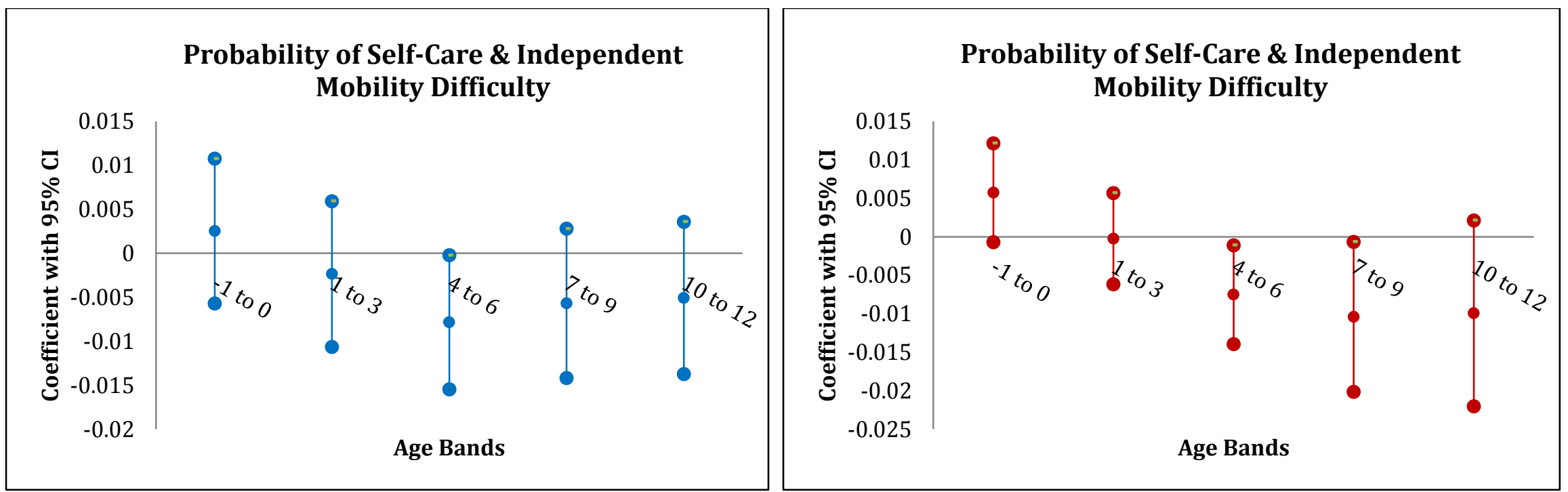

Figure A10a: Men

Figure A10b: Women 